$$
\angle A-97004943
$$

TWCP-PLAN-0.2.3-001,R.1

\title{
LOS ALAMOS NATIONAL LABORATORY TRANSURANIC WASTE QUALITY ASSURANCE PROJECT PLAN \\ Revision 1
}

\section{INFORMATION ONLY}

Controlled Copy No. JF5 $4 / 4 / 97$

Los Alamos National Laboratory Transuranic Waste Characterization Project

Los Alamos National Laboratory

$$
\text { P.O. Box } 1663
$$

Los Alamos, New Mexico 87545

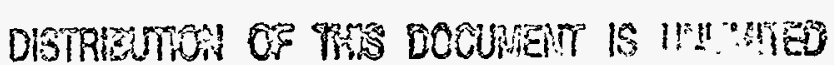<smiles>CCCCCC(C)C</smiles>

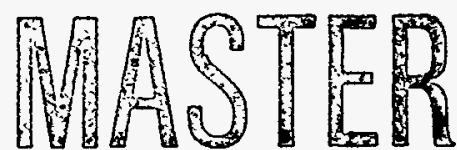




\section{DISCLAIMER}

This report was prepared as an account of work sponsored by an agency of the United States Government. Neither the United States Government nor any agency thereof, nor any of their employees, make any warranty, express or implied, or assumes any legal liability or responsibility for the accuracy, completeness, or usefulness of any information, apparatus, product, or process disclosed, or represents that its use would not infringe privately owned rights. Reference herein to any specific commercial product, process, or service by trade name, trademark, manufacturer, or otherwise does not necessarily constitute or imply its endorsement, recommendation, or favoring by the United States Government or any agency thereof. The views and opinions of authors expressed herein do not necessarily state or reflect those of the United States Government or any agency thereof. 


\title{
LOS ALAMOS NATIONAL LABORATORY TRANSURANIC WASTE QUALITY ASSURANCE PROJECT PLAN Revision 1
}

\author{
April 14, 1997
}

Reviewed/Approved by:

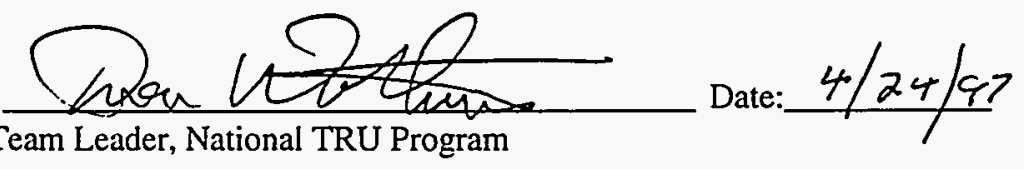

Reviewed/Approved by: PHene falciso RDB Date: $4 / 24 / 97$

Manager, Quality Assurance, Carlsbad Area Office

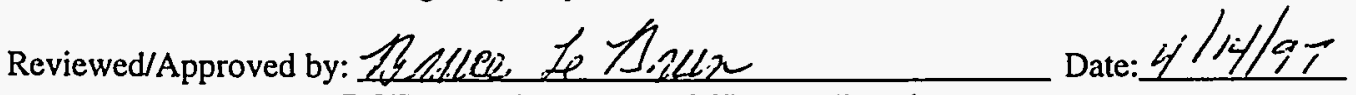

DOE, Los Alamos Area Office, Radioactive

Waste Manager

Reviewed/Approved by:

Project Leader/TRU Waste Type Managen

Su cur

Reviewed/Approved by:

$7)$

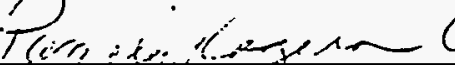

TRU Waste Site Project-Manager

Reviewed/Approved by: 1 ij, if

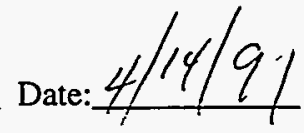

\section{1}


LIST OF TABLES vi vi

LIST OF FIGURES $\quad$ ix

LIST OF ACRONYMS, ABBREVIATIONS, AND SYMBOLS $\quad \mathbf{x}$

1.0 PROJECT MANAGEMENT $\quad 1-1$

1.1 Project Organization $1-1$

1.1.1 Department of Energy, Los Alamos Area Office,
Waste Management

1.1.2 Project Leader/TRU Waste Type Manager 1-1

1.1.3 Site Project Manager $1-2$

1.1.4 Site Project Quality Assurance Officer $\quad 1-2$

1.1.5 TRU Waste Certification Team 1-3

1.1.6 TRU Waste Certification Official 1-3

1.1.7 TRU Waste Transportation Certification Official 1-3

1.1.8 TWCP Operations Leader $1-3$

1.1.9 Newly-Generated Waste Generators 1-4

1.1.9.1 Communication and Interface Responsibilities 1-6

1.1.9.2 Resolution of Disputes 1-6

1.2 Project Documents $\quad 1-6$

1.2.1 Quality Assurance Program Plan $\quad 1-6$

1.2.2 Quality Assurance Project Plan 1-6

1.2.3 Laboratory Documents 1-7

1.2.4 TRU Waste Certification Plan 1-7

1.2.5 Document Review, Approval, and Control 1-7

1.3 Problem Definition and Background 1-11

$\begin{array}{lll}1.4 & \text { Project Description } & 1-12\end{array}$

$\begin{array}{ll}\text { 1.4.1 Sampling and Analysis } & 1-12\end{array}$

1.4.2 Acceptable Knowledge $\quad 1-12$

$\begin{array}{lll}\text { 1.5 Data Quality Objectives for Measurement Data } & 1-16\end{array}$

$\begin{array}{lll}1.6 & \text { Training and Certifications } & 1-18\end{array}$

$\begin{array}{llr}1.7 & \text { Records Management } & 1-18\end{array}$

1.7.1 Site Project Files $\quad 1-18$

1.7.2 Flow of Records $\quad 1-20$

$\begin{array}{lll}1.8 & \text { Procurement } & 1-21\end{array}$

1.8.1 Procurement Document Control 1-21

1.8.2 Control of Purchased items and Services $\quad 1-21$

$\begin{array}{ll}\text { 1.8.3 Control of Subcontractors } & 1-22\end{array}$

$\begin{array}{lll}1.9 & \text { Work Processes } & 1-22\end{array}$

1.9.1 Control of Processes $1-22$

1.9.2 Identification and Control of Items $\quad 1-22$

1.9.3 Computer Hardware and Software $\quad 1-22$

$\begin{array}{ll}\text { 1.9.4 Grading Items and Activities } & 1-23\end{array}$

$\begin{array}{lll}1.10 & \text { Procedures Specific to This Section } & 1-23\end{array}$ 
2.1 Assessment and Response Actions 2-1

2.1.1 Carlsbad Area Office Audits 2-1

2.1.2 Nonconformances and Operational Variances 2-1

2.1.3 Quality Improvement $\quad 2-2$

2.1.4 Management Assessments 2-2

2.1.5 Independent Assessments $\quad 2-2$

2.2 Reports to Management $2-3$

2.3 Performance Demonstration Program 2-3

2.4 Procedures Specific to This Section 2-4

3.0 DATA VALIDATION, USABILITY, AND REPORTING 3-1

3.1 Data Review, Validation, and Verification 3-1

3.1.1 Data Generation Level 3-1

3.1.2 Project Level 3-2

3.1.3 CAO Level 3-3

3.2 Validation Methods $3-4$

3.3 Reconciliation with Data Quality Objectives $3-4$

3.3.1 Reconciliation at the Project Level 3-4

3.3.2 Reconciliation at the CAO Level 3-5

3.4 Data Reporting Requirements 3-6

3.4.1 Data Generation Level $3-6$

3.4.2 Project Level $3-6$

$\begin{array}{ll}\text { 3.5 Procedures Specific to This Section } & 3-10\end{array}$

4.0 ACCEPTABLE KNOWLEDGE 4-1

4.1 Quality Assurance Objectives 4-1

4.2 Methods Requirements 4-1

4.2.1 Assembling Acceptable Knowledge Documentation 4-2

4.2.2 Confirmatory Testing 4-4

4.3 Acceptable Knowledge Information 4-4

4.3.1 TRU Waste Management Program Information 4-4

4.3.2 TRU Waste Stream Information 4-4

4.3.3 Supplemental Acceptable Knowledge Documentation 4-4

4.4 Acceptable Knowledge Program Control 4-4

4.4.1 Training 4-4

4.4.2 Management Controls of Nonconforming Items 4-5

4.4.3 Confirmation of Acceptable Knowledge 4-5

4.4.4 Resolution of Discrepancies 4-5

4.4.5 Re-evaluation of Acceptable Knowledge 4-5

4.5 Audits 4-5

4.6 Procedures Specific to This Section 4-5

5.0 SAMPLING PROCESS DESIGN $5-1$

5.1 Description of Acceptable Matrix Parameter Categories $5-1$

5.2 Parameters, Rationale, and Test Methods 5-1

5.2.1 Homogeneous Solids and Soil/Gravel 5-2

$\begin{array}{ll}5.2 .2 & \text { Debris Waste } \\ 5-2\end{array}$ 
5.3 Confirmation of EPA Hazardous Waste Numbers for Spent

Solvents Using Headspace Gas Analytical Results

5.4 Sampling Plan

5.4.1 RCRA Characterization of Retrievably Stored Homogeneous Solids and Soil/Gravel

5.4.2 Visual Examination of Retrievably Stored Homogeneous Solids. Soil/Gravel, and Debris Wastes

5.4.3 Characterization of Newly Generated Homogeneous

Solids, Soil/Gravel, and Debris Wastes

5.4.3.1 Verification Sampling of Homogeneous Solids and Soil/Gravel from Continuous Processes $\quad 5-5$

5.4.3.2 Verification Sampling of Homogeneous Solids and Soil/Gravel from Process Batches

\subsubsection{Characterization of Newly Generated Debris Waste}

5.5 Procedures Specific to This Section

6.0 SAMPLE HANDLING AND CUSTODY REQUIREMENTS 6-1

6.1 Field Documentation 6-1

6.2 Labeling 6-2

6.2.1 Waste Container Labeling 6-2

6.2.2 Innermost Layer of Confinement 6-2

6.2.3 Headspace Gas Sample Containers 6-3

6.2.4 Homogeneous Solids and Soil/Gravel Sample Containers $\quad 6-4$

6.3 Chain of Custody 6-4

6.3.1 Waste Container 6-5

6.3.2 Sample Containers $6-5$

6.4 Handling 6-6

6.4.1 Waste Container $6-6$

6.4.2 Gas Sample Container 6-6

6.4.3 Newly Generated Homogeneous Solids and Soil/Gravel
Sample Containers

6.5 Procedures Specific to This Section 6-7

7.0 HEADSPACE GAS SAMPLING 7-1

7.1 Quality Assurance Objectives $7-1$

$\begin{array}{ll}7.2 & \text { Method Requirements }\end{array}$

7.2.1 Direct Sampling Method 7-4

7.2.2 Modified Manifold System 7-4

$\begin{array}{ll}7.2 .3 \text { Direct Canister } & 7-5\end{array}$

7.2.4 Sampling Heads $\quad 7-5$

$\begin{array}{lll}7.3 & \text { Quality Control } & 7-6\end{array}$

7.4 Equipment Testing, Inspection, and Maintenance Requirements

$\begin{array}{lll}7.5 & \text { Equipment Calibration and Frequency } & 7-8\end{array}$

$\begin{array}{ll}7.6 \text { Data Management } & 7-8 \\ 7.8 & 7-8\end{array}$

$\begin{array}{ll}7.7 & \text { Procedures Specific to This Section }\end{array}$ 
8.0 SAMPLING OF HOMOGENEOUS SOLIDS AND SOIL/GRAVEL

8.1 Quality Assurance Objectives

$8-1$

8.2 Methods Requirements

$8-2$

8.2.1 Core Collection

$8-2$

8.2.2 Sample Collection

$8-2$

8.3 Quality Control

8-2

8.4 Equipment Testing. Inspection, and Maintenance

8.5 Equipment Calibration and Frequency

8.6 Data Management

8.7 Procedures Specific to This Section

9.0 NONDESTRUCTIVE ASSAY

9.1 Quality Assurance Objectives

9.2 Methods Requirements

$9-3$

9.3 Quality Control

$9-4$

9.3.1 Measurement System Checks 9-4

9.3.2 Intercomparison Programs 9-5

9.3.3 NDA Operator Training 9-5

9.4 Instrument Testing, Inspection, and Maintenance Requirements

9.5 Calibration Procedures and Frequencies 9-5

$\begin{array}{ll}9.6 \text { Data Management } & 9-6 \\ 9.7 & 9-8\end{array}$

9.7 Procedures Specific to This Section 9-8

10.0 RADIOGRAPHY

$10-1$

10.1 Quality Assurance Objectives 10-1

$\begin{array}{ll}10.2 & \text { Methods Requirements } \\ 10.3 & 10-2\end{array}$

10.3 Quality Control 10-3

10.4 Instrument Testing, Inspection, and Maintenance Requirements 10-4

$\begin{array}{ll}10.5 & \text { Instrument Calibration and Frequency }\end{array}$

$\begin{array}{ll}10.6 & \text { Data Management } 10-4\end{array}$

10.7 Procedures Specific to This Section 10-6

11.0 HYDROGEN AND METHANE ANALYSIS

11.1 Quality Assurance Objectives 11-1

11.2 Methods Requirements $11-2$

11.2.1 Criteria for Standards 11-2

11.2.2 Criteria for Qualitative an Quantitative Analysis 11-2

11.3 Quality Control 11-3

11.4 Instrument Testing, Inspection, and Maintenance Requirements $\quad 11-4$

11.5 Instrument Calibration and Frequency 11-5

11.6 Data Management $11-6$

11.7 Procedures Specific to This Section 11-7

12.0 GAS VOLATILE ORGANIC COMPOUND ANALYSIS 12-1

12.1 Quality Assurance Objectives 12-1

$\begin{array}{ll}12.2 & \text { Methods Requirements } \\ 12.3 & 12-3\end{array}$

$\begin{array}{ll}12.3 & \text { Quality Control } \\ & 12-4\end{array}$ 
12.4 Instrument Testing, Inspection, and Maintenance Requirements 12-6

12.5 Instrument Calibration and Frequency

12.6 Data Management

12.7 Procedures Specific to This Section

13.0 TOTAL VOLATILE ORGANIC COMPOUND ANALYSIS 13-1

13.1 Quality Assurance Objectives 13-1

$\begin{array}{ll}13.2 & \text { Methods Requirements } \\ 13.3-3\end{array}$

13.3 Quality Control 13-4

13.4 Instrument Testing, Inspection, and Maintenance Requirements 13-6

$\begin{array}{ll}\text { 13.5 Instrument Calibration and Frequency } & 13-6\end{array}$

$\begin{array}{ll}13.6 \text { Data Management } 13-7 & 13-6\end{array}$

$\begin{array}{ll}\text { 13.7 Procedures Specific to This Section } & 13-9\end{array}$

14.0 TOTAL SEMIVOLATILE ORGANIC COMPOUND ANALYSIS 14-1

14.1 Quality Assurance Objectives 14-1

14.2 Methods Requirements 14-3

14.3 Quality Control 14-4

14.4 Instrument Testing, Inspection, and Maintenance Requirements 14-6

14.5 Instrument Calibration and Frequency 14-6

$\begin{array}{ll}14.6 & \text { Data Management }\end{array}$

14.7 Procedures Specific to This Section 14-9

15.0 TOTAL METAL ANALYSIS 15-1

15.1 Quality Assurance Objectives 15-1

15.2 Methods Requirements 15-3

15.3 Quality Control 15-5

15.4 Instrument Testing, Inspection, and Maintenance Requirements 15-7

$\begin{array}{lr}15.5 \text { Instrument Calibration and Frequency } & 15-7\end{array}$

$\begin{array}{ll}15.6 & \text { Data Management } \\ 15.7 & 15-11\end{array}$

$\begin{array}{ll}15.7 & \text { Procedures Specific to This Section } \\ \end{array}$

I6.0 REFERENCES $16-1$ 


\section{LIST OF TABLES}

Table

Page

1-1 Requirements for Review, Approval, Implementation, and Control of the QAPjP and Procedures

1-2 Summary of Waste Characterization Requirements

1-3 Minimum Training and Qualifications Requirements

1-4 Required Program Records Maintained in Site Project Files

1-5 Section 1.0 Procedures

2-1 Section 2.0 Procedures

3-1 TC Levels Expressed as RTL Values in the Waste

3-2 Requirements for Electronic Transmittal of Data Packages

3-3 Section 3.0 Procedures

4-1 Section 4.0 Procedures

5-1 Section 5.0 Procedures 5-6

6-1 Section 6.0 Procedures $\quad 6-8$

7-1 Analyses Required for Each Type of Headspace Sample Collected

7-2 Summary of Drum Field QC Headspace Sample Frequencies

7-3 Summary of Sampling QC Sample Acceptance Criteria

7-4 Section 7.0 Procedures

8-1 Section 8.0 Procedures $\quad 8-5$

9-1 QAOs for Nondestructive Assay $\quad 9-2$

9-2 NDA Systems and Procedures $\quad 9-9$

10-1 Waste Material Parameters and Descriptions $\quad 10-2$

10-2 Section 10.0 Procedures $\quad 10-6$ 


\section{LIST OF TABLES, CONTINUED}

11-1 Hydrogen and Methane Analysis QAOs

11-2 Summary of Laboratory QC Samples and Frequencies for Hydrogen and Methane Analysis

11-3 Summary of GC Calibration Requirements for Hydrogen and Methane Analysis

11-4 Section 11.0 Procedures

12-1 Gas VOC Target Analyte List and QAOs

12-2 Flammable and Nonflammable VOC

12-3 Summary of Laboratory QC Samples and Frequencies for Gas VOC Analysis

12-4 Summary of GC/MS Calibration Requirements for Gas VOC Analysis

12-5 Section 12.0 Procedures

13-1 Total VOCs Target Analyte List and QAOs

13-2 Summary of Laboratory QC Samples and Frequencies

for Total VOC Analysis

13-3 Summary of Calibration Requirements for Total VOC Analysis

13-4 Section 13.0 Procedures

14-1 SVOC Target Analyte List and QAOs

14-2 Summary of Laboratory QC Samples and Frequencies for Total SVOC Analysis

14-3 Summary of Calibration Requirements for SVOCs

14-4 Section 14.0 Procedures

15-1 Total Metal Target Analyte List and QAOs 


\section{LIST OF TABLES, CONTINUED}

Table

Page

15-3 Summary of Laboratory QC Samples and Frequencies

$15-6$ for Total Metal Analysis

15-4 Summary of Calibration Requirements and Analysis QC for Total Metal Analysis

15-5 Section 15.0 Procedures

15-12 


\section{LIST OF FIGURES}

Figure

Page

1-1 TRU Waste Characterization Project (TWCP) Organization Chart (for Retrievably Stored Waste)

1-2 TWCP Document Hierarchy $1-8$

6-1 Example Sample Canister Label 


\section{LIST OF ACRONYMS, ABBREVIATIONS, AND SYMBOLS}

AA

ALARA

ANSI

ASTM

BFB

BIR

CAO

CAR

CAS

CCC

CFR

CMR

COC

CRM

CVAA

CVAF

$\% \mathrm{D}$

DFTPP

DOE

DQO

DTP

EDS

EICP

EPA

FRC

GC

GC/ECD

GC/FID

GC/MS

GFAA

HPLC

ICP-AES

ICP-MS

IDC

IDL

ILIG

LAAO

LANL

LCS atomic absorption

as low as reasonably achievable

American National Standards Institute

American Society for Testing and Materials

4-bromofluorobenzene

Waste Isolation Pilot Plant Transuranic Waste Baseline

Inventory Report

Carlsbad Area Office

corrective action report

Chemical Abstract Service

calibration check compounds

Code of Federal Regulations

Chemistry and Metallurgy Research

chain of custody

Communications and Records Management

cold vapor atomic absorption spectroscopy

cold vapor atomic fluorescence spectroscopy

percent difference

decafluorotriphenylphosphine

Department of Energy

data quality objective

detailed technical procedure

Employee Development System

Extracted Ion Current Profile

U.S. Environmental Protection Agency

Federal Records Center

gas chromatography

gas chromatography/election capture detection

gas chromatography/flame ionization detector

gas chromatography/mass spectrometry

graphite furnace atomic absorption spectrometry

high pressure liquid chromatography

inductively coupled plasma - atomic emission spectroscopy

inductively coupled plasma - mass spectroscopy

item description code

instrument detection limit

Interim Laboratory Implementation Guide

Los Alamos Area Office

Los Alamos National Laboratory

laboratory control sample 


\section{LIST OF ACRONYMS, ABBREVIATIONS, AND SYMBOLS}

$\begin{array}{ll}\text { LLW } & \text { low-level waste } \\ \mathrm{m}^{3} & \text { cubic meters } \\ \text { M\&O } & \text { management and operating } \\ \text { MDC } & \text { minimum detectable concentration } \\ \text { MDL } & \text { method detection limit } \\ \mathrm{mg} / \mathrm{kg} & \text { milligrams per kilogram } \\ \mathrm{mg} / \mathrm{L} & \text { milligrams per liter } \\ \mathrm{mL} & \text { milliliter } \\ \mathrm{MS} & \text { mass spectrometry } \\ \text { MSA } & \text { method of standard addition } \\ \text { nCi/g } & \text { nanocuries per gram } \\ \text { NDA } & \text { nondestructive assay } \\ \text { NDE } & \text { nondestructive examination } \\ \text { NIST } & \text { National Institute of Standards and Technology } \\ \text { NMED } & \text { New Mexico Environment Department } \\ \text { NQA-1 } & \text { Quality Assurance Requirements for Nuclear Facility } \\ & \text { Applications } \\ \text { NTP } & \text { National TRU Program } \\ \text { OJT } & \text { on-the-job training } \\ \text { OVA } & \text { organic vapor analyzer } \\ \text { PAN } & \text { passive-active neutron } \\ \text { PBT } & \text { performance-based training } \\ \text { PCBs } & \text { polychlorinated biphenyls } \\ \text { PDP } & \text { Performance Demonstration Program } \\ \text { PFTBA } & \text { perfluorotributylamine } \\ \text { PLTWM } & \text { project leader/TRU waste type manager } \\ \text { ppm } & \text { parts per million } \\ \text { ppmv } & \text { parts per million by volume } \\ \text { PRD } & \text { program requirements documents } \\ \text { PRQL } & \text { program required quantitation limit } \\ \text { QA } & \text { quality assurance } \\ \text { QAO } & \text { quality assurance objective } \\ \text { QAPD } & \text { Quality Assurance Program Description } \\ \text { QAPjP } & \text { Quality Assurance Project Plan } \\ \text { QAPP } & \text { Quality Assurance Program Plan } \\ \text { QA/QC } & \text { quality assurance/quality control } \\ \text { QC } & \text { quality control } \\ \text { QP } & \text { quality procedure } \\ \text { \%R } & \text { percent recovery } \\ \text { \%RSD } & \text { percent relative standard deviation } \\ \text { RA } & \text { radioassay } \\ & \end{array}$




\section{LIST OF ACRONYMS, ABBREVIATIONS, AND SYMBOLS}

RAMROD

RANT

RCRA

$\mathrm{RH}$

RMDC

RPD

RRT

RT

RTL

RTR

SAR

SOP

SPC

SPCCs

SPM

SVOC

TA

TC

TIC

TRAMPAC

TRU

TRUCON

TRUPACT-II

TWCP

TWID

TWISP

$\mathrm{UCL}_{90}$

VOC

VTSR

WAC

WBS

WCRRF

WG

WIPP

WWIS
Radioactive Materials Research, Operations and Demonstration

Radioactive Nondestructive Testing facility

Resource Conservation and Recovery Act

remote handled

Records Management/Document Control

relative percent difference

relative retention time

retention time

regulatory threshold limit

real-time radiography

Safety Analysis Report

safe operating procedure

statistical process control

system performance check compounds

Site Project Manager

semivolatile organic compound

technical area

toxicity characteristic

tentatively identified compounds

TRUPACT-II Authorized Methods for Payload Control

transuranic

TRUPACT-II Content Codes

Transuranic Package Transporter-II

TRU Waste Characterization/Certification Program

TRU Waste Interface Document

TRU Waste Inspectable Storage Project

upper 90-percent confidence limit

volatile organic compound

validated time of sample receipt

waste acceptance criteria

work breakdown structure

Waste Characterization, Reduction, and Repackaging Facility

weapons grade

Waste Isolation Pilot Plant

WIPP Waste Information System 


\subsection{PROJECT MANAGEMENT}

This Transuranic (TRU) Waste Quality Assurance Project Plan (QAPjP) serves as the quality management plan for the characterization of transuranic waste in preparation for certification and transportation. The Transuranic Waste Characterization/Certification Program (TWCP) consists of personnel who sample and analyze waste; validate and report data; and provide project management, quality assurance, audit and assessment, and records management support, all in accordance with established requirements for disposal of TRU waste at the Waste Isolation Pilot Plant (WIPP) facility. This QAPjP addresses how the TWCP meets the quality requirements of the Carlsbad Area Office (CAO) Quality Assurance Program Description (QAPD) and the technical requirements of the Transuranic Waste Characterization Quality Assurance Program Plan (QAPP).

The TWCP characterizes and certifies retrievably stored and newly generated TRU waste using the waste selection, testing, sampling, and analytical techniques and data quality objectives (DQOs) described in the QAPP, the Los Alamos National Laboratory Transuranic Waste Certification Plan (Certification Plan), and the CST Waste Management Facilities Waste Acceptance Criteria and Certification [Los Alamos National Laboratory (LANL) Waste Acceptance Criteria (WAC)]. At the present, the TWCP does not address remote-handled $(\mathrm{RH})$ waste.

\subsection{Project Organization}

This section describes the TWCP organizational structure, primary interfaces, functional responsibilities, and levels of authority established to implement the TRU Waste Quality Assurance (QA) Program. This section is applicable to all personnel who perform activities for the TWCP. Responsibility for TWCP quality at the Laboratory is shared by all project staff who comprise the TWCP. Responsibilities may be delegated to other TWCP personnel as necessary. The personnel described in Sections 1.1.2 through 1.1.8 and those working directly under their supervision on TWCP activities are considered TWCP personnel. The TWCP organization is described below and depicted in Figure 1-1.

\subsubsection{Department of Energy, Los Alamos Area Office, Waste Management Team}

The radioactive waste manager for the U.S. Department of Energy (DOE) Los Alamos Area Office (LAAO) Waste Management Team has reviewed and approved this QAPjP and is responsible for serving as a liaison between the Laboratory and the National TRU Program (NTP) team leader to resolve any problems that could affect the quality of the TWCP. LAAO is responsible for ensuring that the QAPjP requirements are in compliance with all DOE orders and that the resources and funding are available to accomplish TWCP activities. LAAO must approve all revisions to this QAPjP that affect compliance with the $\mathrm{QA} /$ quality control $(\mathrm{QC})$ requirements before the revisions are implemented and notifies the NTP team leader of any revisions.

\subsubsection{Project Leader/TRU Waste Tvpe Manager}

The LANL project leader/TRU waste type manager (PLTWM) oversees all components of the TRU waste characterization, certification, and transportation activities at LANL. The PLTWM ensures that program plans and operations are coordinated, integrated, and consistent with CAO/NTP/WIPP programs, policies, and guidance. 


\subsubsection{Site Project Manager}

The Site Project Manager (SPM) is responsible for overseeing TWCP activities at the Laboratory. The SPM ensures that program plans and operations are coordinated, integrated, and consistent with CAO programs, policies, and guidance, and reports TWCP activities to LAAO. The SPM is responsible for overseeing the specific activities being performed and ensuring that TWCP requirements are met with regard to TRU waste testing, sampling, and analysis; sample handling and custody; and associated data management. The SPM is responsible for the development, implementation, and revision of this QAPjP. The SPM is responsible for project planning, including waste selection (Section 5.0), tracking (Section 6.0), and data validation (Section 3.0). Specific TWCP responsibilities assigned to the SPM include the following:

- Selecting and tracking waste

- Approving operational variances

- Validating/verifying analytical data

- Reconciling analytical data with data quality objectives

- Assigning U.S. Environmental Protection Agency (EPA) Hazardous Waste Numbers

- Submitting QA/QC reports to LAAO

- Transmitting analytical data to CAO

\subsubsection{Site Project Quality Assurance Officer}

The Site Project QA Officer is responsible for QA oversight and planning for the TWCP, which includes implementing the requirements of this QAPjP. The Site Project QA Officer provides the necessary day-to-day guidance to TWCP personnel on quality-related matters. The Site Project QA Officer also ensures that audits and assessments are conducted to verify TWCP compliance and approves the participation of audit team members.

The Site Project QA Officer has the authority to suspend TWCP activities at the Laboratory if quality is not assured or controlled. Specific TWCP responsibilities assigned to the Site Project QA Officer include the following:

- Establishing a coordinated and consistent QA approach among all LANL organizations that generate TRU waste by reviewing and approving interface documents and facility-specific procedures

- Approving operational variances

- Assessing laboratory/testing facilities

- Tracking nonconformances 
- Verifying corrective actions

- Validating/verifying analytical data

- Verifying analytical data QA documentation

- Evaluating trends in compliance with TWCP objectives

- Coordinating responses to deficiency reports such as corrective action reports generated by $\mathrm{CAO}$ or other external assessment organizations

- Providing QA oversight for the TRU waste database and its interface with the WIPP Waste Information System (WWIS)

- Submitting QA/QC reports to the SPM

- Reviewing and approving this QAPjP and any revisions

\subsubsection{TRU Waste Certification Team}

The TRU waste certification team is responsible for determining whether newly generated waste and retrievably stored waste is acceptable for certification under the WIPP WAC. The team includes representatives from the characterization, storage, certification, and transportation operations. The team is responsible for informing waste generators of revisions to the WIPP WAC.

\subsubsection{TRU Waste Certification Official}

The TRU waste certification official is responsible for documenting and certifying that all TRU waste containers prepared for shipment to WIPP meet all specified criteria.

\subsubsection{TRU Waste Transportation Certification Official}

The TRU waste transportation manager is responsible for the Laboratory's site-specific program to comply with the TRUPACT-II Authorized Methods for Payload Control (TRUPACT-II is the Transuranic Package Transporter-II). The TRU waste transportation certification official is responsible for documenting the Laboratory's approval of the packaging authorized contents (payload) and complying with all packaging and records requirements. He or she obtains WIPP authority to ship and ensures that all parameters are met before the transportation packaging is released to a carrier for transport.

\subsubsection{TWCP Operations Leaders}

The TWCP operations leaders are responsible for ensuring that TWCP personnel are qualified and trained to perform their assigned tasks. They must ensure that required programs, plans, and procedures are developed and that all work is performed according to established procedures. They must coordinate TWCP activities with the SPM and Site Project QA Officer and must ensure that team activities comply with the requirements of this QAPjP, such as chain of custody, audits and assessment, nonconformance reporting and tracking, corrective action, equipment calibration, and 
reporting requirements. In addition, they will ensure compliance with the requirements of this QAPjP as listed below for their specific operation.

- Nondestructive Examination Operations Leader

The nondestructive examination (NDE) operations leader verifies matrix parameter categories through radiography according to Section 10.0, "Radiography."

- Nondestructive Assay Operations Leader

The nondestructive assay (NDA) operations leader determines if waste is TRU or low-level radioactive based on radioassay according to Section 9.0, "Nondestructive Assay."

- Visual Examination Operations Leader

The visual characterization operations leader will supervise visual examinations to verify the radiography results and ensure that operations follow the sample handling custody requirements of Section 6.0, "Sample Handling and Custody Requirements," of this QAPjP.

- Headspace Gas Sampling and Analysis Operations Leader

The headspace gas sampling operations leader ensures that sampling operations comply with the requirements of Section 7.0, "Headspace Gas Sampling," and the sample handling custody requirements of Section 6.0, "Sample Handling and Custody Requirements," of this QAPjP.

- Coring Operations Leader

The coring operations leader ensures that coring and sampling operations comply with the requirements of Section 8.0, "Sampling of Homogeneous Solids and Soil/Gravel," and the sample handling custody requirements of Section 6.0, "Sample Handling and Custody Requirements," of this QAPjP.

- Analytical Services Operations Leaders

The analytical services operations leaders ensure that the analytical laboratory personnel comply with the requirements of Section 4.0, "Measurement and Data Acquisition," and that personnel follow the analytical methods described or referenced in Sections 11.0 through 15.0 of this QAPjP. They are responsible for ensuring that data generation level validation is performed on all analytical data generated in support of the TWCP according to Section 3.0, "Data Validation, Usability, and Reporting." They are responsible for ensuring that the validated data is forwarded to the Site Project QA Officer.

\subsubsection{Newly-Generated Waste Generators}

The generators of newly generated waste, or their operating organizations, are responsible for ensuring that the QA and data quality requirements of this document are satisfied through their QA, sampling, packaging, nondestructive testing, and other procedures and operations. They must also ensure that requirements of this QAPjP are met by their analytical services contractors. They describe their waste generation and certification program and how it meets the requirements of the Certification Plan through TRU Waste Interface Documents (TWID). See Section 2.5 of the Certification Plan for a discussion of the waste generators. They are not considered TWCP personnel. 


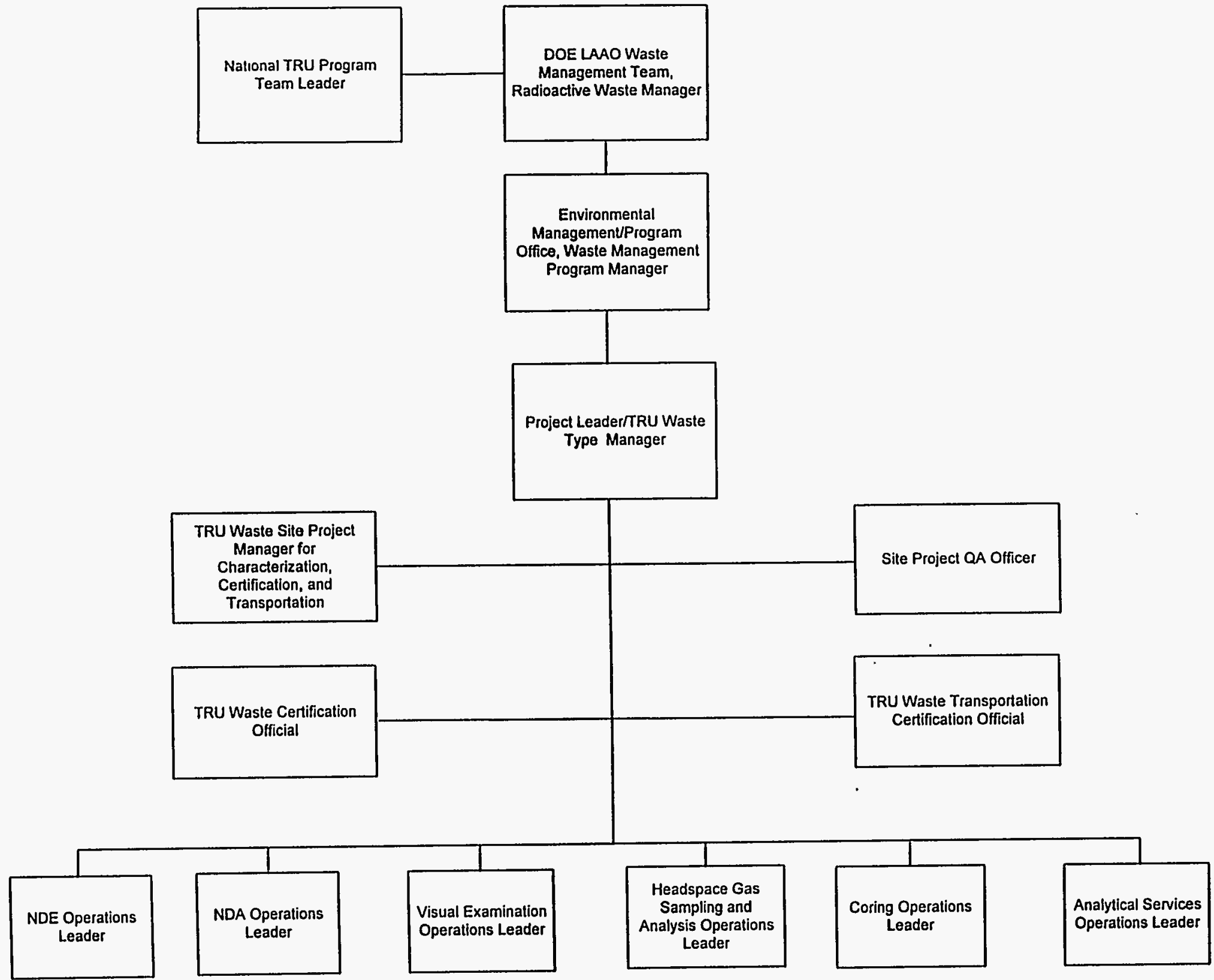

Figure 1-1. TRU Waste Characterization /Certification Project (TWCP)

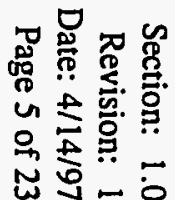

Organization Chart

(for Retrievably-Stored Waste) 


\subsubsection{Communication and Interface Responsibilities}

Participating organizations at all management levels shall establish communication channels that provide timely, routine, and wide dissemination of information pertinent to quality performance. A TWID must be prepared and approved before TWCP certification activities begin, according to the requirements in Section 6.0 of the Certification Plan. This document specifies QA, technical, and other requirements for the scope of work. QA requirements will include review and acceptance of the organization's QA plan and procedures by the Site Project QA Officer.

\subsubsection{Resolution of Disputes}

If there are differences of opinion regarding implementation of QA program requirements, the Site Project QA Officer and the responsible manager shall provide the resolution; if not resolved, the issue will be elevated progressively to successively higher levels of management.

\subsection{Project Documents}

The TWCP includes a hierarchy of documents that will guide QA activities. Figure 1-2 shows the hierarchy and relationship of TWCP QA documents.

\subsubsection{Quality Assurance Program Plan}

The QAPP describes the activities to be undertaken at participating sites to characterize TRU waste. The QAPP includes the data quality requirements that the Laboratory must meet in characterizing TRU wastes intended for disposal at the WIPP facility. The QAPP and the QAPD also includes the performance-based QA/QC requirements that the Laboratory must comply with and the performance criteria for QAPjP preparation, review, and approval.

\subsubsection{Quality Assurance Project Plan}

This QAPjP follows the guidelines recommended by the EPA in QA/R-5, EPA Requirements for Quality Assurance Project Plans for Environmental Data Operations and the criteria mandated by the QAPP and the QAPD. This QAPjP satisfies applicable requirements of 10 CFR 830, which governs the conduct of the DOE management and operating (M\&O) contractors and other persons at DOE nuclear facilities. Nothing in this document relieves the Laboratory from the responsibility of complying with any of the DQOs. The SPM will ensure that any conflicts between this QAPjP and any existing requirements are resolved.

This QAPjP identifies the quality of data necessary and the procedures developed by the Laboratory to attain and maintain quality in the TWCP. The SPM will review this QAPjP annually, and revise it as necessary, to incorporate lessons learned during waste characterization activities and any changes made to the QAPP.

This QAPjP addresses all the QAPP requirements and identifies the Laboratory organization(s) and position(s) responsible for implementation of QAPP requirements. The Site Project QA Officer or designee shall prepare and maintain a procedure matrix, identifying all current and applicable documents of each organization or project that serve to implement each applicable requirement in the 
QAPD. The procedure matrix shall be submitted to the CAO QA manager for review. The matrix shall be updated as implementation procedures and the CAO QAPD are revised.

\subsubsection{Laboratory Documents}

The Laboratory has developed a document hierarchy to communicate management's expectations and the methods by which Laboratory activities should be conducted. TWCP operations leaders are responsible for developing programs or plans to comply with Laboratory directives and applicable regulations. They must develop written procedures for all TWCP activities, and TWCP personnel must comply with these procedures to ensure that operations are performed in a consistent manner to achieve the quality required for the TWCP. For the purposes of this QAPjP, Laboratory implementing documents are termed safe operating procedures (SOPs), quality procedures (QPs), and detailed technical procedures (DTPs). SOPs are operating procedures with a safety emphasis (mostly facility related), QPs are procedures that are written to address implementation of the quality elements of the quality assurance program, and DTPs are technical procedures with an emphasis on details of the technical operating processes. TWCP personnel write DTPs according to the requirements in Developing TWCP Procedures (TWCP-QP 1.1-001).

\subsubsection{TRU Waste Certification Plan}

The Certification Plan establishes the Laboratory's program for certifying TRU waste before it is sent to the WIPP facility. The Certification Plan is distributed to all Laboratory TRU waste generating organizations and describes the following certification requirements:

- Waste acceptance forms

- Waste verification

- Generator site audits

- Records management

- Document control

- Independent assessments

\subsubsection{Document Review, Approval, and Control}

The Laboratory controls the preparation, distribution, and revision of all TWCP documents to ensure that correct and current documents are used and cited. The Laboratory's Communications and Records Management (CRM) Division is responsible for records management and has developed a Program Requirements Document, Document Control (PRD115-01.0), that Laboratory groups follow to develop site-specific document control procedures. TWCP personnel follow Document Control (TWCP-QP1.1-002) to control the review and approval of controlled documents. 


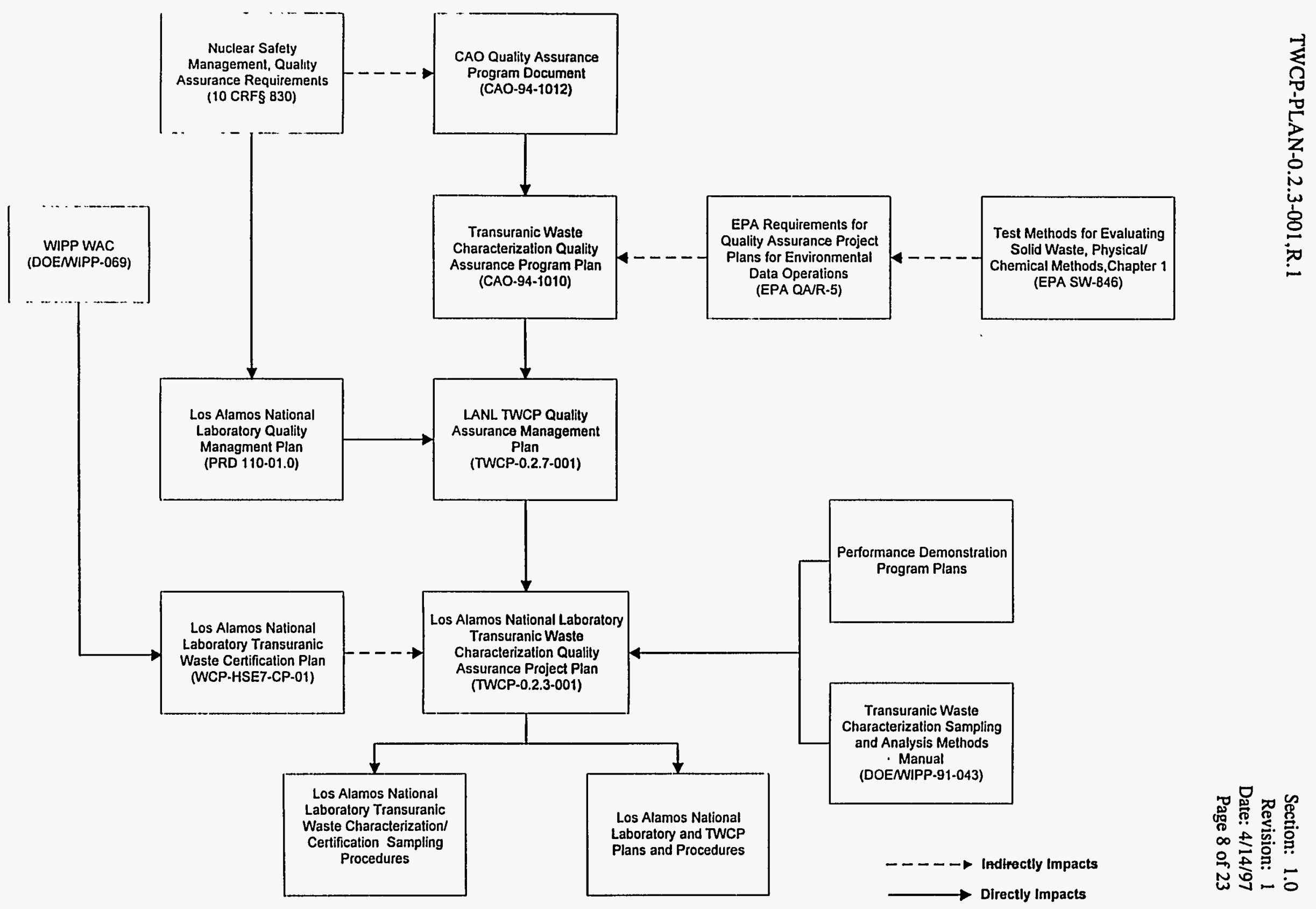

Figure 1-2. TWCP Document Hierarchy 
TWCP documents will follow the QAPjP document control format, consisting of a unique document identification number on each page and the section number, current revision number, date, and page number on each page. Prior to approval and distribution, all documents for the TWCP are reviewed by the Site Project QA Officer and a qualified technical staff member. The reviewers consider, as appropriate, the technical adequacy, completeness, and correctness of the documents and the inclusion of appropriate quality requirements. The reviewers indicate approval or concurrence on a signature and date page on the front of each document. Table 1-1 shows the parties responsible for project document review, review/approval, review/concurrence, implementation, change approval, and change control. Whenever documents are revised, review, concurrence, and approval of the revision are conducted by the same level of approval authority and in accordance with the same review requirements as the original documents.

This QAPjP is controlled by the SPM and the Site Project QA Officer and is distributed to all project participants, LAAO, and others identified on the controlled distribution list. The SPM establishes the distribution list for this QAPjP. If changes to this QAPjP are required, the SPM is responsible for scheduling and coordinating the review and approval of the revised document.

At a minimum, revisions to documents are denoted by including the current revision number on the document title page, the revised signature page, and each page that has been revised. Only revised forms need to be reissued as revised pages. A vertical bar, indicating the change to the text, is included along the left-hand margin of the page as revised pages. Revised document submittals also identify the changes, the reason for the changes, and the justification for concluding that the revised contents continue to satisfy the requirements of the TWCP.

This QAPjP, procedures, and revisions will be reviewed, approved, and concurred with by those individuals indicated in Table 1-1. The QAPjP will be reviewed at least annually by the SPM. The SPM is responsible for revising the QAPjP to comply with any approved changes to the QAPP and to reflect current operations. The SPM reports changes to LAAO for NTP notification.

The SPM and the Site Project QA Officer will evaluate and approve all changes to this QAPjP before implementation. The SPM will notify LAAO of the changes. The SPM will ensure that changes that affect performance criteria or data quality, such as sample handling and custody requirements, sampling and analytical procedures, quality assurance objectives (QAOs), calibration requirements, or QC sample acceptance criteria are approved by LAAO and the NTP team leader before implementation. Minor changes to the QAPjP and procedures that do not affect TWCP performance criteria or data quality will be made without prior notification of LAAO and the NTP team leader. 
Table 1-1. Requirements for Review, Approval, Implementation, and Control of the QAPjP and Procedures

\section{Responsible Party}

\begin{tabular}{|c|c|c|c|c|c|c|c|c|c|}
\hline & $\begin{array}{c}\text { Team Leader } \\
\text { National TRU } \\
\text { Program } \\
\end{array}$ & $\begin{array}{c}\text { Manager, } \\
\text { CAO Quality } \\
\text { Assurance }\end{array}$ & $\begin{array}{c}\text { LAAO } \\
\text { Radioactive } \\
\text { Waste } \\
\text { Manager }\end{array}$ & $\begin{array}{c}\text { Project } \\
\text { Leader/ } \\
\text { TRU Waste } \\
\text { Type Manager }\end{array}$ & $\begin{array}{c}\text { Site } \\
\text { Project } \\
\text { Manager }\end{array}$ & $\begin{array}{l}\text { Site Project } \\
\text { QA Officer }\end{array}$ & $\begin{array}{l}\text { TWCP } \\
\text { Operations } \\
\text { Leaders }\end{array}$ & $\begin{array}{c}\text { Technical } \\
\text { Staff } \\
\text { /Facility } \\
\text { Manager }\end{array}$ & $\begin{array}{c}\text { Document } \\
\text { Control } \\
\text { Staff }\end{array}$ \\
\hline \multicolumn{10}{|l|}{ QAPjP } \\
\hline Review/Approval & $\mathrm{x}$ & $x$ & $x$ & $\mathrm{x}$ & $\mathrm{x}$ & $\mathrm{x}$ & & & \\
\hline Implementation & & & & & $\mathrm{x}$ & & & & \\
\hline Change Approval & & & $x$ & $\mathrm{x}$ & $x$ & $x$ & & & \\
\hline Change Control & & & & & $\mathrm{x}$ & & & & \\
\hline $\begin{array}{l}\text { DOPs, QP, and SOPs } \\
\text { Review }\end{array}$ & & & & & & $\mathrm{x}$ & $\mathrm{x}$ & $\mathrm{x}$ & \\
\hline Review/Approval & & & & & & $\mathrm{x}$ & $\mathrm{x}$ & & \\
\hline Iniplementation & & & & & & & $\mathrm{x}$ & $\mathrm{x}$ & \\
\hline Change Approval & & & & & & $x$ & $\mathrm{x}$ & & \\
\hline Change Control & & & & & & & & & $\mathrm{x}$ \\
\hline
\end{tabular}




\subsection{Problem Definition and Background}

Most of the TRU waste generated at the Laboratory is generated at the plutonium processing facility at Technical Area (TA)-55, the Chemistry and Metallurgy Research (CMR) Building at TA-3, and the Waste Characterization, Reduction, and Repackaging Facility (WCRRF) at TA-50. The TRU waste is generated during plutonium-processing activities and during research, development, waste characterization, and reduction activities in support of TA-55. Examples of the Laboratory's TRU waste generated are discarded labware (glassware, windows, and bottles), pyrochemical salts, concreted aqueous waste, solidified inorganic and organic process solids, solidified aqueous waste, graphite waste, a small fraction of combustible waste (such as paper, rags, plastic, and rubber), combustible debris (room trash and glovebox trash), scrap metals, leaded rubber and metal waste (leadlined gloveboxes, motors, and tools), leaded gloves, cemented/immobilized residues and/or powders, filter media, and personal protective equipment.

From 1971 to 1979 the Laboratory stored TRU waste in underground pits and shafts at TA-54, Area G. Between 1979 and 1991 the Laboratory stored containers of solid, TRU waste on three abovegrade asphalt pads under earthen cover at TA-54, Area G. This method of retrievable storage was intended to provide weather protection and to comply with DOE's principle of maintaining exposure as low as reasonably achievable (ALARA). The Laboratory currently stores newly generated TRU waste in inspectable storage domes and plans to retrieve the waste containers from earthen cover and place them into the inspectable storage domes. Waste generated before development and implementation of the QA/QC requirements specified in this QAPjP is defined as retrievably stored TRU waste, while waste generated after the development and implementation of the QA/QC requirements specified in this QAPjP is defined as newly generated waste.

Approximately 80 to 90 percent of the Laboratory-generated TRU waste also contains hazardous waste that is regulated under the Resource Conservation and Recovery Act (RCRA). Any discussion in this QAPjP that refers to RCRA regulations promulgated by Title 40 Code of Federal Regulations (CFR) Parts 260 through 270 also refers to the corresponding New Mexico Environment Department (NMED) regulations in Title 20 of the New Mexico Administrative Code, Chapter 4, Part 1. Mixed waste refers to waste regulated by both the Atomic Energy Act and RCRA. In this QAPjP, the term TRU waste includes TRU and TRU mixed waste.

Over the WIPP facility's 25-year disposal phase, the Laboratory plans to dispose of approximately 8,757 cubic meters $\left(\mathrm{m}^{3}\right)$ of contact handled TRU waste and approximately $91 \mathrm{~m}^{3}$ of remote handled TRU waste. These are the volumes retrievably stored in various container types such as drums, boxes, and crates. In addition, the Laboratory plans to dispose of approximately $180 \mathrm{~m}^{3}$ per year of newly generated TRU waste. To ensure that TRU waste is characterized according to established requirements, the Laboratory has established the TWCP, which will consist of teams that retrieve, sample, and analyze waste; validate and report data; and provide project management, quality assurance, audit and assessment, and records management support.

The TWCP will characterize retrievably stored and newly generated TRU waste using the waste selection, testing, sampling, and analytical techniques described or referenced in this QAPjP. TWCP personnel will initiate TRU waste characterization for retrievably stored waste currently held in inspectable storage domes and will continue over the course of waste retrieval from earthen-covered storage units. This effort and characterization of newly generated TRU waste are coordinated with the Certification Plan and associated attachments 1 through 7 and the LANL WAC. 


\subsection{Project Description}

TWCP personnel characterize TRU waste on a waste stream basis. A waste stream is defined as waste material generated from a single process or activity that is similar in material, physical form, and hazardous constituents. TWCP personnel characterize TRU waste by obtaining chemical, radiological, and physical data as described in this QAPjP.

TWCP personnel use waste description nomenclature outlined in the DOE Waste Treatability Group Guidance. The nomenclature includes three broad matrix parameter categories of waste: homogeneous solids (summary category S3000), soil/gravel (summary category S4000), and debris wastes (S5000). The matrix parameter categories describe the physical form of the waste and are used to determine characterization requirements.

Table 1-2 lists the parameters to be determined by the various characterization activities, the techniques to be used, and the regulatory compliance programs to be undertaken by data users. All the compounds to be determined by sampling and analysis of wastes are also included in Table 1-2.

\subsubsection{Sampling and Analysis}

The frequency of waste selection, testing, sampling, and analysis required for retrievably stored and newly generated TRU waste is specified in Section 5.0 of this QAPjP. The Sampling Plan describes specific requirements for sampling retrievable and newly-generated TRU waste. The Laboratory uses methods from the Transuranic Waste Characterization Sampling and Analysis Methods Manual (Methods Manual) and Test Methods for Evaluating Solid Waste, Physical/Chemical Methods, Third Edition, Final Update I and Final Update II (SW-846). The SPM will submit any alternate methods the TWCP proposes to use to CAO for approval. Any alternate method must meet all of the requirements specified in Sections 7.0 through 15.0 of this QAPjP.

\subsubsection{Acceptable Knowledge}

LANL uses acceptable knowledge to assign matrix parameter categories and EPA hazardous waste numbers to waste streams, and to determine the waste material parameters and radionuclides present in waste streams. For each TRU waste stream, acceptable knowledge information is compiled in an auditable record; confirmed through radiography, visual examination, headspace gas analysis, and solidified waste sampling and analysis; and audited periodically to ensure adequacy of the information.

The criteria that will be used by auditors to evaluate the logic and defensibility of the acceptable knowledge documentation include completeness and traceability of the information, clarity of presentation, degree of compliance with regard to acceptable knowledge confirmation data, nonconformance procedures, and oversight procedures. Auditors will verify if sites include all required information and conservatively include all potential EPA hazardous waste numbers indicated by acceptable knowledge records.

The Laboratory's policy concerning the use and documentation of acceptable knowledge is defined in the Acceptable Knowledge Interim Laboratory Implementation Guidance (ILIG) Document and the implementation is described in Acceptable Knowledge Documentation (TWCP-QP-1.1-021). 
Table 1-2. Summary of Waste Characterization Requirements

\begin{tabular}{|c|c|c|}
\hline Parameter & Techniques & Compliance Program \\
\hline Radionuclide & Radioassay & Regulatory Requirement \\
\hline \multirow{2}{*}{$\begin{array}{l}\text { Pu-239 Fissile Gran Equivalents } \\
\text { Total Alpha Activity } \\
\text { TRU Activity } \\
\text { Individual Radioisotopes } \\
\text { Thermal Power }\end{array}$} & \multirow[t]{2}{*}{$\begin{array}{l}\text { Nondestructive Assay } \\
\text { (QAPjP Section 9.0) }\end{array}$} & $\begin{array}{l}\text { Performance Assessment } \\
\text { ( } 40 \text { CFR Part 191) }\end{array}$ \\
\hline & & $\begin{array}{l}\text { Transportation of } \\
\text { Radioactive Waste } \\
\text { (10 CFR Part 71) }\end{array}$ \\
\hline Physical Waste Form & Waste Inspection Procedures & Regulatory Requirement \\
\hline Matrix Parameter Categories & \multirow{5}{*}{$\begin{array}{l}\text { Radiography } \\
\text { Visual Examination } \\
\text { (QAPjP Section 10.0) }\end{array}$} & $\begin{array}{l}\text { Performance Assessment } \\
\text { (40 CFR Part 191) }\end{array}$ \\
\hline $\begin{array}{l}\text { Summary } \\
\text { Calegery Names }\end{array}$ & & $\begin{array}{l}\text { Land Disposal Restrictions } \\
\text { (40 CFR Part 268) }\end{array}$ \\
\hline $\begin{array}{ll}\text { S3000 } & \text { Homogeneous Solids } \\
\text { S4000 } & \text { Soil/Gravel } \\
\text { S5000 } & \text { Debris Wastes }\end{array}$ & & $\begin{array}{l}\text { General Waste Analysis } \\
\text { (40 CFR Part 270) }\end{array}$ \\
\hline \multicolumn{2}{|l|}{ Waste Material Parameters } & \\
\hline \multicolumn{2}{|l|}{$\begin{array}{l}\text { Iron-Based Metals/Alloys } \\
\text { Aluminum-Based Mctals/Alloys } \\
\text { Other Metals } \\
\text { Other Inorganic Materials } \\
\text { Cellulosics } \\
\text { Rubber } \\
\text { Plastics (waste material) } \\
\text { Organic Matrix } \\
\text { Inorganic Matrix } \\
\text { Soil } \\
\text { Steel (packaging material) } \\
\text { Plastics (packaging material) }\end{array}$} & \\
\hline
\end{tabular}




\section{DISCLAIMER}

This report was prepared as an account of work sponsored by an agency of the United States Government. Neither the United States Government nor any agency thereof, nor any of their employees, make any warranty, express or implied, or assumes any legal liability or responsibility for the accuracy, completeness, or usefulness of any information, apparatus, product, or process disclosed, or represents that its use would not infringe privately owned rights. Reference herein to any specific commercial product, process, or service by trade name, trademark, manufacturer, or otherwise does not necessarily constitute or imply its endorsement, recommendation, or favoring by the United States Government or any agency thereof. The views and opinions of authors expressed herein do not necessarily state or reflect those of the United States Government or any agency thereof. 
Table 1-2. Summary of Waste Characterization Requirements, Continued

\begin{tabular}{|c|c|c|c|}
\hline \multicolumn{2}{|l|}{ Parameter } & Techniques & Compliance Program \\
\hline \multicolumn{2}{|l|}{ Headspace Gases } & Gas Analysis & Regulatory Requirement \\
\hline \multirow{2}{*}{\multicolumn{2}{|c|}{$\begin{array}{l}\text { Hydrogen Methane } \\
\text { Yolatile Organic Compounds }\end{array}$}} & \multirow{3}{*}{$\begin{array}{l}\text { Gas Mass Spectroscopy (MS) } \\
\text { Gas Chromatography (GC) } \\
\text { (QAPjP Section 11.0) }\end{array}$} & $\begin{array}{l}\text { Land Disposal Restrictions } \\
\text { (40 CFR Part 268) }\end{array}$ \\
\hline & & & \\
\hline Elammable & Non-flammable & & $\begin{array}{l}\text { General Waste Analysis } \\
\text { (40 CFR Part 270) }\end{array}$ \\
\hline $\begin{array}{l}\text { Acetone } \\
\text { Benzene } \\
\text { Butanol } \\
\text { Chlorobenzene } \\
\text { Cyclohexane } \\
\text { 1,1-Dichloroethane } \\
\text { 1,2-Dicliloroethane } \\
\text { 1,1-Dichloroethylene } \\
\text { cis-1,2-Dichloroethylene } \\
\text { Ethyl benzene } \\
\text { Ethyl ether } \\
\text { Melhanol } \\
\text { Methyl ethyl ketone } \\
\text { Methyl isobutyl ketone } \\
\text { Toluene } \\
\text { 1,2,4-Trimethylbenzene } \\
\text { 1,3,5-Trimethylbenzene } \\
\text { Xylenes }\end{array}$ & $\begin{array}{l}\text { Bromoform } \\
\text { Carbon tetrachloride } \\
\text { Chloroform } \\
\text { Formaldehyde } \\
\text { Methylene chloride } \\
\text { 1,1,2,2-Tetrachloroethane } \\
\text { Tetrachloroethylene } \\
\text { 1,1,1-Trichloroethane } \\
\text { Trichloroethylene } \\
\text { 1,1,2-Trichloro-1,2,2-trifluoroethane }\end{array}$ & $\begin{array}{l}\text { Gas Chromatography/ } \\
\text { Mass Spectrometry (GC/MS) } \\
\text { Gas Chromatography/Flame lonization } \\
\text { Detector (GC/FID) } \\
\text { (QAPjP Section 12.0) }\end{array}$ & $\begin{array}{l}\text { Transportation of } \\
\text { Radioactive Waste } \\
\text { (10 CFR Part 71) }\end{array}$ \\
\hline \multicolumn{2}{|c|}{ Volatile Organic Compounds } & Total Volatile Organic Compound Analysis & Regulatory Requirement \\
\hline $\begin{array}{l}\text { Acetone } \\
\text { Benzene } \\
\text { Bromoform } \\
\text { Butanol } \\
\text { Carbon disulfide } \\
\text { Carbon tetrachloride } \\
\text { Chlorobenzene } \\
\text { Chloroform } \\
\text { 1,2-Dichloroethane } \\
\text { 1,1-Dichloroethylene } \\
\text { Ethyl benzene } \\
\text { Ethyl ether } \\
\text { Formaldehyde } \\
\end{array}$ & $\begin{array}{l}\text { Methanol } \\
\text { Methyl ethyl ketone } \\
\text { Methylene chloride } \\
\text { 1,1,2,2-Tetrachloroethane } \\
\text { Tetrachloroethylene } \\
\text { Toluene } \\
\text { 1,1,1-Trichloroethane } \\
\text { 1,1,2-Trichloroethane } \\
\text { Trichloroethylene } \\
\text { Trichlorofluoromethane } \\
\text { 1,1,2-Trichloro-1,2,2-trifluoroethane } \\
\text { Vinyl chloride } \\
\text { Xylenes }\end{array}$ & $\begin{array}{l}\text { Gas Chromatography/ } \\
\text { Mass Spectrometry (GC/MS) } \\
\text { Gas Chromatography/Flame Ionization } \\
\text { Detector (GCC/FID) } \\
\text { (QAPjP Section 13.0) } \\
\text { Acceptable Knowledge for } \\
\text { Matrix parameter summary category S5000 } \\
\text { (Debris Wastes) }\end{array}$ & $\begin{array}{l}\text { Land Disposal Restrictions } \\
\text { (40 CFR Part 268) } \\
\text { General Waste Analysis } \\
\text { (40 CFR Part 270) }\end{array}$ \\
\hline
\end{tabular}


Table 1-2. Summary of Waste Characterization Requirements, Continued

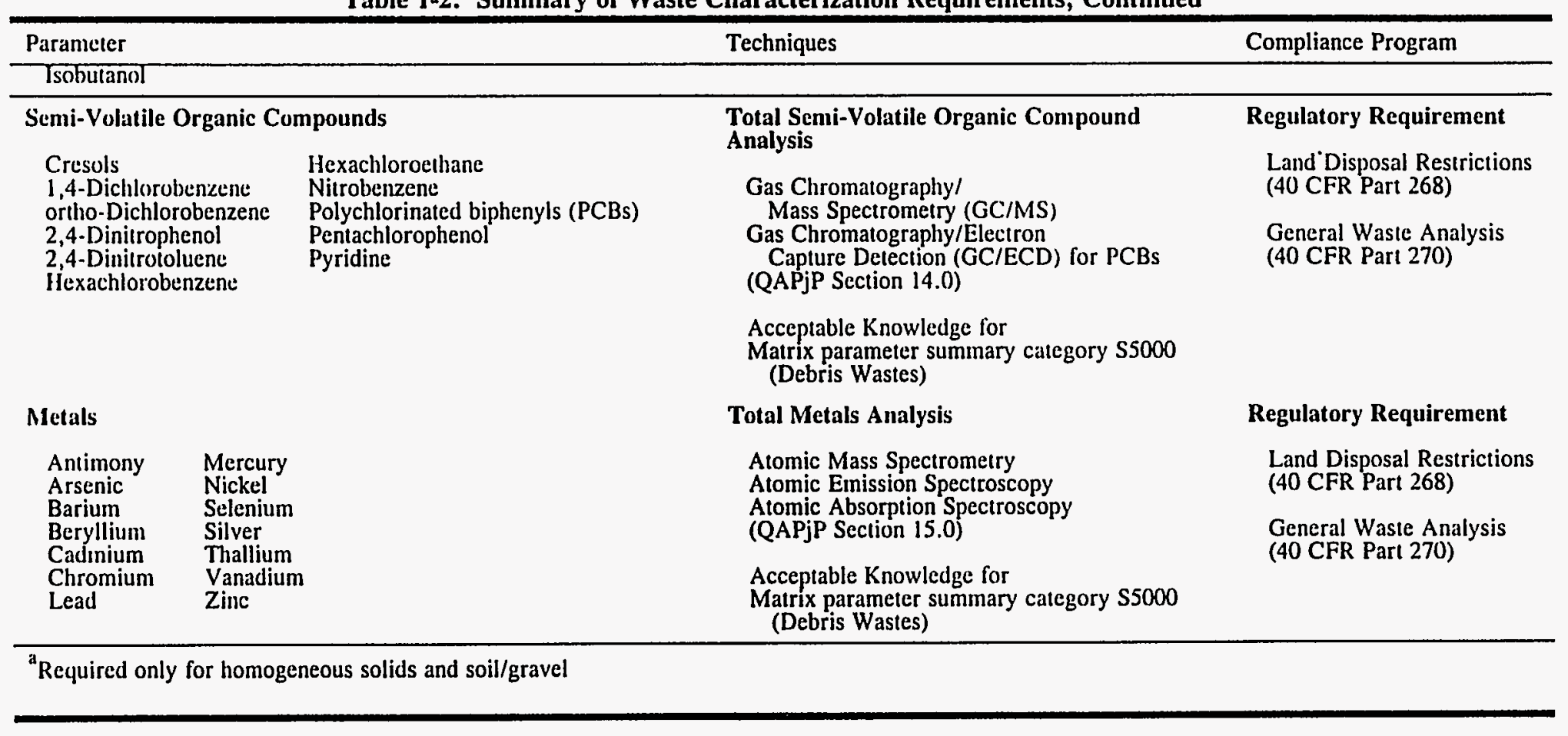




\subsection{Data Quality Objectives for Measurement Data}

DQOs are qualitative and quantitative statements that clarify TWCP technical and quality objectives, define the appropriate type of data, and specify tolerable levels of potential decision errors that will be used as the basis for establishing the quality and quantity of data needed to support decisions. CAO will use the waste characterization data obtained from the TWCP in regulatory compliance programs. During the WIPP disposal phase, the data also will be evaluated by regulatory agencies to assess DOE's compliance with applicable regulations at the WIPP facility. The DQOs established for the program (and adopted in this QAPjP) support these efforts and address the specific waste characterization parameters that will be evaluated. The DQOs for TWCP activities are as follows:

\section{Performance Assessment (40 CFR Part 191)}

- Radioassay

- To classify waste by activity as low-level radioactive waste (LLW) versus TRU by demonstrating with a 95-percent probability that the total TRU activity is less than or equal to 100 nanocuries per gram $(\mathrm{nCi} / \mathrm{g}$ ) of waste. The $\mathrm{QAO}$ for the minimum detectable concentration for TRU measurements was selected to help ensure that measurements in the 60 to $80 \mathrm{nCi} / g$ region can be made with sufficient precision to avoid designating excessive quantities of alpha-contaminated TRU waste as LLW.

- To confirm the radionuclide inventory on which the 40 CFR Part 191 Certification Application is based and assess compliance with the individual protection requirements, ground water protection standards, and containment requirements (40 CFR Part 191).

- Radiography

- To classify and verify the TRU waste inventory by matrix parameter category and waste material parameter, as described in the Waste Isolation Pilot Plant Transuranic Waste Baseline Inventory Report (BIR), on which the 40 CFR Part 191 Certification Application is based.

\section{RCRA Land Disposal Restrictions (40 CFR Part 268)}

- Radiography

- To verify the TRU waste streams by matrix parameter category, as described in the BIR, for purposes of physical waste form identification and determination of sampling and analytical requirements (Section 5.0).

- Gas Sampling and Analysis

- To quantify the concentrations of hydrogen, methane, and flammable volatile organic compounds (VOCs) by waste container and determine the potential flammability of TRU waste headspace gases.

- To quantify the concentrations of volatile organic hazardous constituents in the total waste inventory to support a demonstration that volatile organic hazardous constituents will not migrate through the air beyond the WIPP unit boundary in concentrations greater than EPA-determined health-based limits during the WIPP disposal phase. 
- Homogeneous Solids and Soil/Gravel Sampling and Analysis

- To compare the upper 90-percent confidence limit $\left(U C L_{90}\right)$ values for the mean measured contaminant concentrations in a waste stream to the specified regulatory levels (40 CFR Part 261, Subpart C). That is, to determine if a waste stream exhibits a toxicity characteristic (TC).

- To report the average concentrations, standard deviation, UCL 90 , and number of samples collected for hazardous constituents in a waste stream, as specified in $40 \mathrm{CFR}$ Part 261, Appendix VIII.

\section{RCRA General Waste Analysis (40 CFR Part 270)}

- Radiography

- To verify the TRU waste streams by matrix parameter category, as described in the BIR, for purposes of physical waste form identification and determination of sampling and analytical requirements (Section 5.0).

- Gas Sampling and Analysis

- To quantify the concentrations of hydrogen, methane, and flammable VOCs in waste containers and determine the potential flammability of TRU waste headspace gases.

- Homogeneous Solids and Soil/Gravel Sampling and Analysis

- To compare the UCL $\mathrm{U}_{90}$ values for the mean measured contaminant concentrations in a waste stream to the specified regulatory levels (40 CFR Part 261, Subpart C). That is, to determine if a waste stream exhibits a TC.

\section{Transportation of Radioactive Waste (10 CFR Part 71)}

- Radioassay

- To classify waste by activity as low level versus TRU by demonstrating with a 95percent probability that the TRU activity is less than or equal to $100 \mathrm{nCi} / \mathrm{g}$ of waste.

- To obtain the total activity in TRU waste to support revision of the thermal power restrictions for shipment of waste in the TRUPACT-II.

- Gas Sampling and Analysis

- To quantify the concentrations of hydrogen, methane, and flammable VOCs in waste containers and determine the potential flammability of TRU waste headspace gases during transport in the TRUPACT-II.

- To quantify hydrogen and methane headspace concentrations in waste containers to support revision of the thermal power restrictions for shipment of TRU waste in the TRUPACT-II.

The TWCP will meet action levels to support compliance decisions, including the detection limits and reporting units (if applicable) for each testing, sampling, and analytical technique, as presented in Sections 7.0 through 15.0 of this QAPjP. These sections also describe the requirements for precision, accuracy, bias, method detection limit, program required detection limit, minimum detectable concentration, program required quantitation limit, total uncertainty, completeness, comparability, and representativeness (if applicable) in the form of QAOs. TWCP personnel will refer to descriptions and calculation methods for these QAOs in Section 3.0 or in the specific section describing the applicable technique. 


\subsection{Training and Certifications}

The Laboratory has adopted performance-based training (PBT) as its standard for training. PBT is a systematic approach to training based on tasks and the related skills and knowledge required for competent job performance. The Laboratory's Training and Development Group is responsible for developing the training standards to be implemented by Laboratory organizations. Laboratory organizations implement these training standards and develop and implement site-specific training programs to ensure compliance with the CAO QAPD and 10 CFR $\S 830.120$ training and qualification requirements and other applicable federal or state laws, orders, or regulations.

TWCP operations leaders, together with qualified training staff, identify and implement TWCP personnel training needs according to the TWCP Training Implementation Plan (TWCP-QP-1.1-003). Before performing TWCP activities, all TWCP personnel will also receive training on the TWCP's scope, purpose, objectives, and the specific QAOs of the assigned task. Each TWCP operations leader will ensure that TWCP personnel under his or her supervision have the education, experience, and training applicable to their assigned TWCP tasks and that they maintain proficiency and competency in these task(s). Each TWCP operations leader will determine the positions that require qualification or certification and will ensure that TWCP personnel assigned to these positions meet initial and continuing qualification or certification requirements. Each TWCP operations leader will ensure that auditable records that document the required personnel qualification or certification are maintained in the Laboratory's employee development system (EDS) database.

TWCP personnel follow the TWCP Training Implementation Plan (TWCP-QP-1.1-003) to implement the requirements of the QAPD and QAPP. Analytical laboratories follow their own training plan, as detailed in the interface document, to ensure that the analytical personnel are adequately qualified and trained. TWCP operations leaders evaluate and document TWCP personnel job performance every year and identify revised qualification requirements or training needs. Many of the positions identified in the QAPP require a two-year recertification, and are described in the TWCP Training Implementation Plan (TWCP-QP-1.1-003). The minimum qualifications for certain TWCP positions are summarized in Table 1-3.

\subsection{Records Management}

The Laboratory's records inventory, retention, and disposition procedures meet the requirements of the QAPD; DOE Order 200.1, "Information Management Program"; and the CAO QAPD. TWCP personnel follow the procedure Records Management for the TWCP (TWCP-QP-1.1-004) developed and implemented by the TWCP. The TWCP Records Management/Document Control (RMDC) Center is responsible for indexing and maintaining TWCP records.

\subsubsection{Site Project Files}

The SPM sends data and related information to CAO, as described in Section 3.0. The SPM ensures that all summarized data reported to the $\mathrm{CAO}$ are traceable to the original, raw data records and that all records are legible, clearly identified, retrievable, and secured in dual controlled-access facilities. The SPM will ensure that electronically transmitted data are compatible with and formatted in accordance with the WIPP computer system requirements. 
The CRM, TWCP, and analytical services records management systems provide control and retention for all the TWCP-related information. The CST Analytical Chemistry records management staff are responsible for managing records generated by analytical laboratories. All waste characterization data and related QA/QC records in the site project files for waste to be shipped to the WIPP facility are designated as either lifetime records or nonpermanent records. TWCP records management personnel will maintain lifetime records for the life of the TWCP, plus 6 years, then offer them to CAO or transfer to the appropriate Federal Records Center (FRC) in accordance with DOE Order 200.1. They will maintain nonpermanent records for 10 years from the date of generation and then discard them. Table 1-4 lists records designated as lifetime records and nonpermanent records. Records management personnel follow the procedures discussed in Section 1.7 for receiving records from external sources, transmitting records, transferring records to storage, and storing records. They also follow these procedures for maintaining records in central TWCP files to ensure that records are protected from damage or deterioration from excessive light, stacking, electromagnetic fields, temperature, and humidity.

Table 1-3. Minimum Training and Qualification Requirements ${ }^{\mathbf{a}}$

\begin{tabular}{|c|c|}
\hline Personnel & Requirements $^{\mathrm{a}}$ \\
\hline Radiography Operators $^{c}$ & $\begin{array}{l}\text { Site-specific training based on matrix } \\
\text { parameter categories and waste material } \\
\text { parameters; requalification every } 2 \\
\text { years }\end{array}$ \\
\hline
\end{tabular}

Gas Chromatography Technical Supervisors ${ }^{b}$

Gas Chromatography Operators ${ }^{c}$

Gas Chromatography/Mass Spectrometry Operators ${ }^{c}$

Mass Spectrometry Operators ${ }^{c}$

Gas Chromatography/Mass Spectrometry

Technical Supervisors ${ }^{b}$

Mass Spectrometry Technical Supervisors ${ }^{\mathrm{b}}$

Atomic Absorption Spectroscopy Technical Supervisors ${ }^{b}$

Atomic Absorption Spectroscopy Operators ${ }^{\mathrm{c}}$

Atomic Mass Spectrometry Operators ${ }^{c}$

Atomic Emission Spectroscopy Operators ${ }^{\epsilon}$

Atomic Mass Spectrometry Technical Supervisors ${ }^{b}$

Atomic Emission Spectroscopy Technical Supervisors ${ }^{b}$
B.S. or equivalent experience and 6 months previous applicable experience

B.S. or equivalent experience and 1 year independent spectral interpretation or demonstrated expertise

B.S. or equivalent experience and 1 year applicable experience
B.S. and specialized training in atomic mass spectrometry and 2 years applicable experience

B.S. and specialized training in atomic emission spectroscopy and 2 years applicable experience.

\footnotetext{
${ }^{2}$ Based on requirements contained in US EPA Contract Laboratory Program Statement of Work for Organics Analysis (OLM 01.0) and Statement of Work for Inorganics Analysis (ILM 03.0).

${ }^{b}$ Technical supervisors are those persons responsible for the overall technical operation and development of a specific laboratory technique.

'Operators are those persons responsible for the actual operation of analytical equipment.
} 
Table 1-4. Required Program Records Maintained in Site Project Files

Lifetime Records

- Field sampling data forms

- Field and laboratory chain-of-custody forms

- Test facility and laboratory analytical data reports

- Summary data packages

- Sampling plans

- Data reduction, validation, and reporting documentation

- Acceptable knowledge documentation

- Data reconciliation report

- Waste Stream Profile Form

\section{Non-Permanent Records}

- Nonconformance documentation

- Variance documentation

- Assessment documentation

- Gas canister tags

- Methods performance documentation

- Performance Demonstration Program documentation

- Sampling equipment certifications

- Calculations and related software documentation

- Training/qualification documentation

- QAPP (CAO)/ QAPjP (sites) documentation (all revisions)

- Calibration documentation

- Analytical raw data

- Procurement documentation

- QA procedures (all revisions)

- Technical implementing procedures (all revisions)

- Audio/video recording [real time radiography (RTR, visual, etc.)]

\subsubsection{Flow of Records}

The SPM ensures that a Drum Information and Tracking form is initiated in accordance with Waste Container Tracking (TWCP-DTP-1.2-020) for each waste container to be characterized. When a waste container is transferred from one characterization process to another, the operations leaders involved update the on-line tracking form. The appropriate TWCP operations leader submits completed radiography, radioassay, and visual examination data forms to the Site Project QA Officer. The operations leaders responsible for headspace sampling and homogeneous solid and soil/gravel sampling initiate a sample chain of custody (COC) form for each waste container sampled. Following waste container sampling, the operations leader ensures that the sample COC form accompanies the sample to the analytical laboratory. The operations leader submits the appropriate sampling data reports and a copy of the sample COC form to the Site Project QA Officer. Following analyses, the analytical 
services personnel submit the original sample $\mathrm{COC}$ form and the analytical data package to the Site Project QA Officer, who performs project-level validation and verification according to Section 3.0 of this QAPjP.

The Site Project QA Officer then prepares a Site Project QA Officer Summary and forwards the summary, all the waste characterization documentation, and a signature release to the SPM (or designee) (Section 3.1.2). The SPM (or designee) prepares a Data Validation Summary and transmits a hard copy of the data, the SPM signature release, and the Site Project QA Officer's signature release to $\mathrm{CAO}$ (Section 3.4.2). The CAO notifies the SPM in writing if the data package is acceptable.

\subsection{Procurement}

The Laboratory has implemented procedures to ensure that procured items and services meet established requirements and perform as specified. These procedures address control of purchased items, services, subcontractors, and suppliers. Procurement controls specified by this QAPjP are applicable to equipment and services that directly affect the quality of testing, sampling, and analytical data.

\subsubsection{Procurement Document Control}

The Laboratory ensures that the design bases and other requirements necessary to ensure adequate quality are included or referenced in procurement documents for any equipment and services directly affecting the quality of TWCP data. Each TWCP operations leader ensures that QA requirements for purchase requests are met according to the Procurement (TWCP-QP-1.1-005). The Quality Assurance Support Group Receiving and Inspection Team reviews all procurement documents for completeness and accuracy before release to the suppliers.

To the extent necessary, Laboratory procurement documents specify the quality elements for which the supplier is responsible, and require suppliers of equipment or analytical services to have a QA program that meets or exceeds the applicable criteria of the QAPjP. If suppliers do not have a QA program that addresses the QAPjP requirements, they must agree to comply with the applicable section(s) of this QAPjP. The SPM is responsible for verifying supplier compliance with the applicable $\mathrm{QA} / \mathrm{QC}$ requirements.

\subsubsection{Control of Purchased Items and Services}

The Laboratory controls the procurement of items and services that directly affect the quality of testing, sampling, and analytical data to ensure conformance with specified requirements. Such control includes, as appropriate, the evaluation of selected services or equipment, review and evaluation of the QA program provided by the supplier, and inspection, audit, and examination of items or services upon delivery or completion. These controls are described in Procurement (TWCP-QP-1.1-005).

The Laboratory's Business Support Services Division personnel document and control the purchase or use of all equipment and replacement parts, or design modifications to existing equipment. The SPM ensures that material or equipment from a supplier is verified, inspected, or tested before acceptance and that services are reviewed, inspected, or audited according to the General Inspection Procedure (RIT-2R1). Each TWCP operations leader maintains documents traceable to the material or equipment used by TWCP personnel. 


\subsubsection{Control of Subcontractors}

If the Laboratory should use off-site analytical laboratories for waste characterization, the Site Project QA Officer may perform prequalification audits to determine subcontractor acceptability. The Laboratory will include QAPjP and performance requirements as part of subcontractor agreements associated with the TWCP. The Site Project QA Officer will ensure that each subcontractor complies with all QAPjP requirements through an inspection or audit, and the results and tracking of any corrective actions are documented as discussed in Section 2.0 of this QAPjP. Subcontractors providing analytical services are to participate in the PDP. Subcontractors complete and submit copies of all TWCP-related records to the SPM. The Laboratory will review documentation prepared by subcontractors to verify subcontractor conformance to the TWCP QA/QC requirements and will, as necessary, perform assessments of subcontractor activities. Subcontractors shall provide access to their work areas and records for inspection and auditing.

\subsection{Work Processes}

TWCP personnel follow approved DTPs. TWCP personnel conducting the work are trained to implement these procedures through classroom, on-the-job, or self-paced training.

\subsubsection{Control of Processes}

Each TWCP operations leader ensures that TWCP activities are controlled and conducted in accordance with controlled procedures. They ensure that procedures are reviewed annually and updated, as necessary.

\subsubsection{Identification and Control of Items}

TWCP personnel follow written procedures described in Equipment Calibration and Maintenance (TWCP-QP-1.1-018) for identifying and controlling materials or equipment. The QAPjP also describes methods for controlling items that have a limited shelf life or operating life to preclude use of items whose shelf life or operating life has expired.

\subsubsection{Computer Hardware and Software}

TWCP personnel maintain computer software in compliance with the CAO QAPD and Software Management (TWCP-QP-1.1-006). They test computer software and hardware/software configurations developed as part of the program according to Software Management (TWCP-QP-1.1-006). Computer software and hardware/software configurations specifically developed as part of the TWCP are verified, validated, tested, and documented with user's manuals prior to use in accordance with these requirements. Commercially available software does not require testing prior to use.

TWCP personnel maintain the results of such testing in the TWCP files in a manner traceable to the specific equipment configuration. Computer hardware/software configurations that are regularly calibrated for a specific purpose (e.g., automated analytical equipment) do not require further testing unless the scope of use changes or the hardware/software configuration is modified. 


\subsection{Grading Items and Activities}

The TWCP approach to QA requires the use of a graded application of QA criteria. The extent of management and QA controls applied to an item or activity will vary as a function of the degree of confidence needed to achieve the desired quality of the item or activity. In general, items and activities will be assigned to one of two levels based on potential consequences and probability of those consequences occurring without QA controls. The grading process is conducted in accordance with Grading TWCP Activities (TWCP-QP-1.1-029) and is based on the following factors:

- Level of risk

- Status and condition of a facility or process

- History of problems within the process or program

- Adequacy of existing safety documentation

- Complexity of products or services involved

The Site Project QA Officer evaluates the TRU waste program activities and recommends to the operations leaders those activities that should be classified as quality-affecting within their areas of responsibility, using the WBS (work breakdown structure) list. The SPM reviews and concurs with the quality level assignment, and the quality-affecting activity list is maintained in the RMDC as a record.

\subsection{Procedures Specific to This Section}

Table 1-5 lists the procedures specific to this section of the QAPjP.

Table 1-5. Section 1.0 Procedures

\section{Document Number}

TWCP-QP-1.1-001

TWCP-QP-1.1-002

TWCP-QP-1.1-003

TWCP-QP-1.1-004

TWCP-QP-1.1-005

TWCP-QP-1.1-006

TWCP-QP-1.1-018

TWCP-QP-1.1-029

TWCP-DTP-1.2-020

PRD115-01.0

RIT-2 RI, ESH-14
Title

Developing TWCP Proceduress

Document Control

TWCP Training Implementation Plan

Records Management for the TWCP

Procurement

Software Management

Equipment Calibration and Maintenance

Grading TWCP Activities

Waste Container Tracking

Document Control

General Inspection Procedure 


\subsection{ASSESSMENT AND OVERSIGHT}

The Laboratory TWCP participates in assessment and oversight activities to ensure that the requirements of the QAPjP are being met. These activities include formal audits of project activities by CAO; Laboratory management audits of the project; independent audits by site personnel; and participation in the Performance Demonstration Program (PDP). Corrective actions are taken when conditions adverse to quality are identified.

\subsection{Assessment and Response Actions}

When conditions are identified that are adverse to the QAPjP requirements, the Laboratory initiates and documents corrective actions (CARs). The Site Project QA Officer tracks all corrective actions through final resolution in accordance with the procedure Corrective Action Reporting (TWCP-QP-1.1008). The TWCP documents these activities in the semiannual report.

\subsubsection{Carlsbad Area Office Audits}

The TWCP participates in the audit program conducted by CAO personnel. The TWCP participates in an initial audit before any TRU waste is shipped to WIPP and annually thereafter. The SPM and Site Project QA Officer coordinate the audit scheduling with the NTP team leader. The Laboratory provides the audit team with access to appropriate site programs, managers, and personnel. The Site Project QA Officer obtains audit results, responds to findings identified in CAO audit reports, schedules and tracks corrective actions, and finalizes resolution of all findings. The Site Project QA Officer is responsible for forwarding details of the audits to the SPM and LAAO.

\subsubsection{Nonconformances and Operational Variances}

The SPM and the Site Project QA Officer monitor and control the project activities and status of work by a system that tracks conditions adverse to quality and their corrective actions; nonconforming items and their dispositions; and identifies, documents, and reports variances. Management shall foster a "no-fault" attitude to encourage the identification of nonconforming items and processes.

Conditions adverse to quality is a term used for failures, malfunctions, deficiencies, and nonconforming items and processes. Conditions adverse to quality shall be identified and documented in accordance with the requirements in Corrective Action Reporting (TWCP-QP-1.1-008).

Documentation shall clearly identify and describe the characteristics that do not conform to specified criteria. Conditions adverse to quality shall be classified as either (1) conditions adverse to quality or (2) significant conditions adverse to quality. Corrective actions shall be developed accordingly. Significant conditions adverse to quality are conditions that if not corrected could have a serious effect on safety, operability, waste isolation, compliance, or the reliability of the QA program.

Nonconforming items shall be identified, segregated when practical, and controlled to prevent any adverse impact on test, installation, or use. Project staff, laboratory staff, or QA personnel may identify a nonconformance during any process or activity relating to this project. The individual identifying the nonconformance shall prepare a report, as detailed in Nonconformances (TWCP-QP-1.1-007). 
Variances are changes to project-related plans or procedures that require approval and control. All project staff members are responsible for identifying the need to initiate a variance for the work they are performing. completing a Record of Variance form, and obtaining the approval signature of their operations leader and the Site Project QA Officer. A Record of Variance must follow the procedure found in Record of Variance Preparation and Implementation (TWCP-QP-1.1-019) and as detailed by the QAPD and QAPP.

\subsubsection{Quality Improvement}

The Laboratory TWCP is continually evaluating and improving project activities. The Site Project QA Officer is responsible for implementing quality improvements to the project and will use Root Cause Analysis (TWCP-QP-1.1-020) to determine causes of any conditions adverse to quality and will analyze trends in the QA data in accordance with Trend Analysis (TWCP-QP-1.1-026). The TWCP uses processes such as initial planning, appropriate training, control of work operations by procedures, audits, control charts, nonconformance and corrective action tracking, and data review, validation, and verification to detect and prevent unacceptable quality problems. Each analytical team tracks the results of matrix spikes, blanks, duplicates, and other QC samples in the form of control charts to identify trends in data quality. Team personnel verify calibrations and document results to track instrument operation parameters. The Site Project QA Officer ensures that DQOs are met by data validation.

\subsubsection{Management Assessments}

Management assessments are conducted to assess the performance of all aspects of the organization. They may be performed by TWCP personnel or by outside personnel. TWCP waste management and technical supervisory staff participate in assessments. Management assessments focus on the identification and resolution of both systemic and management issues and problems while encouraging an atmosphere of creativity and improvement. Processes assessed include strategic planning, organizational interfaces, cost control, use of performance indicators, staff training and qualification, and supervisory oversight and support. The assessment will also consider such things as employee knowledge, motivation, morale, mutual trust, and communication among workers and organizations. Assessments are performed using Assessments and Assessment Resolution (TWCP-QP-1.1-013).

\subsubsection{Independent Assessments}

\section{General}

The TWCP participates annually in an independent assessment conducted by site personnel independent of the program in compliance with Assessments and Assessment Resolution (TWCP-QP-1.1-013). The assessment may be performed by an outside agency to evaluate TWCP performance in meeting the management requirements of the QAPP, QAPD, QAPjP, procedures, and other site-specific documents. The SPM and Site Project QA Officer may provide representatives from their offices to conduct the assessments of the analytical and testing facilities. Line management is responsible for tracking and resolving any problems or findings identified by the independent assessment team according to Assessments and Assessment Resolution (TWCP-QP-1.1-013). 


\section{Surveillances}

When surveillances of activities are required to (1) monitor work in progress; (2) document compliance or noncompliance with established requirements and procedures; (3) identify actual and potential conditions adverse to quality; (4) obtain timely corrective action commitment from managers for identified conditions adverse to quality; (5) provide notification to responsible managers of the status and performance of work under surveillance: and (6) verify timely implementation of corrective action, the procedure Surveillances (TWCP-QP-1.1-009) is used.

\section{Audits}

When an audit of activities is required to determine the adequacy of and compliance with procedures, and the effectiveness of implementation, the procedure Audits (TWCP-QP-1.1-027) is used.

\subsection{Reports to Management}

The Site Project QA Officer is responsible for obtaining all pertinent QA/QC information and reporting to the SPM and LAAO semiannually, in accordance with the QAPP. The semiannual report will include the following elements:

- Changes in the QAPjP

- Significant QA/QC problems, recommended solutions, and corrective actions

- Assessment of QC data obtained during the past reporting period, frequency of repeated analysis, reason for unacceptable performances, and corrective actions

- Discussion of meeting QA objectives, including subsequent impacts, on decision making

- Limitations of the measurement data

- Status of PDP sample results

- Results of audits, assessments, and surveillance

\subsection{Performance Demonstration Program}

The PDP is described in the most current revision of the following documents or plans:

- Performance Demonstration Program Plan for Nondestructive Assay for the TRU Waste Characterization Program (NDA PDP Plan)

- Performance Demonstration Program Plan for the Analysis of Simulated Headspace Gases for the TRU Waste Characterization Program (Gas PDP Plan)

- Performance Demonstration Program Plan for the RCRA Constituent Analysis Analysis of Solidified Wastes (Solid PDP Plan) 
Testing and analytical facilities demonstrate conformance with the QA objectives of the project. TWCP analytical and testing personnel receive single-blind audit samples semiannually from CAO. Each analytical and testing facility operations leader is responsible for accepting, preparing, and analyzing the PDP blind audit samples and reporting the results to the Site Project QA Officer. The Site Project QA Officer is responsible for forwarding all results and documentation to CAO in accordance with the applicable PDP Plan. The Site Project QA Officer receives written notification from the NTP waste characterization manager of the adequacy of the testing and analytical facilities' performance and the approval for participation in the TWCP.

\subsection{Procedures Specific to This Section}

Table 2-1 lists the procedures specific to this section of the QAPjP.

Table 2-1. Section 2.0 Procedures

\begin{tabular}{ll}
\hline \multicolumn{1}{c}{ Document Number } & \multicolumn{1}{c}{ Title } \\
\hline TWCP-QP-1.1-007 & $\begin{array}{l}\text { Nonconformances } \\
\text { Corrective Action Reporting } \\
\text { TWCP-QP-1.1-008 }\end{array}$ \\
TWCP-QP-1.1-009 & Surveillances \\
TWCP-QP-1.1-013 & Assessments and Assessment Resolution \\
TWCP-QP-1.1-019 & Record of Variance Preparation and Implementation \\
TWCP-QP-1.1-020 & Root Cause Analysis \\
TWCP-QP-1.1-022 & PDP Blind Audit Sample Management, Analysis, and Reporting \\
TWCP-QP-1.1-026 & Trend Analysis \\
TWCP-QP-1.1-027 & Audits \\
\hline
\end{tabular}




\subsection{DATA VALIDATION, USABILITY, AND REPORTING}

TWCP personnel perform data reviews, data validations, and data verifications on 100 percent of testing, sampling, and analytical data, except where noted. The SPM and the Site Project QA Officer are responsible for ensuring that all batch data packages and reports are complete and accurate.

TWCP personnel test waste containers in testing batches. A testing batch is a suite of waste containers undergoing radioassay or radiography using the same testing equipment. A testing batch consists of up to 20 waste containers without regard to waste matrix. TWCP personnel collect samples in sampling batches. A sampling batch is a suite of samples of similar matrix (i.e., gas or solid) collected consecutively using the same sampling equipment within a specific time period. A sampling batch consists of up to 20 samples (excluding field QC samples), all of which are collected within 14 days of the first sample in the batch. TWCP personnel analyze samples in analytical batches. An analytical batch is a suite of samples of similar matrix (i.e., gas or solid) processed as a unit, using the sample analytical method within a specific time period. An analytical batch consists of up to 20 samples (excluding laboratory QC samples), all of which have been received by the analytical laboratory within 14 days of the validated time of sample receipt (VTSR) of the first sample in the batch.

\subsection{Data Review, Validation, and Verification}

TWCP personnel review, validate, and verify data at the data generation level, and validate and verify data at the project level. Operation leaders are responsible for these activities at the data generation level, and the SPM and Site Project QA Officer are responsible for these activities at the project level.

\subsubsection{Data Generation Level}

All operation leaders are responsible for ensuring data review, validation, and verification in their respective technical areas. Data Generation Level Review (TWCP-QP-1.1-011) details review, validation, and verification procedures. The procedures referenced in Sections 7.0 through 15.0 detail the data reduction requirements for testing, sampling, and analytical personnel. The TWCP ensures that the raw data collection and management requirements are met through the use of Laboratory Notebooks and Logbooks (TWCP-QP-1.1-012).

The Site Project QA Officer documents any nonconformances according to Section 2.5. The TWCP uses checklists that address all items in this section, which include tables of sampling and analytical batch QC sample results. The Site Project QA Officer receives the completed checklists with the testing, sampling, and analytical batch data reports.

The operation leaders are responsible for ensuring that a technical review by an independent reviewer is performed on 100 percent of the data. The independent reviewer, by his or her signature, documents that data generation personnel have completed their data generation level review in accordance with Data Generation Level Review (TWCP-QP-1.1-011). 
Operation leaders or technical supervisors ensure and document that:

- The data are technically reasonable based on the method and written procedure used

- An independent review was performed on 100 percent of the data except radiography tapes, which receive a technical review on 10 percent of the waste containers

- Testing, sampling, and analytical batch data QA documentation is complete and includes raw data, calculation records, COC forms, calibration records, QC sample results, and gas sample canister tags

- Sample holding time requirements were met and exceptions documented

- Complete field sampling records are included with the documentation specified in Section 6.0

- Any problems or comments noted in the independent technical review that can be addressed are.

Finally, the data generation level QA officer, following TWCP-QP-1.1-011, ensures by his or her signature that:

- Both independent technical and technical supervisory reviews were performed as evidenced by the reviewers' signatures

- The testing, sampling, and analytical batch data QA documentation is complete

- Sampling and analytical QC checks were performed according to the appropriate procedure and QC data not meeting the acceptance criteria are documented

- Appropriate QAOs were met according to the procedures referenced in Sections 7.0 through 15.0.

\subsubsection{Project Level}

The TWCP validates and verifies the testing, sampling, and analytical data on the project level in accordance with Project Level Data Validation and Verification (TWCP-QP-1.1-010). The Site Project QA Officer releases 100 percent of the testing, sampling, and analytical data to the SPM, and by signature ensures that:

- Sampling batch QC checks were collected according to the procedures referenced in Sections 7.0 and 8.0 and meet the established QAOs

- Testing batch QC checks were performed in accordance with procedures referenced in Sections 9.0 and 10.0 
- Analytical batch QC checks were analyzed in accordance with procedures referenced in Sections 11.0 through 15.0 and meet the established QAOs

- Representative samples of headspace gas, homogeneous solids, and soil/gravel were taken in accordance with procedures referenced in Sections 5.0 and 6.0

- Complete and acceptable radiography data were obtained based on the videotape review of at least one waste container per testing batch

- Radioassay data are complete and acceptable.

The Site Project QA Officer prepares the Site Project QA Officer Summary based on the validation and verification process stated above in accordance with TWCP-QP-1.1-010.

The SPM releases 100 percent of the testing, sampling, and analytical data, and by his or her signature ensures that:

- The data generation level independent technical, technical supervisory, and QA officer review, validation, and verification are complete, as evidenced by appropriate signatures

- Testing, sampling, and analytical batch data review checklists are complete

- Testing, sampling, and analytical batch data reports are complete and data are properly reported

- DQOs were reconciled according to Section 3.3.

The SPM prepares the Data Validation Summary based on the validation and verification process stated above in accordance with TWCP-QP-1.1-010 and notifies the data generation facilities. Analytical laboratories retain samples until this notification is received.

\subsubsection{CAO Level}

The third and final level of data verification is at CAO and consists of an inventory check of the data packages to verify completeness. The data packages need to include the following:

- $\quad$ Project-level signature releases

- Listing of all waste containers being reported in the package

- Listing of all testing, sampling, and analytical batch numbers associated with each waste container being reported in the package

- Data package case narrative

- $\quad$ Site Project QA Officer Summary

- Data Validation Summary

- $\quad$ Complete summarized qualitative and quantitative data for all waste containers. 
The CAO Regulatory Compliance Manager will verify that each data package is complete and notify LANL in writing of the acceptance status of the data within two weeks of data package receipt.

\subsection{Validation Methods}

The data generation level QA officer performs quantitative data validations according to Data Generation Level Review (TWCP-QP-1.1-011). He or she compares these quantitative determinations to the QAOs specified in Sections 11.0 through 15.0 and also performs a qualitative determination of representativeness. Section 9.0 of this $\mathrm{QAPjP}$ presents validation methods for radioassay. The TWCP uses visual examination results to verify the matrix parameter category and waste material parameter weights determined by radiography, as described in Section 10.0.

The SPM documents that the selected waste containers from within a waste stream are randomly selected according to Random Selection of Containers and Sampling Locations for TRU Waste Characterization Activities (TWCP-DTP-1.2-014). Sampling personnel verify that proper procedures are followed to ensure that samples are representative of the waste contained in a particular waste container or a waste stream by following the procedures listed in Sections 7.0 and 8.0.

Precision, accuracy, method detection limit, completeness, and comparability are described in detail in Data Generation Level Review (TWCP-QP-1.1-011).

\subsection{Reconciliation with Data Quality Objectives}

\subsubsection{Reconciliation at the Project Level}

The SPM ensures that all data generated meet the DQOs provided in Section 1.6, according to Determination of Sufficient Data for Waste Stream Characterization and Reconciliation with Data Quality Objectives (TWCP-QP-1.1-023). As part of this reconciliation, the SPM performs the following:

- Assesses whether data of sufficient type, quality, and quantity have been collected

- Determines if the variability of the data set is small enough to provide the required confidence in the results

- Determines if, based on the desired error rates and confidence levels, a sufficient number of valid data points have been determined

- Documents that random sampling of containers was adequate to characterize a waste stream.

Furthermore, the SPM determines if sufficient data have been collected to determine the following Program-required waste parameters for each waste stream, according to Project Level Data Validation and Verification (TWCP-QP-1.1-010), Determination of Sufficient Data for Waste Stream Characterization and Reconciliation with Data Quality Objectives (TWCP-QP-1.1-023), and Calculation of UCL 90 Values for Total VOC, SVOC, and Metals Data (TWCP-DTP-1.2-006). 
- Matrix parameter category

- Waste material parameter weights

- Average mass and activity of each radionuclide of concern

- Whether the waste in the container is TRU radioactive waste

- Average concentration of hydrogen, methane, and each VOC in the headspace gas of waste containers in the waste stream

- Total masses of VOCs, hydrogen, and methane in the headspace gas of the waste stream

- The potential flammability of TRU waste headspace gases

- Mean concentrations, $\mathrm{UCL}_{90}$ for the mean concentrations, standard deviations, and number of samples collected for VOCs, semivolatile organic compounds (SVOCs), and metals in the waste stream

- Total masses of VOCs, SVOCs, and metals in the waste stream

- Whether the waste stream exhibits a TC under 40 CFR Part 261, Subpart C

- Whether the waste stream can be classified as hazardous or nonhazardous at the 90 -percent confidence level

- Whether a sufficient number of waste containers have been visually examined to determine with a reasonable level of certainty that the UCL 90 for the miscertification rate is less than 14 percent.

The SPM evaluates and reports waste characterization data from the analysis of homogeneous solids and soil/gravel using the statistical procedures presented in the QAPP. He or she calculates UCL90 values in accordance with Calculation of UCL ${ }_{90}$ Values for Total VOC, SVOC, and Metals Data (TWCP-DTP-1.2-006) to assess compliance with the DQOs in Section 1.6 and with RCRA regulations. He or she applies TWCP-DTP-1.2-006 to all laboratory analytical data for total VOCs, total SVOCs, and total metals. He or she compares data from the analysis of the appropriate metals and organic compounds with the TC levels expressed as total values, called the regulatory threshold limit (RTL) values, as listed in Table 3-1 for RCRA regulatory compliance (40 CFR $§ 261.24$ ).

\subsubsection{Reconciliation at the CAO Level}

CAO must ensure that data if of sufficient type, quality, and quantity to meet the DQOs. The CAO Regulatory Compliance Manager is responsible for determining if sufficient data have been collected to determine the following: 
- The concentration of headspace gas VOCs in the total waste inventory to support a demonstration that VOCs will not migrate through the air beyond the WIPP unit boundary in concentrations greater than EPA-determined health-based limits during WIPP operations;

- The concentration of VOCs, SVOCs, and metals in the total waste inventory to support a demonstration that hazardous constituents will not migrate beyond the WIPP unit boundary in concentrations greater than EPA-determined health-based limits;

- The total curie, hydrogen, and methane concentrations in TRU waste to support revision of the thermal power restrictions for shipment of waste in the TRUPACT-II;

- An inventory of radioactive materials and physical waste forms to support an assessment of repository performance;

- Whether waste streams proposed for disposal in WIPP have been adequately characterized; and

- Whether data supports the preparation of the WIPP RCRA permit application, the WIPP facility 40 CFR Part 191 Certification Application, and a revised Safety Analysis Report (SAR) for the TRUPACT-II.

\subsection{Data Reporting Requirements}

\subsubsection{Data Generation Level}

Operation leaders ensure that data are transmitted electronically or by hard copy from the data generation level to the Site Project QA Officer. Transmitted data include testing, sampling, and analytical batch data reports, data review checklists, and the signature releases described in Section 3.1. Example report forms and checklists are included in the procedures listed in Sections 7.0 through 15.0 .

Batch reports are normally transmitted to the Site Project QA Officer within 28 days of the completion of sampling or testing. However, verbal extension of the transmittal time is available to the SPM at his or her discretion because the number of TWCP personnel available for batch report review is limited. (See Record of Variance number 97-008.)

\subsubsection{Project Level}

The SPM transmits summarized testing, sampling, and analytical data electronically to CAO, or by hard copy when requested, according to Reporting Summarized Characterization Data and Waste Stream Summaries to CAO (TWCP-QP-1.1-024). Hard copy data packages consist of the following:

- Cover page with the Laboratory name, TWCP identification, waste container numbers for containers included in the data package, and release signatures of the SPM and Site Project QA Officer

- Table of contents 
- A concise narrative that summarizes the results of the project level review and briefly describes any problems or other noteworthy items of interest associated with the data (i.e., nonconformance reports, operational variances). The narrative includes separate sections that address the results of duplicates or replicates and nonconformance reports associated with the waste containers being reported in the package.

Prior to shipment of waste to the WIPP facility, data on an individual container basis must be transmitted to CAO M\&O contractor and CAO National TRU Program team using the WWIS. The required report elements, data fields, and field types are presented in Table 3-2.

In addition to the reporting requirements for individual waste containers, once a waste stream is fully characterized, the SPM must submit a Waste Stream Profile Form and the reconciliation with DQOs report to CAO M\&O contractor and CAO National TRU Program team. The Waste Stream Profile Form is included in the WIPP Waste Acceptance Criteria.

Hard copy data packages are submitted to the CAO at present. Once the WWIS is finalized, electronic data packages will be submitted.

Table 3-2. Requirements for Electronic Transmittal of Data Packages

\begin{tabular}{|c|c|c|c|}
\hline Report Element & $\begin{array}{l}\text { Number of } \\
\text { Required } \\
\text { Fields }\end{array}$ & Description of Required Fields & Field Type ${ }^{2}$ \\
\hline Cover Page & 2 & $\begin{array}{l}\text { Site name } \\
\text { Program identification }\end{array}$ & $\begin{array}{l}\text { Memo } \\
\text { Memo }\end{array}$ \\
\hline Table of Contents & 1 & $\begin{array}{l}\text { Listing of the types of data included } \\
\text { in the data package }\end{array}$ & Memo \\
\hline Case Narrative & 1 & $\begin{array}{l}\text { Concise narrative which summarizes } \\
\text { results of project-level review and } \\
\text { any problems associated with the } \\
\text { date }\end{array}$ & Memo \\
\hline Waste Container List & 2 & $\begin{array}{l}\text { Waste container number } \\
\text { Waste container package date }\end{array}$ & $\begin{array}{l}\text { Alpha-numeric } \\
\text { Alpha-numeric }\end{array}$ \\
\hline \multirow[t]{10}{*}{ Radiography Data } & \multirow{10}{*}{13} & Waste container number & Alpha-numeric \\
\hline & & Item Description Code & Alpha-numeric \\
\hline & & TRUCON code & Alpha-numeric \\
\hline & & Matrix parameter category & Alpha-numeric \\
\hline & & Waste container examination date & Date \\
\hline & & $\begin{array}{l}\text { Item description Code changed } \\
(\text { yes/no })^{b}\end{array}$ & Logical \\
\hline & & $\begin{array}{l}\text { Visual examination performed } \\
\text { (yes/ no) }\end{array}$ & Logical \\
\hline & & $\begin{array}{l}\text { Matrix parameter category confirmed } \\
\text { (yes/no) }\end{array}$ & Logical \\
\hline & & Waste material parameters & Memo \\
\hline & & Weight of waste material parameters & Numeric \\
\hline
\end{tabular}




\begin{tabular}{|c|c|c|c|}
\hline Report Element & $\begin{array}{l}\text { Number of } \\
\text { Required } \\
\text { Fields }\end{array}$ & Description of Required Fields & Field Type $^{\mathrm{a}}$ \\
\hline & & $\begin{array}{l}\text { Weight of waste material parameters } \\
\text { confirmed (yes/no) }\end{array}$ & Logical \\
\hline & & Layers of packaging present & Numeric \\
\hline & & Comment Section & Memo \\
\hline RA Data & 16 & $\begin{array}{l}\text { Waste container number } \\
\text { Item Description Code } \\
\text { TRUCON code } \\
\text { Matrix parameter category } \\
\text { NDA examination date } \\
\text { NDA Method } \\
\text { Total Pu-239 (fissile gram } \\
\text { equivalents, g) } \\
\text { Pu-239 uncertainty (fissile gram } \\
\text { equivalents, g) } \\
\text { Total alpha activity (Ci) } \\
\text { Alpha activity uncertainty (Ci) } \\
\text { Thermal power (W) } \\
\text { Thermal power uncertainty (W) } \\
\text { Total TRU (nCi/g) } \\
\text { TRU uncertainty (nCi/g) } \\
\text { Individual radioisotopes (Ci) } \\
\text { Individual radioisotopes uncertainty } \\
\text { (Ci) }\end{array}$ & $\begin{array}{c}\text { Alpha-numeric } \\
\text { Alpha-numeric } \\
\text { Alpha-numeric } \\
\text { Alpha-numeric } \\
\text { Date } \\
\text { Memo } \\
\text { Numeric } \\
\text { Numeric } \\
\text { Numeric } \\
\text { Numeric } \\
\text { Numeric } \\
\text { Numeric } \\
\text { Numeric } \\
\\
\text { Numeric } \\
\text { Numeric } \\
\text { Numeric } \\
\end{array}$ \\
\hline $\begin{array}{l}\text { Waste Container Headspace Gas } \\
\text { Data }\end{array}$ & 12 & $\begin{array}{l}\text { Waste container number } \\
\text { Item Description Code } \\
\text { TRUCON code }{ }^{\mathrm{b}} \\
\text { Matrix parameter category } \\
\text { Date sampled } \\
\text { Date analyzed } \\
\text { Analyte name } \\
\text { Concentration (vol\% for } \mathrm{H}_{2} \text { and } \\
\mathrm{CH}_{4} \text { ) } \\
\text { Concentration (ppmv for VOCs) } \\
\text { Total flammables (vol\% or ppmv) } \\
\text { Total VOCs (ppmv) } \\
\text { Reporting flag }\end{array}$ & $\begin{array}{c}\text { Alpha-numeric } \\
\text { Alpha-numeric } \\
\text { Alpha-numeric } \\
\text { Alpha-numeric } \\
\text { Date } \\
\text { Date } \\
\text { Alpha 1 } \\
\text { Numeric } \\
\\
\text { Numeric } \\
\text { Numeric } \\
\text { Numeric } \\
\text { Alpha } 2\end{array}$ \\
\hline $\begin{array}{l}\text { Solid Waste } \\
\text { Total VOC Data }\end{array}$ & 9 & $\begin{array}{l}\text { Waste container number } \\
\text { Item Description Code } \\
\text { TRUCON code } \\
\text { Matrix parameter category } \\
\text { Date sampled } \\
\text { Date analyzed } \\
\text { Analyte name } \\
\text { Concentration }(\mathrm{mg} / \mathrm{kg}) \\
\text { Reporting flag }\end{array}$ & $\begin{array}{c}\text { Alpha-numeric } \\
\text { Alpha-numeric } \\
\text { Alpha-numeric } \\
\text { Alpha-numeric } \\
\text { Date } \\
\text { Date } \\
\text { Alpha 1 } \\
\text { Numeric } \\
\text { Alpha 2 }\end{array}$ \\
\hline $\begin{array}{l}\text { Solid Waste } \\
\text { Total SVOC Data }\end{array}$ & 9 & $\begin{array}{l}\text { Waste container number } \\
\text { Item Description Code } \\
\text { TRUCON code }\end{array}$ & $\begin{array}{l}\text { Alpha-numeric } \\
\text { Alpha-numeric } \\
\text { Alpha-numeric }\end{array}$ \\
\hline
\end{tabular}




\begin{tabular}{|c|c|c|c|}
\hline Report Element & $\begin{array}{l}\text { Number of } \\
\text { Required } \\
\text { Fields }\end{array}$ & Description of Required Fields & Field Type ${ }^{a}$ \\
\hline & & $\begin{array}{l}\text { Matrix parameter category } \\
\text { Date sampled } \\
\text { Date analyzed } \\
\text { Analyte name } \\
\text { Concentration }(\mathrm{mg} / \mathrm{kg}) \\
\text { Reporting flag }\end{array}$ & $\begin{array}{l}\text { Alpha-numeric } \\
\text { Date } \\
\text { Date } \\
\text { Alpha 1 } \\
\text { Numeric } \\
\text { Alpha 2 }\end{array}$ \\
\hline $\begin{array}{l}\text { Solid Waste } \\
\text { Total Metals Data }\end{array}$ & 9 & $\begin{array}{l}\text { Waste container number } \\
\text { Item Description Code } \\
\text { TRUCON code } \\
\text { Matrix parameter category } \\
\text { Date sampled } \\
\text { Date analyzed } \\
\text { Analyte name } \\
\text { Concentration }(\mathrm{mg} / \mathrm{kg}) \\
\text { Reporting flag }\end{array}$ & $\begin{array}{c}\text { Alpha-numeric } \\
\text { Alpha-numeric } \\
\text { Alpha-numeric } \\
\text { Alpha-numeric } \\
\text { Date } \\
\text { Date } \\
\text { Alpha } 1 \\
\text { Numeric } \\
\text { Alpha } 2\end{array}$ \\
\hline Summaries & 2 & $\begin{array}{l}\text { Site Project QA Officer Summary } \\
\text { completed? (yes/no) } \\
\text { Data Validation Summary } \\
\text { completed? (yes/no) }\end{array}$ & $\begin{array}{l}\text { Logical } \\
\text { Logical }\end{array}$ \\
\hline WIPP Certification & 2 & $\begin{array}{l}\text { WIPP-WAC certifiable (yes/no) } \\
\text { TRAMPAC certifiable (yes/no) }\end{array}$ & $\begin{array}{l}\text { Logical } \\
\text { Logical }\end{array}$ \\
\hline
\end{tabular}

${ }^{2}$ Field types have the following minimum space requirements: Alpha $1-50$ spaces; Alpha 2 - 2 spaces: Alpha-numeric - 20 spaces; Date (MMDDYY) - 8 spaces; Logical - 1 space; Memo - N/A.

These items are not addressed by this program but are reported to consolidate information from the WIPP WAC and TRUPACT-II Authorized Methods for Payload Control (TRAMPAC).

\subsection{Procedures Specific to This Section}

Table 3-3 lists the procedures specific to this section of the QAPjP.

Table 3-3. Section 3.0 Procedures

\begin{tabular}{|c|c|}
\hline Document Number & Title \\
\hline TWCP-QP-1.1-010 & Project Level Data Validation and Verification \\
\hline TWCP-QP-1.1-011 & Data Generation Level Review \\
\hline TWCP-QP-1.1-012 & Laboratory Notebooks and Logbooks \\
\hline TWCP-QP-1.1-023 & $\begin{array}{l}\text { Determination of Sufficient Data for Waste Stream } \\
\text { Characterization and Reconciliation with Data Quality Objectives }\end{array}$ \\
\hline TWCP-QP-1.1-024 & $\begin{array}{l}\text { Reporting Summarized Characterization Data and Waste Stream } \\
\text { Summaries to CAO }\end{array}$ \\
\hline TWCP-DTP-1.2-006 & $\begin{array}{l}\text { Calculation of UCL } L_{90} \text { Values for Total VOC, SVOC, and Metals } \\
\text { Data }\end{array}$ \\
\hline TWCP-DTP-1.2-014 & $\begin{array}{l}\text { Random Selection of Containers and Sampling Locations for TRU } \\
\text { Waste Characterization Activities }\end{array}$ \\
\hline
\end{tabular}




\subsection{ACCEPTABLE KNOWLEDGE}

Acceptable knowledge refers to information about a waste that is based on knowledge of the materials or processes used to generate the waste. Acceptable knowldege is used to assign matrix parameter catagories, EPA hazardous waste numbers, and determine the radionuclides and types of materials present in the waste. The collection and use of acceptable knowledge information applies to both retrievably stored and newly generated waste.

\subsection{Quality Assurance Objectives}

LANL TWCP complies with the QAOs for precision, accuracy, completeness, comparability, and representativeness as defined in the QAPP. For newly generated waste, accuracy is measured as the percentage of waste containers that require designation of a different or additional EPA hazardous waste number based on sampling and analysis data. For retrievably stored waste, the assignment of waste matrix parameters is made from acceptable knowledge information. The primary measure of acceptable knowledge accuracy for retrievably stored waste is defined as the percentage of waste containers that require reassignment to a new matrix parameter category based on the results of radiography or visual inspection. Addition of more detail to the waste matrix parameter as the result of radiography (e.g., assignment of S5310 to a waste container previously assigned S5300) is not considered a reassignment. This measure of acceptable knowledge accuracy also will be used for retrievably stored waste that is transferred into the newly generated waste category through repackaging activities.

A significant percentage of retrievably stored waste has had EPA hazardous waste numbers assigned on a waste container, or other, basis. When these waste containers are consolidated into a waste stream, all EPA hazardous waste numbers assigned to containers in the waste stream are combined and used for the waste stream assignment. A qualitative measure of accuracy that will be reported is whether additional EPA hazardous waste numbers are added to a waste stream based on the results of sampling and analysis.

\subsection{Methods Requirements}

For retreivably stored waste, LANL TWCP is assembling acceptable knowledge documentation in two parts. The first part, which is complete, consists of information documented in the Sampling Plan. This document provides a summary overview of TRU waste inventory, projected TRU waste generation, facility missions, waste generation processes, flow diagrams, times, and material inputs; assigns waste containers to waste streams; and identifies the physical form of the waste, waste material parameters, and radionuclides present in each waste stream. Preliminary assignment of waste matrix parameters and EPA hazardous waste numbers to waste streams also is recorded. A description of how the Sampling Plan information was assembled is contained in the Sampling Plan.

The second part of acceptable knowledge documentation is in progress and is expected to require several years to complete. It consists of assembling more detailed acceptable knowledge information into auditable records. The additional information includes more detailed process descriptions and documents such as those listed in Section 4.3.3 of the QAPP, "Supplemental Acceptable Knowledge Documentation." As compilation of this more detailed information is completed for each waste stream, resolution of acceptable knowledge discrepancies and a reevaluation of waste material parameters, matrix parameter category, and EPA hazardous waste numbers will be performed. Documentation of these 
activities will be contained in the auditable acceptable knowledge record package. Summary information in the Sampling Plan will be updated to reflect changes resulting from the more detailed information.

\subsubsection{Assembling Acceptable Knowledge Documentation}

\section{$\underline{\text { Retrievably Stored Waste }}$}

The Sampling Plan satisfies the following criteria:

- Acceptable knowledge information must be compiled in an auditable record, including a road map for all applicable information

- Facility operations must be correlated to specific waste stream information

- Waste stream generation times, processes, and facilities must be described and correlated

- A reference list must be provided that identifies documents, databases, QA protocols, and other sources of information that support the acceptable knowledge information

Several additional elements that sites must satisfy are listed in the QAPP, Section 4.2.1. LANL TWCP satisfies them through procedures and documents as follows.

The Sampling Plan satisfies the requirements that LANL:

- Assemble and evaluate acceptable knowledge information from published documents, controlled databases, unpublished data, internal procedures and notes (such as logbooks), and correspondence (such as memoranda, letters, phone logs, and interviews)

- Identify the physical form of the waste and assign the appropriate matrix parameter category to each waste stream

- Identify the waste material parameters and radionuclides present in each waste stream

- Identify hazardous wastes and assign appropriate EPA hazardous waste numbers to each waste stream

Develop adequate documentation to demonstrate consistency in assigning matrix parameter categories, assigning EPA hazardous waste numbers, and determining waste material parameters and radionuclides The procedure Acceptable Knowledge Documentation (TWCP-QP-1.1-021) satisfies the requirements that LANL:

- Prepare a written procedure outlining the specific methodology used to assemble acceptable knowledge records, including the origin of the documentation, how it will be used, and any limitations associated with the information (e.g., identify the purpose and scope of a study that included limited sampling and analysis data) 
- Describe how acceptable knowledge information is evaluated and any discrepancies in documentation are resolved

The TWCP procedure Nonconformances (TWCP-QP-1.1-007) satisfies the requirement that LANL:

- Ensure unacceptable wastes are identified and segregated

- Ensure nonconforming items are documented and managed

The Certification Plan describes the procedures used to ensure that waste is certified for shipment to the WIPP facility.

The TWCP procedures WCRRF Visual Examination Procedure for TWCP (TWCP-DTP-1.2-001) and Performing Nondestructive Testing Using the Mobile Real-Time Radiography System (TWCP-DTP-1.2008) include lists of nonconforming items that the operator must verify are not present in each container of waste.

The procedure Reconciliation of Waste Stream Information (TWCP-QP-1.1-028) describes how TWCP:

- Confirms acceptable knowledge in accordance with Figure 4-2 of the QAPP

- Verifies that all of the required confirmation data has been evaluated and the proper EPA hazardous waste numbers have been assigned

- Reevaluates acceptable knowledge information if radiography or visual examination results in reassignment of a different matrix parameter category

- Reassigns a waste container to a different waste stream and assigns appropriate EPA hazardous waste numbers

- Describes how changes to matrix parameter categories, waste stream assignment, and EPA hazardous waste numbers based on material composition are documented

\section{Newly Generated Waste}

For newly generated waste, the facility-specific TWIDs contain information covering (1) scope (i.e., waste streams) and purpose; (2) responsible organization(s); (3) management controls; (4) material inputs to process; (5) process controls and range of operation that affect final matrix parameter category, waste material parameter, radionuclide, and hazardous waste determinations; (6) rate and quantity of the waste generated; (7) list of applicable operating procedures relevant to the waste determinations; (8) nonconformance reporting; (9) acceptable knowledge confirmation sampling (i.e., headspace gas sampling and/or solidified waste annual sample); and (10) reporting and records management. Description of visual examination practices prior to or during waste packaging (or reference to facilityspecific procedures) also are contained in these documents. 
To ensure Lab-wide consistency in assigning EPA hazardous waste numbers to all waste streams (hazardous and low-level mixed as well as TRU mixed), this activity is performed by LANL waste management personnel in accordance with applicable procedures. To ensure Lab-wide consistency, generators are required to assemble acceptable knowledge documentation according to the format presented in Acceptable Knowledge Documentation (TWCP-QP-1.1-021) and to submit the documentation packages to the SPM for review and approval.

\subsubsection{Confirmatory Testing}

Waste characterization (radiography, headspace gas sampling and analysis, and solidified waste sampling and analysis) will be used to confirm acceptable knowledge information according to the requirements of Section 4.2.2 of the QAPP. These requirements are implemented in Reconciliation of Waste Stream Information (TWCP-QP-1.1-028).

\subsection{Acceptable Knowledge In formation}

\subsubsection{TRU Waste Management Program Information}

The section "TRU Waste Management Program Overview" of the Sampling Plan includes the information required in the QAPP Section 4.3.1, except for waste certification procedures, which are described in the Certification Plan.

\subsubsection{TRU Waste Stream Information}

The Sampling Plan contains the minimum waste process information as described in Section 4.3 .2 of the QAPP.

\subsubsection{Supplemental Acceptable Knowledge Documentation}

Supplemental documentation used for acceptable knowledge is assembled into an auditable record as described in Acceptable Knowledge Documentation (TWCP-QP-1.1-021).

\subsection{Acceptable Knowledge Program Control}

\subsubsection{Training}

Training and qualification records for TWCP personnel responsible for assessing information and resolving discrepancies associated with acceptable knowledge are maintained in the TWCP RMDC. Training and qualification records for LANL waste management personnel involved in assigning EPA hazardous waste numbers are tracked through a TWID. Training shall include the following minimum requirements:

- WIPP Waste Analysis Plan, WIPP-WAC, and QAPP requirements

- State and Federal RCRA regulations associated with solid and hazardous waste determinations 
- Matrix parameter category and waste material parameter designations

- Nonconformance process, including discrepancy resolution and reporting

- Site-specific procedures associated with waste characterization using acceptable knowledge

\subsubsection{Management Controls of Nonconforming Items}

Management of nonconformances and corrective actions is implemented through Nonconformances (TWCP-QP-1.1-007).

\subsubsection{Confirmation of Acceptable Knowledge}

Data associated with waste stream characterization will be submitted to the CAO M\&O contractor through completed Waste Stream Profile Forms, the WWIS, and, when requested, copies of the data packages so that confirmation of acceptable knowledge may be performed by the contractor. Changes to waste determinations will be documented according to Nonconformances (TWCP-QP-1.1-007).

\subsubsection{Resolution of Discrepancies}

The method for resolving discrepancies in acceptable knowledge documentation is presented in Acceptable Knowledge Documentation (TWCP-QP-1.1-021).

\subsubsection{Re-evaluation of Acceptable Knowledge}

If a waste container must be assigned to a different matrix parameter category based on radiography or visual examination, the steps taken to re-evaluate acceptable knowledge are listed in Reconciliation of Waste Stream Information (TWCP-QP-1.1-028).

\subsection{Audits}

Acceptable knowledge documentation, procedures, characterization data packages, and other QA records are available at LANL for audit.

\subsection{Procedures Specific to This Section}

Table 4-1 lists the procedures specific to this section of the QAPjP.

Table 4-1. Section 4.0 Procedures

\begin{tabular}{ll}
\hline \multicolumn{1}{c}{ Document Number } & \multicolumn{1}{c}{ Title } \\
\hline TWCP-QP-1.1-007 & Nonconformances \\
TWCP-QP-1.1-021 & Acceptable Knowledge Documentation \\
TWCP-QP-1.1-028 & Reconciliation of Waste Stream Information \\
TWCP-DTP-1.2-001 & WCRRF Visual Examination Procedure for TWCP \\
TWCP-DTP-1.2-008 & Performing Nondestructive Testing Using the Mobile Real- \\
& Time Radiography System \\
\hline
\end{tabular}




\subsection{SAMPLING PROCESS DESIGN}

TRU waste characterization is based on the data collection design presented in Figure 5-1 of the QAPP for retrievably stored waste and in Figure 5-2 of the QAPP for newly generated waste. Waste generated after the development, approval, and implementation of a TRU waste characterization program that meets the requirements outlined in the Certification Plan is considered newly generated waste. The Laboratory manages all retrievably stored waste that is repackaged as newly generated waste. TWCP personnel characterize all TRU waste to meet the DQOs as specified in Section 1.5. They accomplish most characterization activities for newly generated waste prior to or during packaging operations. The processes used for the efficient characterization of newly generated waste are outlined in the Certification Plan and described in detail for each waste-generating facility in their facility-specific TWID. Processes used to characterize waste must comply with the requirements, DQOs, and methods of the QAPP and the DOE Methods Manual, except as specifically modified in TWCP variances.

The Laboratory has two sources of retrievably stored TRU waste: waste in earthen-covered storage and waste in inspectable arrays in storage domes. The Laboratory also manages newly generated TRU waste. TWCP personnel have used acceptable knowledge to sort waste containers into waste streams, according to the requirements of Section 4.0 of the QAPP. Waste stream descriptions and tables of waste containers assigned to each waste stream are documented in the Sampling Plan.

The TWCP defines a waste stream as waste material generated from a single process or activity; waste may be generated as either process or process batch waste streams. It defines a process as a system or series of continuous or regularly occurring actions taking place in a predetermined manner over extended periods of time resulting in a product that is substantially uniform. It defines a process batch as an amount of material subjected to a particular unit chemical process, unit physical mixing process, or other short-term operation, resulting in a final product that is substantially uniform.

\subsection{Description of Acceptable Matrix Parameter Categories}

TWCP personnel use matrix parameter categories, as described in the DOE Waste Treatability Group Guidance, to group wastes by similar properties. They assign waste streams into one of three broad groups: homogeneous solids (S3000 summary category), soil/gravel (S4000 summary category), and debris wastes (S5000 summary category). They base sampling and analytical requirements on the summary category by which the waste stream is identified. The process used to group wastes into waste streams and assign matrix parameter codes is described in the Sampling Plan.

\subsection{Parameters, Rationale, and Test Methods}

TWCP personnel characterize each waste container by radioassay, according to Section 9.0 , and headspace gas sampling and analysis, according to Sections 7.0,11.0, and 12.0. Each retrievably stored waste container must undergo radiography according to Section 10.0. In addition, waste containers are characterized as described in the following subsections. 


\subsubsection{Homogeneous Solids and Soil/Gravel}

Statistically selected wastes in summary categories $\mathrm{S} 3000$ and $\mathrm{S} 4000$ must be analyzed for total RCRAregulated metals, VOCs and SVOCs, in accordance with the requirements in Sections 8.0, 13.0, 14.0, and 15.0. One exception is salt waste (summary category S3140), which is not required to be analyzed for organic constituents. In addition, organic sludges (summary category S3220) must be analyzed for total polychlorinated biphenyls (PCBs).

\subsubsection{Debris Wastes}

TWCP defines debris waste to be all heterogeneous waste materials, or waste materials whose physical form does not lend itself to sampling and analysis, regardless of the size of the waste materials. RCRA waste characterization of debris waste is accomplished using acceptable knowledge in accordance with Section 4.0.

\subsection{Confirmation of EPA Hazardous Waste Numbers for Spent Solvents Using Headspace Gas Analytical Results}

Headspace gas VOC analytical results for containers within each retrievably stored and newly generated waste stream (or waste stream lot) will be combined to confirm and to update EPA hazardous waste numbers for spent solvents (i.e., F001, F002, F003, F005). Headspace gas analytical results for each constituent associated with these EPA hazardous waste numbers will be evaluated, and if any constituent is determined to be present above the Program-required quantitation limit (PRQL), the associated EPA hazardous waste number, if not previously applied based on acceptable knowledge, will be applied to the entire waste stream.

A statistical method is used for determining whether an EPA hazardous waste number for spent solvents should be added to the waste stream. The method involves calculating, for each constituent, the $\mathrm{UCL}_{90}$ for the mean constituent concentration and comparing it to the PRQL found in Table 12-1 of the QAPP. The EPA hazardous waste number confirmation strategy is illustrated in Figure 5-3 of the QAPP.

The $\mathrm{UCL}_{90}$ for the mean concentration of each constituent will be calculated in accordance with the Equations [5-1] through [5-3] presented in the QAPP. If the $\mathrm{UCL}_{90}$ for the mean concentration is less than the PRQL for all constituents associated with a particular EPA hazardous waste number for spent solvents, the waste stream spent solvent designation will not be modified. If the $U C L_{90}$ is greater than or equal to the PRQL for any one constituent associated with a particular EPA hazardous waste number, the appropriate EPA hazardous waste number will be assigned to the waste stream. EPA hazardous waste numbers for spent solvents cannot be removed from a waste stream using this process. If the waste stream is comprised of one drum, the analytical variability derived from the RPD is used in computing the $\mathrm{UCL}_{90}$.

The statistical tests described above are based on the assumption that the measured concentrations of each contaminant are normally distributed. This assumption must be verified as described in Section 5.3 of the QAPP and documented according to the procedure Reconciliation of Waste Stream Information (TWCP-QP-028). 


\subsection{Sampling Plan}

The strategy used at LANL for sampling TRU waste depends on random selection of waste containers from each waste stream, or waste stream lot. Waste containers are assigned to waste streams based on acceptable knowledge as documented in the Sampling Plan. The Sampling Plan contains all of the information required in Section 5.4 of the QAPP, with the following exceptions:

- Issues, operational constraints, and ALARA concerns related to container retrieval are described in the SAR for the TRU Waste Inspectable Storage Project (TWISP) project

- Issues, operational constraints, and ALARA concerns related to container selection for characterization are described in facility-specific WACs, which are derived from facility SARs and permit constraints

- Newly generated waste characterization strategies are described in the facility-specific TWIDS because LANL has several generator facilities each with multiple waste streams

- Information to demonstrate that a random sample of a retrievably-stored waste stream was obtained is documented in the records produced by the TWCP procedure Random Selection of Containers and Sampling Locations for TRU Waste Characterization Activities (TWCP-DTP-1.2-014)

A waste container randomly chosen for a characterization activity may be found unacceptable for that activity for several reasons, including ALARA concerns, facility WAC (which are based primarily on radionuclide content or container size), failure to fit existing devices because of overpacking or odd drum-size, overpacking because of potential lack of drum integrity, or non-availability for shipping to a short-campaign characterization activity during the time of the campaign. If a randomly selected drum cannot be used, the SPM will document the reason and document the selection of a replacement drum in a memo to the TWCP RMDC. The replacement drum will be chosen as the next acceptable drum found by proceeding sequentially down the random number list used for the initial drum selection.

The SPM is responsible for review and approval of the Sampling Plan and for ensuring that samples collected from a waste stream were selected randomly.

\subsubsection{RCRA Characterization of Retrievably Stored Homogeneous Solids and Soil/Gravel}

TWCP personnel select retrievably stored waste containers from waste streams in the homogeneous solids and soil/gravel matrix parameter categories (S3000 and S4000 summary categories) for RCRA characterization according to Random Selection of Containers and Sampling Locations for TRU Waste Characterization Activities (TWCP-DTP-1.2-014). The number of waste containers that must be sampled for the RCRA-hazardous determination ${ }^{1}$ is dependent on defined levels of acceptable error for the RCRA-hazardous decision, on the contaminant mean concentration, on the contaminant

1 Exclusive of determination that the waste is listed, ignitable, corrosive, or reactive. 
concentration standard deviation ${ }^{2}$, and on the total number of waste containers in the waste stream. This number is determined using procedure Determination of Sufficient Data for Waste Stream Characterization and Reconciliation with Data Quality Objectives (TWCP-QP-1.1-023). The RCRAhazardous determination ${ }^{3}$ will be made following the strategy described in Section 5.4.1 of the QAPP according to the procedure Reconciliation of Waste Stream Information (TWCP-QP-1.1-028). A hazardous determination is based on the hypothesis that the mean contaminant concentration in the waste stream is greater than or equal to the RTL. A Type I error rate of 10 percent must be used to test the hypothesis. The hypothesis test assumes that the measured concentrations of each contaminant are normally distributed. If the concentrations are not normally distributed, the data (and the associated RTL) must be transformed for the hypothesis test. Calculation of the mean contaminant concentration is made according to Calculation of $U C L_{90}$ Values for Total VOC, SVOC, and Metals Data (TWCP-DTP-1.2-006).

\subsubsection{Visual Examination of Retrievably Stored Homogeneous Solids, Soil/Gravel, and Debris Wastes}

TWCP personnel select retrievably stored waste containers from waste streams in all matrix parameter categories (S3000, S4000, and S5000 summary categories) for visual examination to confirm the results of radiography according to Calculation for Determining the Number of Containers for Visual Examination (TWCP-DTP-1.2-015). TWCP uses waste containers randomly selected for coring to replace containers from the same waste stream selected for visual examination as allowed in the QAPP. The number of waste containers that must be visually examined as a QC check on radiography is based on the estimated proportion of miscertified waste containers, the number of containers certified in a year, and the hypergeometric distribution. The results of the visual examination are compared with the radiography interpretation according to the procedure Reconciliation of Waste Stream Information (TWCP-QP-1.1-028). Records from this procedure are reviewed annually by the SPM and used to update the estimated proportion of miscertified waste containers for future container selections as described in Section 5.4.2 of the QAPP. This activity will be documented in a report to file entitled "Annual Calculation of Waste Container Miscertification Rate for (year)," released by the SPM. Since TWCP radiography activities for certification began in January 1997 , the miscertification rate to be used for 1997 is 2 percent.

\subsubsection{Characterization of Newly Generated Homogeneous Solids, Soil/Gravel, and Debris Wastes}

Waste generators randomly sample newly generated waste streams of homogeneous solids and soil/gravel once per year or once per process batch. They ensure that sampling frequency of once per year is used only if a process has operated within established and documented administrative controls, otherwise the waste is considered as process batches. They employ the waste sampling and analysis methods, as referenced in Sections 8.0, 13.0, 14.0, and 15.0 of this QAPjP and the QAPP and detailed in the procedures referenced in the facility-specific TWID for newly generated waste streams of homogeneous solids and soil/gravel. They use acceptable knowledge for RCRA waste characterization

\footnotetext{
${ }^{2}$ The number of containers to sample is determined on the basis of the contaminant with the highest ratio of estimated concentration standard deviation to estimated concentration mean. A minimum of 5 containers must be selected (or 5 samples for the case of a waste stream containing fewer than 5 containers).

${ }^{3}$ Exclusive of determination that the waste is listed. ignitable, corrosive, or reactive.
} 
of newly generated debris wastes. To avoid the requirement of performing radiography on newly generated waste, generators document and verify the matrix parameter category and waste material parameters, and weigh each item to a precision of \pm 1 percent of the total net weight of the waste in each container (e.g., 55 gallon drum or standard waste box) prior to or during waste packaging operations. They accomplish verification according to procedures referenced in the facility-specific TWID.

\subsubsection{Verification Sampling of Homogeneous Solids and Soil/Gravel from Continuous Processes}

Newly generated homogeneous solids and soil/gravel waste streams that have been characterized through acceptable knowledge must be sampled periodically for verification purposes. Verification samples will be evaluated using statistical process control (SPC) charting techniques for each contaminant in each waste stream as described in Section 5.4.3.1 of the QAPP. Procedures for sampling, determining control limits, assigning EPA hazardous waste numbers to waste streams for the purposes of reporting waste stream data to CAO, and recharacterizing a waste stream (if necessary) are facility specific and must be referenced in the TWID for each facility.

\subsubsection{Verification Sampling of Homogeneous Solids and Soil/Gravel from Process Batches}

Newly generated solid process residues and soils waste streams that have been characterized through acceptable knowledge must be sampled periodically for verification purposes. Verification sample results must be compared against the RTLs, and if they exceed the RTLs, the appropriate EPA hazardous waste numbers must be added to the waste stream for the purposes of reporting waste stream information to CAO.

\subsubsection{Characterization of Newly Generated Debris Waste}

Characterization of newly generated debris waste will be conducted using acceptable knowledge. The application of spent solvent EPA hazardous waste numbers to debris waste streams will be updated using headspace gas sampling results as described in Section 5.3.

\subsection{Procedures Specific to This Section}

Table 5-1 lists the procedures specific to this section of the QAPjP. 
Table 5-1. Section 5.0 Procedures

Document Number

TWCP-QP-1.1-023

TWCP-QP-1.1-028

TWCP-DTP-1.2-006

TWCP-DTP-1.2-014

TWCP-DTP-1.2-015
Title

Determination of Sufficient Data for Waste Stream

Characterization and Reconciliation with Data Quality Objectives

Reconciliation of Waste Stream Information

Calculation of UCL $L_{90}$ Values for Total VOC, SVOC, and Metals Data

Random Selection of Containers and Sampling Locations for TRU Waste Characterization Activities

Calculation for Determining the Number of Containers for Visual Examination 


\subsection{SAMPLE HANDLING AND CUSTODY REQUIREMENTS}

The TWCP maintains field logs, sample labels, and COC forms for all samples handled throughout the waste characterization process to ensure that all data meet accepted standards for legal admissibility and defensibility. The TWCP implements the requirements of this QAPjP through procedures in accordance with the QAPP.

\subsection{Field Documentation}

Field sampling personnel record all pertinent information for samples and document any modifications to planned sample activities in a field logbook in accordance with Laboratory Notebooks and Logbooks (TWCP-QP-1.1-012) and comply with all requirements specified in this section. Field sampling personnel record all information legibly, stating only facts and observations in objective language, in field logbooks. The individual making the entry dates and signs every page. Logbooks are maintained in accordance with the requirements of Section 1.7 of this QAPjP. Logbooks include the following information at a minimum:

- Name of sampling facility

- Waste container identification number

- Sample identification number of each sample referenced to the waste container from which it was collected

- Type of sample

- Type of sampling equipment used

- Time and date of sample collection

- Quantity of sample collected

- Type of sample container and the equipment cleaning batch or manufacturer's lot number assigned to that container

- Sample preservatives used

- Analysis requested

- QC designation, if applicable

- COC record number

- Analytical laboratory to perform the analysis

- Shipping information 
- Sampler's name

- Procedure document number and revision

- Real-time instrument readings

- Comments

When sampling headspace gases, the following information is also included:

- Ambient temperature and pressure measurements at the time of sample collection

- If SUMMA ${ }^{\otimes}$ canisters are used, canister pressures before and after sample collection

When homogeneous solids and soil/gravel are sampled, the following information is included:

- Sampling tool identification

- Depth of waste, core recovery, and coring location

- Visual observations of waste and recovered core

- Randomly selected sample location

- Randomly selected coring location

\subsection{Labeling}

LANL labels TRU waste containers in accordance with requirements outlined in CST Waste Management Facilities Waste Acceptance Criteria and Certification and associated procedures. This QAPjP identifies containers and labeling requirements in the following subsections.

\subsubsection{Waste Container Labeling}

The Laboratory has a pre-existing container labeling system for retrievably stored and newly generated waste. TRU waste containers are identified using a bar code labeling system in accordance with CST Waste Management Facilities Waste Acceptance Criteria and Certification and associated procedures.

\subsubsection{Innermost Layer of Confinement}

Requirements for labeling innermost layers of confinement are removed because there is no longer a requirement for headspace gas sampling of innermost layers. 


\subsubsection{Headspace Gas Sample Containers}

The TWCP relies primarily on a headspace gas sampling and analysis system which does not use separate sample containers as described in Headspace Gas Sampling Using the Direct Sampling Method (TWCP-DTP-1.2-017). If SUMMA® canisters are used for storing or shipping samples, the following requirements must be met:

- $\quad$ Each SUMMA ${ }^{\circledR}$ canister used to collect headspace gas samples must be inscribed with a unique canister identification number; sampling personnel include these canister numbers on each sample canister document

- Headspace sampling personnel must document the physical existence of a sample and certification of canister cleaning by the use of canister tags or documentation traceable to the canister through the unique canister identification number; they attach a removable canister tag to each field and field QC sample canister prior to shipment to the field, or include equivalent.documentation with the shipment

- Upon sampling, the sampling personnel must complete the canister tags or equivalent documentation with the information listed in Section 6.2.3 of the QAPP

- Analytical laboratory personnel remove the tag upon completion of analysis and place the tag, or the equivalent documentation, in the project file

- An example of the canister tag, or documentation form, used in the program is included in the technical procedure that describes canister sampling, Headspace Gas Sampling Using the Direct Canister Method (TWCP-DTP-1.2-007)

- Sampling personnel record the canister pressure after cleaning, the manifold gauge pressure, and the canister gauge pressure; the individual performing the measurement signs, dates, and records the time in a logbook or on the canister documentation according to TWCP-DTP-1.2-007

- Sampling personnel record the readings from the canister gauge and sampling manifold in the field prior to and after sample collection; they sign, date, and record the time in the field logbook or on the canister documentation

- Analytical laboratory personnel receiving sample canisters must thermally equilibrate the canisters to ambient temperature and measure canister pressure and ambient temperature/pressure within 24 hours of sample receipt at the laboratory; the individual performing the measurement records this information, signs, dates, and records the time in the laboratory logbook or on a canister documentation form

Sample management personnel assign a unique 13-digit number to each sample canister. They assign the numbers as follows: the two-digit alpha character LA identifying the Laboratory as the sampling site, a six-digit numeric character (MMDDYY) identifying the date, and a five-digit number, which is the canister identification number. 


\subsubsection{Homogeneous Solids and Soil/Gravel Sample Containers}

Sample management personnel assign a 12-digit sample identification number to each retrievably stored sample of homogeneous solids and soil/gravel. They assign the numbers in the following format: a two-alpha character, LA, that identifies the sampling site and a 10-digit alphanumeric of the form TWCP-97-\#\#\#, indicating the program (TWCP), the year, and then the approximate chronological sequence of homogeneous solids and soil/gravel sample collection. The TWCP identifies LA as the sampling identification characters for the Laboratory with CAO approval. For newly generated homogeneous waste samples, the program initials are replaced by four initials unique to each waste generator that maintains a certification program TWID. (See Record of Variance number 97-009.)

The sampling personnel affix a sample label, as shown in Handling and Shipping Samples of TRU Waste Classified as Homogeneous Solids and Soil/Gravel (TWCP-DTP-1.2-021) to each individual sample of retrievably stored or newly generated waste. Each label includes the following information:

- Applicable waste container identification number or process identification number for newly generated wastes

- Sample identification number

- Time and date of sample containers

- Type and number of sample containers

- Sample preservatives

- Analysis requested

- Sampler's initials

- Remarks

\subsection{Chain of Custody}

The TWCP considers a sample under COC control if it is sealed with the custody seal intact and one or more of the following are true:

- It is in the possession of an authorized individual

- It is in the view of an authorized individual, after being in the possession of that individual

- It was in the possession of an authorized individual, and access to the sample was controlled by locking or placing signed custody seals that prevent undetected access

- It is in a designated secure area with controlled access and documented personnel access or a radiological containment area

Both parties sign and date a COC form when a transfer of custody occurs. A copy of the form remains with the relinquishing party. The party accepting custody inspects the custody form and all 
accompanying documentation, ensuring that all information is complete and accurate. The custodian inspects the waste containers and samples for signs of damage or tampering and documents any discrepancies on the $\mathrm{COC}$ form (a nonconformance report is not required). The original $\mathrm{COC}$ is maintained in the project files.

\subsubsection{Waste Container}

For retrievably stored waste, waste containers are tracked according to the procedure Waste Container Tracking (TWCP-DTP-1.2-020). The tracking log is maintained electronically, and operations leaders ensure that it is updated when containers are received and returned, and when characterization operations have been completed on a sampling or analytical batch. An important feature of the tracking log is that it lists the waste matrix parameter for each container and is readily available online, so that the waste matrix parameter does not have to be inscribed on each data form. (See Record of Variance number 97-010.) The tracking log contains the following information:

- Waste container identification number

- Waste matrix parameter code

- LANL Sampling Plan waste stream number

- Notation as to whether the waste is considered mixed or nonmixed

- Container type (optional)

- Characterization activities planned (optional) and completed for each waste container

\subsubsection{Sample Containers}

Sampling personnel initiate the COC form for field samples, including field QC samples, immediately after sample collection or preparation. Sample COC is maintained until the analyses are complete and the data are validated, sample is expended, or until the sample is removed from the project. Figure 6-1 is an example of the $\mathrm{COC}$ form for sample containers. The form includes the following information in accordance with the CST/CMR Chain-of-Custody and Sample Transfer Plan and Sampling TRU Waste Classified as Homogeneous Solids and Soils/Gravel-Drum Monoliths, Loose Aggregates, and Waste of Other Consistencies (TWCP-DTP-1.2-023).

- Signature of individual initiating custody control, date, and time

- Documentation of sample numbers for each sample under custody

- Signatures of custodians relinquishing and receiving custody, date, and time

- Description of final sample container disposition and signature of individual removing sample container from custody

- Comment section 


\begin{tabular}{|c|c|}
\hline SAMPLE ID: & $\begin{array}{l}\text { LABORATORY ID: } \\
\text { (for lab use onfy) }\end{array}$ \\
\hline \multirow[t]{4}{*}{ ANALYSIS REQUESTED:_ } & DATE SAMPLED: \\
\hline & TIME SAMPLED: \\
\hline & PRESERVATIVE: \\
\hline & SAMPLER'S INITIALS: \\
\hline \multicolumn{2}{|c|}{ EQUIPMENT CLEANING BATCH NUMBER OR MANUFACTURER'S LOT NUMBER:_ } \\
\hline REMARKS: & \\
\hline
\end{tabular}

Figure 6-1. Example Sample Container Label

\subsection{Handling}

The TWCP handles waste containers and samples in accordance with the requirements described in the procedures Headspace Gas Sampling Using the Direct Sampling Method (TWCP-DTP-1.2-017), Sampling TRU Waste Classified as Homogeneous Solids and Soils/Gravel-Drum Monoliths, Loose Aggregates, and Waste of Other Consistencies (TWCP-DTP-1.2-023), Sampling TRU Waste Classified as Homogeneous Solids and Soils/Gravel-One Gallon Cans Packed in Drums (TWCP-DTP-1.2-022), Handling and Shipping Samples of TRU Waste Classified as Homogeneous Solids and Soil/Gravel (TWCP-DTP-1.2-021), or facility-specific equivalent procedures. They include sample quantity information, sample container types, preservation methods, and holding times. In addition, the procedures describe the requirements for handling samples and waste containers prior to shipment to the analytical laboratory and tracking throughout the sampling process.

\subsubsection{Waste Container}

Sampling personnel allow waste containers to equilibrate to the temperature of the sampling area for 72 hours before headspace gas sampling. They sample at a temperature between $18^{\circ} \mathrm{C}$ and $29^{\circ} \mathrm{C}$. Room temperature excursions of less than outside these temperature limits are allowed for time periods less than 8 hours, because waste drums have sufficient thermal lag that room temperature excursions at this level will not adversely affect thermal equilibration of the drum contents. (See Record of Variance number 97-011.)

\subsubsection{Gas Sample Container}

The TWCP uses an at-line sampling system for headspace gas sampling and analysis. Gas samples are not stored for a significant length of time or shipped. In the event that special circumstances require sample storage for longer than 48 hours or sample shipping, TWCP personnel will follow the requirements of Section 6.2.3 of this QAPjP and Section 6.4.2 of the QAPP for use of SUMMA® canisters. If sample storage of less than 4 days is required, TWCP personnel may use Tedlar bags for 
sample storage provided the QAPP requirements for sample labeling and COC are met. (See Record of Variance number 97-012.)

\subsubsection{Homogeneous Solids and Soil/Gravel Sample Container}

TWCP sampling and analytical personnel jointly determine the sample amounts necessary for analysis and QC samples and the appropriate sample containers to use. Samples are maintained at a temperature of $4^{\circ} \mathrm{C}\left( \pm 2^{\circ} \mathrm{C}\right)$ from as soon as practical after the time of collection until shipment to the analytical laboratory. Chilled or frozen shipping containers are used for shipping, and the temperature of the inner sample container is measured and recorded on arrival at the analytical laboratory. Sample preservation methods and holding times must meet the requirements in Table 6 of the QAPP.

Sampling personnel package sample jars to prevent breakage of glass containers. They place the COC forms in a waterproof plastic bag and tape the bag to the underside of the shipment container lid. They affix a signed and dated custody seal or a tamper-indicating device to each shipment container across the container lid and body to provide visual evidence of tampering. If the integrity of the custody seal or tamper-indicating device is found to be compromised on receipt, a nonconformance report must be generated.

The tracking system used to monitor the location and status of waste containers on a routine basis is described in Waste Container Tracking (TWCP-DTP-1.2-020). Project Level Data Validation and Verification (TWCP-QP-1.1-010) documents the flow of information between parties responsible for sample acquisition, sample analysis, data validation, data storage, data evaluation, and data use.

Analytical laboratories receiving shipped samples must have written procedures for the following:

- Chronological sample number sequencing

- Sample receipt, log-in, and preservation

- Identification of sample custodian

- Internal sample numbering and tracking systems

- Transfers of custody within the laboratory

- Example custody forms with instructions for use

- Sample storage

- Sample disposal

- Analytical data maintenance and custody

\subsection{Procedures Specific to This Section}

Table 6-1 lists the procedures specific to this section of the QAPjP. 
Table 6-1. Section 6.0 Procedures

\section{Document Number}

TWCP-DTP-1.2-007

TWCP-DTP-1.2-017

TWCP-DTP-1.2-018

TWCP-DTP-1.2-020

TWCP-DTP-1.2-021

TWCP-DTP-1.2-022

TWCP-DTP-1.2-023

TWCP-QP-1.1-010
Title

Headspace Gas Sampling Using the Direct Canister Method

Headspace Gas Sampling Using the Direct Sampling Method

Determination of Volatile Organic Compounds in Waste Container Headspace by the Gas Chromatography/Mass Spectrometry Method

Waste Container Tracking

Handling and Shipping Samples of TRU Waste Classified as Homogeneous Solids and Soil/Gravel

Sampling TRU Waste Classified as Homogeneous Solids and Soils/Gravel-One-Gallon Cans Packed in Drums

Sampling TRU Waste Classified as Homogeneous Solids and Soils/Gravel-Drum Monoliths, Loose Aggregates, and Waste of Other Consistencies

Project Level Data Validation and Verification 


\subsection{HEADSPACE GAS SAMPLING}

The TWCP meets the minimum requirements for collecting headspace samples in accordance with the procedures listed throughout each subsection. The TWCP ensures that representative headspace gas samples and QC samples maintain their integrity during collection by implementation of the procedures and documentation of all activities. Tables 11-1 and 12-1 list the analytes of interest and the QAOs for headspace gas samples.

The procedures for headspace gas sampling are applicable to sampling the headspace gases in retrievably stored TRU waste drums and newly generated TRU waste drums containing waste in each matrix parameter category found at the Laboratory. These procedures are based on methods found in the Methods Manual. However, since participating sites have the option of using either the manifold method or the direct canister method, a combination of the two, or other equivalent methods, LANL TWCP has opted to use a modification of the on-line method for work in 1997 (see Record of Variance number 97-003). The TWCP also maintains procedures for using the direct canister method as presented in Methods Manual Procedure 110.2. For work after approximately September 1997, the TWCP plans to implement a modified manifold system. Facility permitting issues have delayed implementation of this system until at least September 1997, so that detailed procedures for this method have not been prepared. Implementation of this system will require an update to this section of the QAPjP.

\subsection{Quality Assurance Objectives}

\section{Precision and Accuracy}

Sampling personnel collect samples at the drum headspace directly under the drum lid from all 55gallon drums. They collect one field blank for each sampling batch. If the TWCP procedure Headspace Gas Sampling Using the Direct Sampling Method (TWCP-DTP-1.2-017) is used, additional field QC samples are combined with the laboratory QC samples as described in Sections 11.3 and 12.3 of this QAPjP. If SUMMA canisters are used according to Headspace Gas Sampling Using the Direct Canister Method (TWCP-DTP-1.2-007), additional QC samples are collected that include, at a minimum, equipment blanks, field reference standards, and field duplicates to ensure precision and accuracy. Table 7-1 lists the analyses required for each kind of sample taken. Table 7-2 contains the frequency for taking the samples. If the final, reported QC sample results do not meet the requirements listed in Table 7-3, sampling personnel prepare a nonconformance report and submit it to the Site Project QA Officer in accordance with Nonconformances (TWCP-QP-1.1-007).

\section{Completeness}

The TWCP expresses completeness as the number of valid samples collected as a percent of the total number of samples collected. The Site Project QA Officer initiates a corrective action if a minimum of 90 percent completeness is not achieved.

\section{Comparability}

The TWCP ensures comparability by the implementation and documentation of standardized procedures and equipment. 
Table 7-1. Analyses Required for Each Type of Headspace Sample Collected

\begin{tabular}{llcc}
\hline Waste Container & Sample Type & VOCs $^{\mathbf{a}}$ & $\begin{array}{c}\text { Hydrogen, } \\
\text { Methane }\end{array}$ \\
\hline Drum & Drum lid & $\checkmark$ & $\checkmark$ \\
& Field duplicate & $\checkmark$ & $\checkmark$ \\
& Field blank & $\checkmark$ & \\
& Equipment blank & $\checkmark$ & \\
& Field reference standard & $\checkmark$ & $\checkmark$ \\
\hline
\end{tabular}

${ }^{2}$ See Table 12-1.

Table 7-2. Summary of Drum Field QC Headspace Sample Frequencies

\begin{tabular}{lcc}
\hline \multicolumn{1}{c}{ QC Samples } & Manifold & Direct Canister \\
\hline Field blanks $^{\mathrm{a}}$ & 1 per sampling batch & 1 per sampling batch $^{\mathrm{d}}$ \\
Equipment blanks $^{\mathrm{b}}$ & 1 per sampling batch & once $^{\mathrm{d}}$ \\
Field reference standards $^{\mathrm{c}}$ & 1 per sampling batch & once $^{\mathrm{d}}$ \\
Field duplicates $^{\mathrm{d}}$ & 1 per sampling batch & 1 per sampling batch $^{\mathrm{d}}$ \\
\hline
\end{tabular}

${ }^{a}$ Analysis of field blanks and equipment blanks for VOCs (Table 12-1), only, is required.

b One equipment blank sample must be collected, analyzed for VOCs (Table 12-1), and demonstrated clean prior to first use of the headspace gas sampling equipment with each of the sampling heads, then at the specified frequency, for VOCs only thereafter. Daily, prior to work, the sampling manifold. (if in use), must be verified clean using an organic vapor analyzer (OVA).

'One field reference standard must be collected, analyzed, and demonstrated to meet the QAOs specified in Section 7.1 prior to first use, then at the specified frequency thereafter.

dA sampling batch is a suite of samples collected consecutively using the same sampling equipment within a specific time period. A sampling batch can be up to 20 samples (excluding field QC samples), all of which must be collected within 14 days of the first sample in the batch.

'One equipment blank and field reference standard must be collected after equipment purchase, cleaning. and assembly. 
Table 7-3. Summary of Sampling QC Sample Acceptance Criteria

\begin{tabular}{|c|c|c|}
\hline QC Sample & Acceptance Criteria & Corrective Action \\
\hline Field blanks & $\begin{array}{l}\text { VOC amounts }<3 \times \text { MDLs in } \\
\text { Table } 12-1\end{array}$ & $\begin{array}{l}\text { Nonconformance if any VOC amount } \\
\geq 3 \times \text { MDLs in Table } 12-1\end{array}$ \\
\hline Equipment blanks & $\begin{array}{l}\text { VOC amounts }<3 \times \text { MDLs in } \\
\text { Table 12-1 }\end{array}$ & $\begin{array}{l}\text { Nonconformance if any VOC amount } \\
\geq 3 \times \text { MDLs in Table } 12-1\end{array}$ \\
\hline Field reference standards & $70-130 \% R$ & $\begin{array}{l}\text { Nonconformance if } \% R<70 \text { or }> \\
130\end{array}$ \\
\hline Field duplicates & $\mathrm{RPD} \leq 25$ & Nonconformance if RPD > 25 \\
\hline \multicolumn{3}{|c|}{$\begin{aligned} \mathrm{MDL} & =\text { Method detection limit. } \\
\% \mathrm{R} & =\text { Percent recovery. } \\
\mathrm{RPD} & =\text { Relative percent difference. }\end{aligned}$} \\
\hline
\end{tabular}

\section{$\underline{\text { Representativeness }}$}

The TWCP ensures representativeness by following Headspace Gas Sampling Using the Direct Sampling Method (TWCP-DTP-1.2-017) and Headspace Gas Sampling Using the Direct Canister Method (TWCP-DTP-1.2-007), which include the following steps:

- Sample equipment cleaning or disposal after use

- Sampling. equipment leak check

- Use of a low internal volume sampling equipment

- Collection of small sample volume; low sample volume to available headspace volume ratio

- Performance audits

- Collection of field blanks

and if SUMMA ${ }^{\circledast}$ canisters are used:

- Sample canister cleaning and leak check

- Use of sample canisters with passivated internal surfaces

- Careful pressure regulation

- Collection of equipment blanks field reference standard, field blanks, and field duplicates 


\subsection{Method Requirements}

Headspace sampling personnel collect samples for the determination of the analytes listed in Tables 11-1 (Section 11.0) and 12-1 (Section 12.0) in accordance with the sampling procedures listed in Section 7.1, including the sample types listed in Table 7-1. They collect samples within a radiation containment area described in these procedures.

Sampling personnel use a direct canister method or a modification of this method termed the direct sampling method. Before sampling waste containers for headspace gas, sampling personal ensure that the waste containers meet the drum age criteria (142 days for debris waste, 225 days for homogeneous solids) by checking the information recorded on the electronic Drum Information and Tracking Form (see TWCP-DTP-1.2-020).

\subsubsection{Direct Sampling Method}

LANL uses a method of headspace gas sampling that is similar to the Direct Canister Method (Methods Manual Procedure 110.2), except that the gas is drawn into a gas-tight syringe rather than a SUMMA@ canister. Use of a gas-tight glass syringe is authorized by Record of Variance number 97-003, and allows the gas sample to be immediately injected into the gas chromatography/mass spectrometry (GC/MS) system. The detailed technical procedure for gas sampling is provided in Headspace Gas Sampling Using the Direct Sampling Method (TWCP-DTP-1.2-017).

The TWCP generally uses a direct sampling (at-line) method (Headspace Gas Sampling Using the Direct Sampling Method, TWCP-DTP-1.2-017) in which gas-tight syringes for injecting samples into the GC/MS are connected directly to the sampling heads, which are equipped with a changeable filter. Sampling personnel use sampling needles capable penetrating a carbon composite filter. They use sample heads that form a leak-tight connection that allows a sample to be obtained through the drum lid carbon composite filter. They collect combined field and laboratory duplicates at the same time, in the same manner, and using the same type of sampling apparatus as used for the sample. They collect field blanks from samples of room air collected in the immediate vicinity of the waste drum. They collect combined laboratory and equipment blanks using the same needle and syringe as will be used for the following samples. They collect combined laboratory control standards and field reference standards with the same type of sample needle and syringe as used for the samples. Sampling heads used for this project have a minimum internal volume. Sampling personnel determine the sampling head internal volume and document it in their sampling logbook.

\subsubsection{Modified Manifold System}

LANL plans to use a sampling manifold that is constructed of stainless steel and that has SUMMA ${ }^{\otimes}$ canisters for sample collection. This system will be on-line and extensively automated. The system will be cleaned by heating the SUMMA ${ }^{\circledR}$ canisters and evacuating them in accordance with Methods Manual Procedure 210.1. The sampling lines will also be evacuated. The sample inlet for hydrogen/methane is in accordance with Methods Manual Procedure 520.1. The same approach will be used for VOCs; a fixed volume sample loop with sample injection through a split/splitless GC injection port will be used. LANL has demonstrated that samples do not need to be concentrated to meet the PRQL [(and method detection limits) (MDL)] specified in Methods Manual Procedure 430.1 (see Record of Variance number 97-021). VOC dilutions will be handled via GC split injection or via 
additional lower volume fixed injection loops. LANL will use a dynamic injection system for generation of the calibration mixture (based on syringe pump driven injection of the calibration standard into a moving gas stream).

\subsubsection{Direct Canister}

If the direct canister method (Headspace Gas Sampling Using the Direct Canister Method, TWCPDTP-1.2-007) is used, sampling personnel attach the sampling heads directly to the evacuated SUMMA ${ }^{\text {}}$ canister. They use sample heads that form a leak-tight connection that allows a sample to be obtained through the drum lid carbon composite filter. Sampling personnel evacuate canisters to $0.10 \mathrm{~mm} \mathrm{Hg}$ and attach a changeable filter to the sampling head. They use sampling needles capable of penetrating a carbon composite filter. They collect field duplicates at the same time, in the same manner, and using the same type of sampling apparatus as used for the field sample. They collect field blanks from samples of room air collected in the immediate vicinity of the waste drum sampling area prior to removal of the drum lid. They collect equipment blanks and field reference standards using the same components for the field samples.

Sampling personnel determine the sampling head internal volume and document it in their sampling logbook. Sampling heads used for this project have a minimum internal volume.

All SUMMA ${ }^{\oplus}$ canisters have a pressure/vacuum gauge with a range of 30 pounds per square inch gauge (psig) pressure to a vacuum of 30 inches $\mathrm{Hg}$. Sampling personnel evacuate the canisters to 0.10 $\mathrm{mm} \mathrm{Hg}$ prior to sampling. They helium leak test the gauge to $1.5 \times 10^{-7} \mathrm{standard} \mathrm{cc} / \mathrm{sec}$. The gauge is all stainless steel construction and tolerates temperatures up to $125^{\circ} \mathrm{C}$.

\subsubsection{Sampling Heads}

Sampling personnel collect headspace gas samples directly under the drum lid from within each drum. They sample through a carbon filter for drums that have been previously vented.

\section{Sampling Through the Carbon Filter}

When sampling through the carbon filter, sampling personnel press a side port needle through the filter and into the headspace beneath the drum lid. They use a sampling head that consists of a side port needle to reduce plugging, a filter to prevent particles from contaminating the gas sample, and an adapter to connect the two. They clean the sampling head after each sample collection, after collecting a field reference standard, and after collecting the field blank by purging with nitrogen (see Record of Variance number 97-019). The housing of the carbon composite filter allows insertion of the sampling needle through the filter element into the drum headspace. The purge assembly is compatible with the side port needle. The lid of the drum 90 -mil polyethylene liner (if present) contains a hole for venting to the drum. The side-port needle used is not considered sturdy enough to puncture the liner. The drum carbon composite filter is sealed to prevent outside air from entering the drum and diluting or contaminating the sample. 


\subsection{Quality Control}

\section{Field Blanks}

Sampling personnel collect field blanks prior to sample collection at a frequency of one per sampling batch. The SPM uses the field blank data to assess impacts of ambient contamination on sample results. The SPM initiates and resolves a nonconformance report if any VOC in the field blank equals or exceeds three times the MDL for that VOC listed in Table 12-1 in accordance with Nonconformances (TWCP-QP-1.1-007).

\section{Equipment Blanks}

Sampling personnel collect equipment blanks prior to first use of all sampling equipment and at a frequency of one per sampling batch for VOC analysis. Sampling personnel use field blanks in lieu of equipment blanks when using the direct canister method. The SPM uses the equipment blank data to determine impacts of potentially contaminated sampling equipment on sample results. The SPM accepts equipment blank results if the concentration of hydrogen, methane, and each VOC is less than three times the MDLs listed in Tables 11-1 and 12-1.

\section{Field Reference Standards}

Sampling personnel collect field reference standards of VOC, hydrogen, and methane samples using the same sampling equipment. They collect the standards into SUMMA ${ }^{\otimes}$ canisters prior to first use and at a frequency of one per sampling batch thereafter. They submit them blind to the analytical laboratory for analysis. The reference standards contain a minimum of six of the analytes listed in Table 12-1 at concentrations within a linear range of 0-100 parts per million by volume (ppmv) and hydrogen and methane greater than or equal to the PRQLs listed in Table 11-1. Sampling personnel use reference standards with a known valid relationship to a nationally recognized standard. They use commercial gases with a Certificate of Analysis from the manufacturer documenting traceability, and discard the gases when the shelf-life has expired. Sampling personnel may stop collecting field reference standards when using the direct canister method if the QAOs for accuracy are met. The SPM accepts field reference standard results if the accuracy is $70-130$ percent recovery $(\% \mathrm{R})$.

\section{Field Duplicates}

Sampling personnel collect field duplicates simultaneously with the field sample at a frequency of one per sampling batch. The SPM accepts field duplicate data if the relative percent difference (RPD) is less than or equal to 25 .

\subsection{Equipment Testing, Inspection, and Maintenance Requirements}

The TWCP ensures that all sampling equipment components that come into contact with headspace sample gases are constructed of relatively inert materials, such as stainless steel and Teflon, by following Procurement (TWCP-QP-1.1-005). Laboratory personnel clean and leak check the canisters, needles, and syringes prior to headspace gas sampling in accordance with the sampling procedures listed in Section 7.1 and the Methods Manual. 


\section{Headspace Gas Sample Canister Cleaning}

If SUMMA ${ }^{\otimes}$ canisters are used, analytical laboratory personnel clean and certify canisters on an equipment cleaning batch basis, which is the number of canisters cleaned together at one time using the same cleaning method. They use a cleaning system that processes multiple canisters at a time and has a cryogenically trapped vacuum manifold to clean the SUMMA ${ }^{\circledast}$ canisters. They perform a positive pressure check and pass the canister if it does not change by more than plus or minus 2 psig in 24 hours. They check for leaks and repair, and reprocess any canister that does not pass. They fill one canister per cleaning batch with humid zero air or humid high purity nitrogen, which they send to the analytical laboratory for VOC analysis. The canisters are considered clean if the results indicate there are no VOCs above three times the MDLs listed in Table 12-1. Analytical laboratory personnel evacuate the canisters to $0.10 \mathrm{~mm} \mathrm{Hg}$ or less and store the canisters. The analytical laboratory personnel maintain the cleaning and certification documentation and initiate the canister tags or documentation as described in Section 6.0 and implemented in accordance with the sampling procedures listed in Section 7.1 .

\section{Sampling Equipment Initial Cleaning}

The surfaces of gas sampling equipment that will come into contact with the headspace gas sample must be inspected and cleaned prior to first use following Methods Manual Procedures 110.1 and 110.2. This cleaning must be repeated if the sampling heads are contaminated to the extent that routine system cleaning is inadequate.

\section{Sampling Equipment Routine Cleaning and Leak-Check}

Sampling personnel purge the sampling heads, syringes, and needles with humid zero air, nitrogen, or helium for routine cleaning (see Record of Variance number 97-019).

They conduct purging after headspace gas, duplicate, and field blank collection. The SPM ensures that sampling is suspended until corrective action is taken if the analysis of the equipment blank indicates that acceptance limits have been exceeded.

Sampling personnel operating the direct sampling method use a dedicated syringe to inject the laboratory control sample (LCS) (which also serves as the field reference standard) to avoid crosscontamination. They leak-check the sampling assembly by collecting and analyzing an equipment blank to ensure that it does not contain significant levels of oxygen.

\section{Manifold Cleaning After Field Reference Standard Collection}

The sampling manifold is not used at this time.

\section{Sampling Head Cleaning}

Sampling personnel clean the needle, adapters, and filters of the sampling heads in accordance with the sampling procedures listed in Section 7.1. Initial cleaning follows the requirements of Methods Manual Procedures 110.1 and 110.2 . The sampling head is cleaned after sample collection by wiping 
with a clean wipe. The needle is purged with zero air, nitrogen, or helium before each use. The filter is disposed after each use.

\subsection{Equipment Calibration and Frequency}

Sampling personnel certify the ambient air temperature sensor prior to initial use and annually thereafter to National Institute of Standards and Technology (NIST) traceable, or equivalent, temperature standards.

\subsection{Data Management}

Sampling personnel record and report all pertinent information on the collection of samples in accordance with Sections 3.0 and 6.0 of this QAPjP and Laboratory Notebooks and Logbooks (TWCP-QP-1.1-012). If separate SUMMA ${ }^{\circledR}$ canisters are used, sampling personnel submit sampling batch data reports for each sampling batch to the SPM on approved forms. The sampling batch data reports include the following:

- Sampling facility name, sampling batch number, sample numbers included in that sampling batch, and the signature releases of the sampling personnel

- Data review checklist verifying that the data generation level review, validation, and verification is complete

- Information specified in Section 6.1

- Nonconformance reports if applicable

If separate SUMMA ${ }^{\infty}$ canisters are used, sampling personnel record and maintain in their files the following information, which is documented and retrievable by sampling batch number:

- Copies of the sampling reports

- Copies of the completed COC forms used to transfer the sampling batch to the analytical laboratory

- Cylinder gas certification information

- Instrument calibration, maintenance, and repair records

\subsection{Procedures Specific to This Section}

Table 7-4 lists the procedures specific to this section of the QAPjP. 
Table 7-4. Section 7.0 Procedures

\begin{tabular}{ll}
\hline \multicolumn{1}{c}{ Document Number } & \multicolumn{1}{c}{ Title } \\
\hline TWCP-QP-1.1-005 & Procurement \\
TWCP-QP-1.1-007 & Nonconformances \\
TWCP-QP-1.1-012 & Laboratory Notebooks and Logbooks \\
TWCP-DTP-1.2-007 & Headspace Gas Sampling Using the Direct Canister Method \\
TWCP-DTP-1.2-017 & Headspace Gas Sampling Using the Direct Sampling Method \\
\hline
\end{tabular}




\subsection{SAMPLING OF HOMOGENEOUS SOLIDS AND SOIL/GRAVEL}

The Laboratory has developed a protocol for collecting cores from retrievably stored TRU waste containers. The protocol will be based on Methods Manual Procedure 120.1. This protocol is designed for characterization of homogeneous solids and soil/gravel on a waste stream basis. Sampling personnel follow this protocol to ensure that representative samples of these wastes, including QC samples, are consistently collected and transferred to the responsible analytical laboratory in a manner that maintains sample integrity to the fullest extent possible.

For newly generated waste, sampling personnel obtain random grab samples from the waste before it is solidified with cement according to procedures referenced in facility-specific TWIDs. Sampling personnel ensure that representative random samples are collected from retrievably stored waste by following guidance in the QAPP, in Random Selection of Containers and Sample Locations for TRU Waste Characterization Activities (TWCP-DTP-1.2-014), and in the procedures listed in Section 8.7. For retrievably stored waste packaged in small containers (e.g., 1-gallon polyethylene bottles) within the waste container, for ALARA purposes, sampling personnel collect a representative sample from one randomly selected container inside of the randomly chosen large container. (See Record of Variance number 97-013.)

\subsection{Quality Assurance Objectives}

Sampling personnel ensure that sampling is conducted in a representative manner on a waste stream basis for waste containers containing homogeneous solids and soil/gravel and ensure that the QAOs described in this section are met.

\section{Precision}

Sampling personnel measure precision by collecting and sampling duplicates once per sampling batch or once per week during sampling operations, whichever is more frequent. A sampling batch is a suite of homogeneous solids and soil/gravel samples collected consecutively using the same sampling equipment within a specific time period. A sampling batch can be up to 20 samples (excluding field QC samples), all of which must be collected within 14 days of the first sample in the batch. The site project QA officer calculates the RPD between co-located samples and reports it in the waste container data package.

\section{$\underline{\text { Accuracy }}$}

Because waste containers containing homogeneous solids and soil/gravel with known quantities of analytes are not available, sampling personnel cannot determine sampling accuracy. However, they comply with methods and requirements described in this section to minimize sample degradation and maximize sampling accuracy.

\section{Completeness}

Sampling personnel measure completeness by calculating the number of valid samples collected as a percent of the total number of samples collected. The sampling facility achieves a minimum 90-percent completeness. The site project QA officer evaluates sampling facility performance and decides if corrective action should be initiated based on these completeness calculations. 


\section{Comparability}

Sampling personnel achieve comparability by consistent use and application of uniform procedures, sampling equipment, and measurement units. The analysis results of co-located cores are examined to determine comparability (see Section 8.3 ). The analytical laboratories analyzing the samples participate in the PDP.

\section{$\underline{\text { Representativeness }}$}

To ensure representativeness, the coring tools and sampling equipment must be clean prior to sampling, and the entire depth of the waste must be cored. The core collected must have a length greater than or equal to 50 percent of the depth of the waste, as detailed in Handling and Shipping Samples of TRU Waste Classified as Homogeneous Solids and Soil/Gravel (TWCP-DTP-1.2-021), Sampling TRU Waste Classified as Homogeneous Solids and Soil/Gravel-One-Gallon Cans Packed in Drums (TWCP-DTP-1.2-022), and Sampling TRU Waste Classified as Homogeneous Solids and Soil/Gravel-Drum Monoliths, Loose Aggregates, and Waste of Other Consistencies (TWCP-DTP-1.2023). Coring operations and tool selection should be designed to minimize alteration of the in-place waste characteristics. Minimal waste disturbance must be verified by visually examining the core and describing the observation (e.g., undisturbed, cracked, pulverized) in the field logbook. If core recovery is less than 50 percent of the depth of the waste, a second coring location shall be randomly selected. The core from the second location shall be used for sample collection regardless of the core recovery. Sampling personnel ensure that sampling equipment is clean prior to sampling.

\subsection{Method Requirements}

\subsubsection{Core Collection}

Sampling personnel follow the DTPs listed in Section 8.7 for collecting representative samples of retrievably stored homogeneous solids and soil/gravel. To minimize the quantity of investigationderived waste, analytical laboratories may require no more sample than is required for the analysis, based on the analytical methods. Therefore, sampling personnel collect samples using the guidelines in Table 6-2 of the QAPP and following the requirements of the analytical laboratory.

\subsubsection{Sample Collection}

Sampling personnel collect samples for total VOC analysis from retrievably stored waste in accordance with the DTPs listed in Section 8.7, which are based on the procedures found in the Methods Manual and additional guidance in EPA's Soil Sampling and Analysis for Volatile Organic Compounds. Sampling personnel collect samples for total SVOC, metal, and PCB (if applicable) analyses from retrievably stored waste in accordance with the DTPs listed in Section 8.7. They may composite samples for SVOC, PCB, and metal analysis, but not for VOC analysis. Sampling personnel use sampling tools that are constructed of materials inert to the target analytes in the waste.

\subsection{Quality Control}

QC requirements for sampling of homogeneous solids and soil/gravel include collection of co-located cores to determine precision, equipment blanks to verify cleanliness of the coring tools and sampling equipment, and analysis of reagent blanks to ensure that reagents are of sufficient quality. 


\section{Co-Located Cores}

Sampling personnel collect sample duplicates at a frequency of one per sampling batch or once per week, whichever is more frequent. Sampling personnel collect sample duplicates from co-located cores to determine precision. Co-located cores are taken as follows. After taking a core from a drum, personnel position a clean coring tool assembly as closely as practicable to the previous coring position. The new position should be far enough from the previous position that the two sampling holes do not affect each other to compromise the sample quality. The recommended method for establishing acceptance criteria for co-located cores is development of control charts for the RPD in cores. Personnel take a sample from the co-located position according to Sampling TRU Waste Classified as Homogeneous Solids and Soil/Gravel-Drum Monoliths, Loose Aggregates, and Waste of Other Consistencies (TWCP-DTP-1.2-023).

\section{Equipment Blanks}

Sampling personnel use "EPA certified clean" equipment or collect equipment blanks from sampling equipment (e.g., bowis, spoons, chisel, VOC sub-sampler) after it is cleaned. They collect these equipment blanks prior to first use at a frequency of one per equipment cleaning batch. An equipment cleaning batch is a number of sampling equipment items cleaned together at one time using the same cleaning method. They collect the equipment blank by pouring clean water [e.g., deionized water, high pressure liquid chromatography (HPLC) water] over the surface of the sampling equipment. They collect the water in a clean sample container.

The results of the equipment blank are acceptable if the results indicate no analyte at a concentration greater than or equal to three times the MDLs specified for the analytes listed in tables for each section. If analytes are detected at concentrations greater than or equal to three times the MDLs, sampling personnel clean the associated equipment cleaning batch again and collect another equipment blank.

\section{Coring Tool and Sampling Equipment Cleaning}

Sampling personnel clean sampling equipment and ensure that the results of equipment blanks are traceable to the items in the equipment cleaning batch represented by the blank according to the DTPs listed in Section 8.7. They review the equipment blank results to ensure that the sampling equipment is clean prior to use. They maintain a sufficient quantity of sampling equipment in storage to prevent disruption of sampling operations. Disposable sampling equipment is discarded after one use.

Sampling personnel clean all sampling equipment in accordance with the following requirements and the DTPs listed in Section 8.7:

- Sampling personnel clean all sampling equipment prior to use, and in the same manner; they seal all equipment inside protective wrapping after cleaning

- Sampling personnel use sampling tools with unique identification numbers that reference the waste container from which the sample was taken; they record this information in field logbooks. 
- Sampling personnel collect an equipment blank from each equipment cleaning batch; the results of the equipment blank analysis are submitted to the sampling facility with all identification numbers

- Sampling personnel clean all sample containers in accordance with the Specifications and Guidance for Obtaining Contaminant-Free Sample Containers

\subsection{Equipment Testing, Inspection, and Maintenance}

Sampling personnel inspect sampling equipment and work areas according to the DTPs listed in Section 8.7. They must correct any deficiencies discovered during the inspection before continuing with any sampling operation.

Sampling personnel maintain sample collection equipment in accordance with manufacturer's specifications. They ensure that clean sampling equipment is sealed inside clean protective wrapping and maintained in a clean storage area prior to use. They also maintain a sufficient supply of equipment spare parts to prevent delays in sampling activities that result from equipment down time. The sampling project leader ensures that records of equipment maintenance and repair are maintained in the field records in accordance with the DTPs listed in Section 8.7.

Sampling personnel inspect sampling equipment and work areas according to the DTPs listed in Section 8.7, which include the following requirements:

- Sampling personnel inspect the sample collection equipment and work area daily for cleanliness; visible contamination on equipment or the sampling area that has the potential to contaminate a waste core or sample is thoroughly cleaned upon its discovery

- Sampling personnel maintain the sampling work area in a clean condition

- Sampling personnel visually inspect all expendable equipment prior to use and properly discard equipment after each sample

- Sampling personnel visually inspect the protective wrapping around all coring tools and sampling equipment before use; they return for cleaning or discard any equipment with wrapping that is torn

\subsection{Equipment Calibration and Frequency}

Sampling personnel must ensure that the scale used for weighing subsamples is calibrated as necessary to operate within manufacturer's specification, and after repairs and routine maintenance according to the DTPs listed in Section 8.7 and the Laboratory's Calibration Handbook. They use calibration weights that are traceable to a nationally recognized standard, and maintain calibration records in the sample management records.

\subsection{Data Management}

Sampling personnel record information pertinent to sample collection in accordance with Sections 3.0 and 6.0 of this QAPjP and the DTPs listed in Section 8.7. The operations leaders ensure that a sampling batch data report for each sampling batch is sent to the Site Project QA Officer on the form 
provided in the DTPs listed in Section 8.7. The sampling batch data reports include, at minimum, the following information:

- The sampling facility (technical area) name and number, sampling batch number, sample numbers included in that sampling batch, and the signature releases of the sampling personnel as specified in Section 3.1.1

- Data review checklists for each sampling batch verifying that the data generation level review, validation, and verification, as described in Section 3.1.1 has taken place

- Copies of the sampling field log sheets (sampling field log sheets contain the information specified in Section 6.1, heat generation observations, and coring duration, feed rate, and rotational speed)

- Nonconformance reports, if applicable

In addition, sampling personnel record and maintain the following items in their files, documented and retrievable by sampling batch number:

- Copies of the completed COC form used to transfer the samples in that sampling batch to the analytical laboratories

- Coring tool, liner, sampling equipment, and reagent certification information

- Instrument (e.g., scale) calibration, maintenance, and repair records

\subsection{Procedures Specific to This Section}

Table 8-1 lists the procedures specific to this section of the QAPjP.

Table 8-1. Section 8.0 Procedures

Document Number

TWCP-DTP-1.2-014

TWCP-DTP-1.2-021

TWCP-DTP-1.2-022

TWCP-DTP-1.2-023
Title

Random Selection of Containers and Sample Locations for TRU Waste Characterization Activities

Handling and Shipping Samples of TRU Waste Classified as Homogeneous Solids and Soil/Gravel

Sampling TRU Waste Classified as Homogeneous Solids and Soil/Gravel-One-Gallon Cans Packed in Drums

Sampling TRU Waste Classified as Homogeneous Solids and Soil/Gravel-Drum Monoliths, Loose Aggregates, and Waste of Other Consistencies 


\subsection{NONDESTRUCTIVE ASSAY}

The Laboratory achieves the TWCP QA elements defined in this section for NDA. Radioassay methods may include both nondestructive and destructive techniques, as long as the methods address and achieve the QAOs of the program. The selected methods may incorporate supporting data from acceptable knowledge, such as isotope ratios or scaling factors, when such data can be supported by auditable QA records. Data incorporated from acceptable knowledge must meet all the requirements and restrictions described in Section 4.0.

NDA personnel use NDA to determine the TRU content of containerized waste. NDA techniques allow waste to be assayed without altering its physical or chemical form. NDA personnel determine total alpha activity and the activity of the individual isotopes present in the waste for the purposes of characterization and classification. The NDA operations leader is responsible for implementation and compliance with all requirements specified in this section and further defined by the referenced DTPs.

\subsection{Quality Assurance Objectives}

The QAOs for NDA include precision, accuracy, minimum detectable concentration (MDC), completeness, and total bias and are listed in Table 9-1, which defines them over several activity ranges. Key data quality indicators for NDA are defined below, and the methods to assess compliance with these indicators are presented in Section 9.6 of this QAPjP.

\section{Precision}

NDA personnel determine precision through replicate processing of a waste container with a known quantity of the radioactive material of interest. The Site Project QA Officer is responsible for monitoring the results from these measurements and determining if the appropriate precision criterion listed in Table 9-1 has been met. The Site Project QA Officer evaluates the NDA facility performance and decides if corrective action should be initiated based on the results of these precision calculations.

\section{$\underline{\text { Accuracy }}$}

NDA personnel determine accuracy through replicate processing of a waste container with a known quantity of the radioactive material of interest. They calculate accuracy from the ratio of the mean measured estimate to the known value for an accepted verification standard. They use calibration standards to determine the response characteristics of the measurement system, and verification standards to test the validity of the calibration independently from the original calibration standards. Whenever possible, both radioactive calibration and verification standards shall be obtained from NIST, the New Brunswick Laboratory, or from suppliers maintaining measurement systems traceable to NIST. They use accuracy determinations as an estimate of bias for the case of the noninterfering matrix. The Site Project QA Officer is responsible for monitoring the results from these measurements and determining if the appropriate accuracy criterion listed in Table 9-1 has been met. The Site Project QA Officer evaluates the NDA facility performance and decides if corrective action should be initiated based on the results of these accuracy calculations.

\section{Sensitivity Limits}

NDA personnel meet the QAO of sensitivity limits in order to discriminate between LLW and TRUs. They demonstrate that each specific waste type/method combination used in the project achieves the 
required sensitivity limit. The TWCP defines detection limits as that level of radioactivity that, if present, will yield a measured value less than the critical limit with 5-percent probability. It defines critical limit as the value that measurements of the background will exceed with 5-percent probability.

\section{$\underline{\text { Minimum Detectable Concentration }}$}

The TWCP defines MDC as the level of activity that is practically achievable with a given instrument, analytical method, and analyte/matrix combination. NDA personnel determine the MDC for each measurement system, method, and analyte/matrix combination. The DTPs listed in Section 9.7 for each system detail the calculations and requirements for determining the MDC.

Table 9-1. QAOs for Nondestructive Assay

\begin{tabular}{|c|c|c|c|c|c|c|}
\hline $\begin{array}{c}\text { Range of Waste } \\
\text { Activity in } \\
\alpha \text {-Curies }\end{array}$ & $\begin{array}{c}\text { Nominal } \\
\text { Compliance } \\
\text { Point } \\
\alpha \text {-Curies } \\
\text { (g WG Pu) }^{\mathrm{b}}\end{array}$ & $\begin{array}{l}\text { Precision }{ }^{c} \\
\text { (\%RSD) }\end{array}$ & $\begin{array}{c}\text { Accuracy }^{d} \\
(\% \mathrm{R})\end{array}$ & PARAMETER & $\begin{array}{c}\text { Completeness } \\
(\%)\end{array}$ & $\begin{array}{c}\mathrm{MDC} \\
(\mathrm{nCi} / \mathrm{g})^{\mathrm{g}}\end{array}$ \\
\hline 0 & 0 & & & & & 60 \\
\hline $\begin{array}{c}>0.002 \text { to } \\
0.02\end{array}$ & $\begin{array}{l}0.008 \\
(0.1)\end{array}$ & $\leq 20$ & $75-125$ & $\begin{array}{l}\text { Low } 25 \% \\
\text { High } 400 \%\end{array}$ & 100 & \\
\hline$>0.02$ to 0.2 & $\begin{array}{l}0.08 \\
(1.0)\end{array}$ & $\leq 15$ & $50-150$ & $\begin{array}{l}\text { Low 35\% } \\
\text { High 300\% }\end{array}$ & 100 & \\
\hline$>0.2$ to 2.0 & $\begin{array}{l}0.8 \\
(10)\end{array}$ & $\leq 10$ & $75-125$ & $\begin{array}{c}\text { Low } 67 \% \\
\text { High } 150 \%\end{array}$ & 100 & \\
\hline$>2.0$ & $\begin{array}{r}12.5 \\
(160)\end{array}$ & $\leq 5$ & $75-125$ & $\begin{array}{c}\text { Low } 67 \% \\
\text { High } 150 \%\end{array}$ & 100 & \\
\hline
\end{tabular}

${ }^{2}$ Applicable range of TRU activity in a 55-gallon drum to which the QAOs apply; units are Curies of alpha-emitting TRU isotopes with half-lives greater than 20 years.

'The nominal activity (or weight of $\mathrm{Pu}$ ) in the 55-gallon drum used to demonstrate that QAOs can be achieved for the corresponding range in column 1 ; values in parentheses are the approximate equivalent weights of weapons grade plutonium (WG Pu), 15 years after purification; for purposes of demonstrating QAOs, "nominal" means within \pm 10 percent.

${ }^{c} \pm$ one standard deviation based on 15 replicate measurements of a noninterfering matrix.

${ }^{d}$ Ratio of measured to known values based on the average of 15 replicate measurements of a noninterfering matrix; see Section 9.6 for additional details.

'95-percent confidence bounds for system bias established by studies to determine contributions to total uncertainty from all significant sources. Units are confidence bound divided by true value, expressed as a percent. 'Requirement for the QAO for total uncertainty is to determine and document, but no system wide limiting values are established.

'Valid radioassay data are required for all waste containers; see Section 9.6 for additional details.

${ }^{\mathrm{B}}$ As defined in Secrions 9.1 and 9.6. 


\section{Total Uncertainty}

The total uncertainty includes the combined uncertainties for all corrections and factors applied to the analysis of real wastes to compensate for inhomogeneities and interferences from the waste matrix and/or radioactive components. There is no limiting value for the total uncertainty. The total uncertainty is used to determine whether individual assay results exceed specific criteria at set confidence levels. An expert review team determines the Laboratory's ability to achieve this QAO by evaluating the propagation of all uncertainties documented by the project.

\section{$\underline{\text { Total Bias }}$}

The total bias is defined as the systematic error component of the total uncertainty. An expert review team determines the Laboratory's ability to achieve this QAO by evaluating the propagation of all bias elements documented by the project.

\section{Completeness}

The NDA facility obtains acceptable radioassy (RA) data for 100 percent of the waste containers characterized. The TWCP defines acceptable RA data as radioactivity content data obtained from measurement systems that have demonstrated to have met all the QAOs for RA. NDA personnel validate the data in accordance with the requirements of Section 3.1.1. The NDA facility achieves the completeness criterion listed in Table 9-1. The Site Project QA Officer evaluates the NDA facility performance and decides if corrective action should be initiated based on these completeness calculations.

\section{Comparability}

The TWCP participates in and reports to the CAO, in semiannual QA reports, data from multiple, independent radioassays of a sample of waste containers, which serves as evidence of method comparability. The TWCP also participates in appropriate and relevant interlaboratory comparison and reports data from these programs to CAO for evaluation. The TWCP develops modified or new programs if existing programs are inadequate to ensure an appropriate program is available.

\subsection{Methods Requirements}

The TWCP documents the performance characteristics of each method utilized to ensure they meet the project QAOs found in Table 9-1 in accordance with the DTPs listed in Section 9.7. Only systems being used for discriminating TRU from LLW must meet the QAO for MDC. If the concentration of a waste exceeds the LLW/TRU cutoff, the project allows operator control parameters to be modified within established limits or systems not meeting the QAO for the MDC may be used if the appropriate QAOs are met under the new conditions.

The TWCP demonstrates and documents that all software used to control measurement processes complies with the QAPD, Section 6.0, as detailed in Software Management (TWCP-QP-1.1-006). NDA personnel use QC samples that cover the full range of applications to test the software in accordance with TWCP-QP-1.1-006. 
NDA Methods

NDA personnel use the methods and DTPs listed in Section 9.7 to perform NDA testing. Each operator performs all required background and performance checks against predetermined acceptance criteria prior to performing any assays of waste containers in accordance with the DTPs. A nonconformance is identified and corrective action initiated if any criterion is not met. The DTPs listed in Section 9.7 detail the activities for determining and recording the acceptance criteria. As required in Section 2.5, they document and justify all nonconformances and corrective actions. The DTPs listed in Section 9.7 detail all necessary instructions for the operation of computerized data acquisition systems and include explanations of required inputs, options, and prohibitions for operators. The TWCP numbers all DTPs and, by approval signatures, ensures that they were written, approved, and controlled to meet the requirements of this QAPjP. NDA personnel document that the performance characteristics are internally demonstrated and meet the QAOs specified in Table 9-1.

\subsection{Quality Control}

NDA personnel check the NDA systems through the use of calibration checks, background, and replicate determinations. They perform routine performance checks in accordance with the DTPS listed in Section 9.7, and ensure that all systems are operated in statistical control. The SPM reports, in the semiannual management reports to $\mathrm{CAO}$ all performance parameters used to perform the measurements. The Site Project QA Officer monitors and documents procedure performance, including the analysis of QC samples. Nonconformances and corrective actions (Section 2.1.2) are initiated and resolved if any QC measurement fails to meet the QAOs specified in Table 9-1.

\subsubsection{Measurement System Checks}

This section includes calibration and routine performance testing requirements used to ensure that measurement systems are in control and meet the performance specifications established for that measurement system to demonstrate compliance with the QAOs.

\section{Instrument Calibration}

NDA personnel calibrate all instruments at frequencies detailed in the DTPs listed in Section 9.7.

\section{Instrument Performance Checks}

The TWCP requires that all sources are either from NIST-traceable sources or are adequately characterized for usage in accordance with Standard Operating Procedure for Controlling and Handling Radioactive Calibration Sources in FMU66's Waste Management Facilities (SOP-FMU66WM-002). Sources are long-lived or corrected for decay, simple to reposition, of sufficiently high activity to obtain adequate counting statistics in short count times, and are relatively insensitive to handling. NDA personnel perform routine performance checks of efficiency, background, and energy resolution for the instrument in accordance with the applicable DTP. They log data, plot on control charts, and compare with preset control limits. The control charts shall be used to track trends in the parameters measured in the performance checks. Testing batch data reports include performance data covering the same time period over which the analyses occurred. Performance checks for nonspectroscopic instruments include efficiency checks and background checks, while spectroscopic instrument performance checks include energy calibration checks and energy resolution checks. NDA personnel perform and document performance checks at least twice each shift. before any actual waste 
measurements are performed and at the completion of the waste measurements. If shifts overlap, the end-shift performance check is used as the initial performance check for the second shift. NDA personnel count backgrounds on a frequency detailed in the DTPs listed in Section 9.7, consistent with the potential variation of the background signal and the performance of the analytical measurements with which the backgrounds are associated. Only backgrounds associated with analytical data are counted.

\section{$\underline{\text { Replicate Counts }}$}

NDA personnel perform duplicate measurements at a minimum on one waste container per 20 assayed or once per operating day, whichever is more frequent.

\subsubsection{Intercomparison Programs}

NDA facilities and personnel paricipate in measurement comparison programs sponsored by or endorsed by the NTP team leader. PDP Blind Audit Sample Management, Analysis, and Reporting (TWCP-QP-1.1-022) details the procedures for participation in programs as part of the PDP or through other mechanisms.

\subsubsection{NDA Operator Training}

The TWCP uses only trained NDA personnel to operate assay equipment. The standardized training is based upon the requirements of ASME NQA-1, Element 2, with the exception of Supplement 2S-2. The NDA operations leader requalifies operators based on satisfactory performance at a minimum every two years. Unsatisfactory performance results in disqualification of the operator. The TWCP requires retraining and demonstration of satisfactory performance before a disqualified operator is allowed to operate the equipment.

\subsection{Instrument Testing, Inspection, and Maintenance Requirements}

NDA personnel calibrate and maintain RA measurement systems in accordance with controls established in the QAPjP and implemented by the DTPs listed in Section 9.7. DTPs detail the routine system calibration, performance checks, and operation of the system and are consistent with all relevant provisions of the American National Standards Institute (ANSI), American Society for Testing and Materials (ASTM), or other consensus standards.

\subsection{Calibration Procedures and Frequencies}

NDA personnel calibrate all RA measurement instruments for the specific analysis of interest in accordance with Detailed Operating Procedure for Calibrating the Segmented/Tomographic Gamma Scanning System.(TWCP-DTP-1.2-016), Detailed Operating Procedure for Calibrating the Mobile Passive-Active Neutron Assay System (TWCP-DTP-1.2-010), and Detailed Operating Procedure for Calibrating the Canberra High Efficiency Neutron Counter and NAS Software (TWCP-DTP-1.2-012). They determine the counting efficiency and response factors for each type of analysis system. They subject each counting system to a complete calibration in accordance with the specific DTP, for the appropriate usage. They document each calibration and use standards obtained from suppliers maintaining measurement systems traceable to NIST or the New Brunswick Laboratory, or from NIST. If not available from these suppliers, the operator calibrates the actual standard against primary standards obtained from NIST or traceable to NIST. They document the cross calibration in a QA 
record. The calibration is valid until a time limit is exceeded or the instrument fails performance checks. Operators repeat a complete verification of calibrations for at least one counting geometry/sample matrix combination annually. They prepare working calibration standards using isotopes, geometries, and matrices having characteristics as close as possible to those expected for actual waste samples. If measurement values fall outside the applicable range, the measurement is repeated on alternate systems, or corrective actions are taken. The Site Project QA Officer documents and tracks all nonconformances and corrective actions in accordance with Section 2.1.2.

NDA personnel use techniques of transmission and live-time corrections to compensate for matrix variations. They use computer programs to calculate activities of radioisotopes and correction algorithms to compensate for some waste characteristics. They include the determination of calibration factors and functional relationships if correction factors are used. They determine and document the range of waste types that apply to any given calibration and set of correction factors.

TWCP personnel document, verify, and validate all computer programs and revisions before use for analytical data generation, as required by the QAPD, Section 6.0 , in accordance with Software Management (TWCP-QP-1.1-006). They ensure that verification includes the algorithm used and test runs of the program, comparing output to true values, and include all default and boundary values of parameters.

The TWCP identifies the individuals responsible for system operation and maintenance, including documentation and training; database integrity, including data entry, data updating, and $\mathrm{QC}$; and data and system security, backup and archiving in TWCP-QP-1.1-006.

\subsection{Data Management}

\section{Data Reduction}

NDA personnel use computer software specifically designed for each assay method to reduce RA data in accordance with the DTPs listed in Section 9.7. They document, in DTPs or other supporting documents, the exact algorithms used for each measurement system. They review and approve all data, as defined in Section 3.1.1, before reporting it. The Site Project QA Officer demonstrates that the QAOs are met for the specific ranges with all instrument control parameters set at specific values in accordance with the requirements found in Section 3.0.

\section{Data Validation}

NDA personnel demonstrate acceptable levels of precision by replicate processing of a 55-gallon waste drum containing the quantities of weapons grade (WG) plutonium listed in Table 9-1 for each range for which the measurement system is qualified. From the results of these measurements, they calculate the \%RSD in accordance with the DTPs listed in Section 9.7. They distribute the activity in a wellcharacterized, non-interfering matrix that is not one of the standards used to calibrate the counting system. They obtain a total of 15 replicate counts by removing from and reinserting the waste container into the measurement system between measurements and carry the 15 replicates through the entire analytical process.

NDA personnel demonstrate accuracy by replicate processing of a waste container with quantities of TRU isotopes of interest and calculate \% $\mathrm{R}$ in accordance with the DTPs listed in Section 9.7. They use a verification standard that is not one of the calibration standards or derived from or calibrated 
against a calibration standard. They distribute the activity in a well characterized, non-interfering matrix. They obtain 15 replicate counts by removing from and reinserting the waste container into the measurement system between measurements and carry the 15 replicates through the entire analytical process.

NDA personnel determine the MDC by 15 replicate counts of a well-characterized matrix with no added activity. They calculate the MDC using the variances of the background count and Equation [9-1] in accordance with the DTPs list in Section 9.7.

$$
M D C=K_{1} K_{2}\left(2.71+4.65 * s_{b}\right)
$$

where

$K_{l}$ is the proportionality constant relating the detector response (counts) to the activity, such as $K=1 / e$ where $e$ is an overall detection efficiency, or $K=1 / I_{\tau} e_{\tau}$ where $I_{\tau}$ is the gamma rayemission probability per decay and $e_{\tau}$ the detection efficiency for the gamma ray

$K_{2}$ is the factor that relates the total activity determined by the measurement system to an activity concentration in waste under a given set of measurement conditions, such as the weight of waste assayed and a self-absorption correction

$s_{b}$ is the standard deviation of the background

NDA personnel document all factors that add to total uncertainty; their derivation, source, or justification, the range of waste measurements to which they apply; and the uncertainty associated with each factor in accordance with the DTPs listed in Section 9.7. They propagate uncertainties at the 95percent confidence level along with estimates of the uncertainty that resuit from any other source of precision error and make it available for each different set of correction factors as they apply to different waste types.

\section{Data Reporting}

NDA personnel retain all raw data with support documentation to allow a repeat of all calculations as necessary. They report as part of the waste assay for a container any activities of isotopes other than the nominal isotopes of interest. They report all uncertainties at the 95-percent confidence level. The NDA operations leader reports all RA testing data on a testing batch basis to the Site Project QA Officer on approved forms in accordance with the DTPs listed in Section 9.7, which include sample forms. Testing batch data reports consist of the following:

- Cover page, which includes the NDA facility name, testing batch number, drum numbers in the testing batch, and signature releases of the NDA personnel as described in Section 3.1.1

- Table of contents

- Data review checklists for each testing batch verifying that the data generation level review as described in Data Generation Level Review (TWCP-QP-1.1-011) and Section 3.1.1 has taken place 
- Separate testing result sheets for each sample which include the title "Radioassay Data Sheet," DTP number, TRUCON code, matrix parameter category, date of NDA examination, total Pu-239 fissile gram equivalents (g) and associated uncertainty, TRU activity and associated uncertainty ( $\mathrm{nCi} / \mathrm{g}$ ), listing of individual isotopes present (Curies) and associated uncertainty (Curies), thermal power and associated uncertainty (watts), QC replicate (yes/no), total alpha activity and associated uncertainty (Curies), operator signature and date, and reviewer signature and date

All associated uncertainties shall be reported at the 95-percent confidence level. The total uncertainties in the assay must be calculated using the terms derived for compliance with the QAO for total uncertainty. A form containing all this information must be completed and signed, and included as part of the data report.

The NDA facility maintains the following items in its files.

- All raw data, inciuding instrument readouts, calculation records, and RA QC results (documented and retrievable by testing batch number)

- All instrument calibration reports filed by date or record number (see Record of Variance number 97-014)

\subsection{Procedures Specific to This Section}

Table 9-2 lists the procedures specific to this section of the QAPjP. 
Table 9-2. NDA Systems and Procedures

\begin{tabular}{|c|c|c|}
\hline System & Document Number & Title \\
\hline \multirow[t]{2}{*}{ STGS } & TWCP-DTP-1.2-011 & $\begin{array}{l}\text { Detailed Technical Procedure for Waste Assay } \\
\text { Using the Segmented/Tomographic Gamma } \\
\text { Scanning System }\end{array}$ \\
\hline & TWCP-DTP-1.2-016 & $\begin{array}{l}\text { Detailed Technical Procedure for Calibrating } \\
\text { the Segmented/Tomographic Gamma Scanning } \\
\text { System }\end{array}$ \\
\hline \multirow[t]{2}{*}{ Mobile PAN } & TWCP-DTP-1.2-009 & $\begin{array}{l}\text { Detailed Technical Procedure for Waste Assay } \\
\text { Using the Mobile Passive-Active Neutron (PAN) } \\
\text { Assay System }\end{array}$ \\
\hline & TWCP-DTP-1.2-010 & $\begin{array}{l}\text { Detailed Technical Procedure for Calibrating } \\
\text { the Mobile Passive-Active Neutron Assay System }\end{array}$ \\
\hline RANT PAN & EM7-NAE-OI-01 & $\begin{array}{l}\text { Operating Instructions for Operating, } \\
\text { Calibrating, Training, Troubleshooting, } \\
\text { Servicing, and Repairing the Los Alamos TRU } \\
\text { Waste Passive-Active Neutron (PAN) Assay } \\
\text { System Nondestructive Analysis/ } \\
\text { Nondestructive Examination Facility, TA-54 } \\
\text { West, Building MD-38 }\end{array}$ \\
\hline \multirow[t]{2}{*}{ HENC } & TWCP-DTP-1.2-026 & $\begin{array}{l}\text { Detailed Technical Procedure for Waste Assay } \\
\text { Using the Canberra High Efficiency Neutron } \\
\text { Counter and NAS Software }\end{array}$ \\
\hline & TWCP-DTP-1.2-012 & $\begin{array}{l}\text { Detailed Technical Procedure for Calibrating } \\
\text { the Canberra High Efficiency Neutron Counter } \\
\text { and NAS Software }\end{array}$ \\
\hline $\begin{array}{l}\text { RANT PC FRAM Assay } \\
\text { System }\end{array}$ & TWCP-DTP-1.2-027 & $\begin{array}{l}\text { Detailed Technical Instructions for Determining } \\
\text { Isotopic Ratios in Waste Containers Using the } \\
\text { RANT PC FRAM Assay System }\end{array}$ \\
\hline \multirow[t]{5}{*}{ General } & SOP-FMU66-WM-002 & $\begin{array}{l}\text { Standard Operating Procedure for Controlling } \\
\text { and Handling Radioactive Calibration Sources } \\
\text { in FMU66's Waste Management Facilities }\end{array}$ \\
\hline & TWCP-QP-1.1-006 & Software Management \\
\hline & TWCP-QP-1.1-011 & Data Generation Level Review \\
\hline & TWCP-QP-1.1-022 & $\begin{array}{l}\text { PDP Blind Audit Sample Management, } \\
\text { Analysis, and Reporting }\end{array}$ \\
\hline & AP-CST-7GRP-004 & Software \\
\hline
\end{tabular}




\subsection{RADIOGRAPHY}

LANL achieves the TWCP QA elements defined in this section for radiography. The TWCP uses radiography as a nondestructive qualitative and semiquantitative technique to identify and verify the contents of waste containers. TWCP personnel verify the results of radiography through visual examination of a statistically selected portion of retrievably stored waste containers. The procedures referenced in this section include the specific activities to document and verify the matrix parameter category and estimate waste material parameter volumes and weights for containerized waste. The NDE operations leader is responsible for implementation and compliance with all requirements specified in this section and further defined by the referenced procedures.

\subsection{Quality Assurance Objectives}

The NDE operations leader is responsible for ensuring that all QAOs are met, and if not, corrective action is initiated. The objective of radiography is to verify the matrix parameter category as listed in the Sampling Plan for each waste container by estimating the volume of each waste material parameter. Table 10-1 lists and describes the waste material parameters. Section 10.7 lists the procedures for radiography and visual examination that detail all activities to meet the requirements of the QAPP. Radiography personnel obtain data from audio/videotaped scans and document results on a radiography data form found in Detailed Technical Procedure for Performing Nondestructive Examination Using the Mobile Real-Time Radiography System (TWCP-DTP-1.2-008).

\section{Precision}

The Site Project QA Officer measures precision by ensuring that the RPD between the estimated waste material parameter weights determined from volumes determined by radiography and those same parameters determined by visual examination step calculated and reported according to Reconciliation of Waste Stream Information (TWCP-QP-1.1-028).

\section{Accuracy}

The percentage of waste containers that requires a new matrix parameter category after visual examination is reported as a measure of radiography accuracy.

\section{Completeness}

The NDE operations leader is responsible for ensuring that 100 percent of retrievably stored waste containers undergo an audio/videotaped radiography examination and results are documented on radiography data forms and submitted for validation as batch data reports.

\section{Comparability}

Radiography personnel achieve comparability of radiography data by using standardized procedures, listed in Section 10.7. The qualifications of operators are in accordance with the requirements of the QAPP and are described in TWCP Training Implementation Plan (TWCP-QP-1.1-003) and in the operation-specific training plan. 
Table 10-1. Waste Material Parameters and Descriptions

\begin{tabular}{ll}
\hline \multicolumn{1}{c}{ Waste Material Parameter } & \multicolumn{1}{c}{ Description } \\
\hline Iron-based metals/alloys & $\begin{array}{l}\text { Iron and steel alloys in the waste; does not include the waste container } \\
\text { materials }\end{array}$ \\
Aluminum-based metals/alloys & Aluminum or aluminum-based alloys in the waste materials \\
Other metals & All other metals found in the waste materials \\
Other inorganic materials & Nonmetallic inorganic waste, including concrete, glass, firebrick, \\
& ceramics, sand, and inorganic sorbents \\
Cellulosics & $\begin{array}{l}\text { Materials generally derived from high polymer plant carbohydrates } \\
\text { (e.g., paper, cardboard, wood, cloth) }\end{array}$ \\
Rubber & Natural or man-made elastic Latex materials (e.g., surgeons' gloves, \\
& leaded rubber gloves) \\
Plastics (waste materials) & Generally man-made materials, often derived from petroleum \\
& feedstock (e.g., polyethylene, polyvinylchloride) \\
Organic matrix & Cemented organic resins, solidified organic liquids, and sludges \\
Inorganic matrix & Any homogeneous materials consisting of sludge, or aqueous-based \\
& liquids which are solidified with cement, calcium silicate, or other \\
& solidification agents (e.g., waste water treatment sludge, cemented \\
aqueous liquids, and inorganic particulates)
\end{tabular}

SOURCE: Waste Isolation Pilot Plant Transuranic Waste Baseline Inventory Report.

\subsection{Methods Requirements}

The activities required to meet the radiography objectives found in the QAPP are described in Detailed Technical Procedure for Performing Nondestructive Testing Using the Mobile Real-Time Radiography System (TWCP-DTP-1.2-008). LANL is currently using the mobile system but may use a stationary system at a later date. LANL may also use wet-chem radioisotopic analysis in the future, according to TWCP-approved implementing procedures. Radiography personnel use an X-ray-producing device that allows the operator to vary the voltage, thereby controlling image quality for both low-density and high-density materials. Radiography personnel scan the waste container while viewing a television screen and making an audio/videotape as a nonpermanent record. They estimate the volumes of the waste materials according to their waste material parameters and record a brief inventory of the waste items on the radiography data form included in the technical procedure. They assign a waste matrix parameter code to the waste container from the waste volume data. If radiography indicates that the 
waste does not match the waste stream description (which is available on the Drum Information and Tracking Form or in the Sampling Plan), a nonconformance report will be completed according to the Nonconformances (TWCP-QP-1.1-007). A standard weight look-up table is used at a later time to assign weights to each waste material parameter category once the data have been validated and transferred to an electronic database. (See Record of Variance number 97-015.)

\subsection{Quality Control}

Standardized training requirements for radiography operators are based on NQA-1, Element 2, with the exception of Supplement $2 S-2$. Radiography operators are instructed in specific waste generating practices and typical packaging configurations associated with each matrix parameter category at LANL. Formal training and on the-job training (OJT) training include the required elements listed in Section 10.3 of the QAPP. Qualification of radiography operators requires that they pass a comprehensive exam based on training enabling objectives and that they perform a practical capability demonstration in the presence of a qualified radiography OJT trainer that includes correctly identifying items in a test drum. The test drum must include items common to waste streams stored at LANL as well as the required elements listed in Section 10.3 of the QAPP. All of the required elements must be successfully identified by the operator as part of the qualification process. These training requirements are detailed in the operation-specific training plan.

The NDE operations leader requalifies operators every two years on continued satisfactory performance based on audio/videotape reviews. He or she disqualifies any operator if unsatisfactory performance is observed and requires retraining and demonstration of satisfactory performance before returning operators to TWCP radiography activities. Each operator periodically scans a training drum, and the NDE operations leader reviews the videotape of the training operation to ensure that the operators interpretations remain consistent and accurate. Radiography personnel conduct an independent replicate scan of one waste container per day or per testing batch under uniform conditions, document the observation of the scan on the normal radiography data form, and check the correct box on the form to indicate that the scan is a QC replicate. Independent observation of one scan per day or per batch (not the replicate scan) is performed by a qualified radiography operator other than the individual who performed the first examination. The independent observation is documented on the normal radiography data form and the correct box is checked to indicate that the information is for a QC replicate. The independent observation is used to satisfy the requirement of periodic videotape review of accepted waste containers. The technical supervisor is responsible for reviewing the results of this verification with the radiography operator(s) and documents completion of the review by signing the Technical Supervisor's Review form included in the batch data report. The Site Project QA Officer monitors the quality of the radiography data through review of the batch data reports and initiates nonconformances and corrective actions, if necessary, in accordance with Section 2.1.2.

TWCP personnel verify the radiography results directly by visual examination of a statistically determined portion of the waste containers (based on hypergeometric distribution) in accordance with WCRRF Visual Examination Procedure for TWCP (TWCP-DTP-1.2-001). Visual examination personnel review the documentation and videotapes provided by radiography personnel prior to opening the waste container for ALARA purposes (see Record of Variance number 97-027). They record the visual examination on audio/videotape in accordance with the visual examination procedure and WCRRF Procedure for Video System Operations for TWCP (TWCP-DTP-1.2-002). They record a 
description of the waste container contents, waste material parameters, and the measured weight of each unopened bag on the form provided in the visual examination procedure. In cases where bags were not opened, an estimate is made of the amount of each waste type in the bags. Visual examination data forms are transferred to the project level in visual examination batch data reports.

Independent comparison of radiography and visual examination results, which includes comparison of the assigned matrix parameter categories and the waste material parameter volumes or weights, is performed at the project level according to Reconciliation of Waste Stream Information (TWCP-QP1.1-028). The project level reviewer forwards a report of comparison of the visual examination and radiography results to the NDE operations leader, the NDA operations leader, and the visual examination operations leader.

The TWCP may use simulated waste, real waste, or a combination of waste in the visual examination training program in addition to covering the specific formal and OJT training requirements listed in Section 10.3 of the QAPP. This is done before the operators characterize actual waste by visual examination and is described in the operation-specific training plan.

The TWCP designates a visual examination expert who is familiar with LANL waste generating processes and the types of waste being characterized by TWCP. The expert is responsible for the overall direction and implementation of the visual examination procedure. The visual examination expert decides and documents the extent of waste segregation required to meet TWCP objectives in accordance with the criteria found in WCRRF Visual Examination and Repackaging Procedure for TWCP (TWCP-DTP-1.2-001). The selection, qualification, and training requirements of the visual examination expert are specified in the operation-specific training plan.

\subsection{Instrument Testing, Inspection, and Maintenance Requirements}

Radiography personnel test and maintain all equipment in accordance with the manufacturers' instructions and Detailed Technical Procedure for Performing Nondestructive Testing Using the Mobile Real-Time Radiography System (TWCP-DTP-1.2-008). They document all testing results and maintenance in logbooks in accordance with Laboratory Notebooks and Logbooks (TWCP-QP-1.1-012).

\subsection{Instrument Calibration and Frequency}

LANL radiography equipment does not require calibration. Instead operational checks and container observations to ensure adequate video quality are performed at the beginning of each shift as described in Detailed Technical Procedure for Performing Nondestructive Testing Using the Mobile Real-Time Radiography System (TWCP-DTP-1.2-008). (See Record of Variance number 97-007.)

\subsection{Data Management}

\section{Radiography Batch Data Report}

The radiography technical supervisor ensures assembly of testing batch data reports for each testing batch using approved forms in accordance with Detailed Technical Procedure for Performing 
Nondestructive Testing Using the Mobile Real-Time Radiography System (TWCP-DTP-1.2-008). Testing batch data reports consist of the following:

- Cover page with radiography facility name, testing batch number, waste container numbers in that testing batch, and signature releases, as required in Section 3.1.1

- Table of contents

- A table with summarized results of the data forms, QC replicate scan, and independent observation that correspond to the testing batch

- Data review checklists verifying that data generation level review, validation, and verification have been completed

- Nonconformance reports

- Report forms, for each waste container and QC replicates, that include the title "Radiography Data Form," date of examination, waste container number, TRUCON code, matrix parameter category assigned in the Sampling Plan, estimate of each applicable waste material parameter volume, presence or absence of waste container liner, brief inventory of waste container contents, description of packaging materials for contents, estimated number of packaging layers, audio/videotape identification numbers, and operator signature and date items description codes [(IDC) codes and waste stream numbers are not reported because they are traceable through the waste container number; see Record of Variance number 97-026].

- RTR Contamination Survey Forms or equivalent computer-generated form

- All instrument calibration reports, as applicable

The TWCP maintains three copies of each audio/videotape, two at the Radioactive Nondestructive Testing (RANT) facility, and one that is transferred to the RMDC with the batch report, retrievable by testing batch number. Performance of operational checks and any operator notes are documented and retrievable by date in the instrument logbook, which is maintained with the instrument.

\section{Visual Examination Batch Data Report}

The visual examination technical supervisor ensures assembly of testing batch data reports for each testing batch using approved forms in accordance with WCRRF Visual Examination Procedure for TWCP (TWCP-DTP-1.2-001). Batch data reports consist of the following:

- Cover page with visual examination facility name, testing batch number, waste container numbers in that testing batch, and signature releases, as required in Section 3.1.1

- Table of contents 
- Visual examination summary table listing estimated volumes and measured weights of each waste material parameter and results of the one-in-twenty reweighing of a container item (labeled with an R)

- Data review checklists verifying that data generation level review, validation, and verification have been completed

- Nonconformances reports

- Report forms for each waste container that include the waste container number, date of visual examination, estimated volume and measured weight of each applicable waste material parameter, videotape number, information sufficient to QC check the total weight of the drum contents (the full and tare weights of the new drum that the waste is repackaged into is acceptable), presence of absence of rigid container liner, observed number of layers of packaging materials, and two operator's signatures and date [waste matrix parameters are determined from visual examination data at a later time according to Reconciliation of Waste Stream Information (TWCP-QP-1.1-028)].

- Copies of logbook and notebook pages containing information pertinent to the batch data report

\subsection{Procedures Specific to This Section}

Table 10-2 lists the procedures that are specific to this section of the QAPjP.

Table 10-2. Section 10.0 Procedures

Document Number

TWCP-QP-1.1-007

TWCP-QP-1.1-012

TWCP-QP-1.1-028

TWCP-DTP-1.2-001

TWCP-DTP-1.2-002

TWCP-DTP-1.2-008

NAE-EM7-OI-02
Title

\section{Nonconformances}

Laboratory Notebooks and Logbooks

Reconciliation of Waste Stream Information

WCRRF Visual Examination Procedure for TWCP

WCRRF Procedure for Video System Operations for TWCP

Detailed Technical Procedure for Performing Nondestructive Examination Using the Mobile Real-Time Radiography System

Operating Instructions (OI) TRU Waste X-Ray RTR System for Nondestructive Analysis/Nondestructive Examination Facility, TA-54 West, Building MD-38 


\subsection{HYDROGEN AND METHANE ANALYSIS}

The TWCP achieves the QA elements defined in this section for the analysis of hydrogen and methane in headspace gas samples. The analytical techniques and methods referenced include the specific activities to determine the concentration of hydrogen and methane in TWCP samples. The headspace gas operations leader is responsible for implementation and compliance with all requirements specified in this section and in the Methods Manual and further defined by the referenced procedures.

\subsection{Quality Assurance Objectives}

The QAOs for hydrogen and methane analysis are listed in Table 11-1. Key data quality indicators for organic laboratory measurements are defined below, and the methods to assess compliance with these indicators are presented in Section 3.2 of this QAPjP.

\section{Precision}

Headspace gas sample analysts measure precision by determining percent relative standard deviation (\% RSD) or RPD through the analysis of laboratory duplicates, replicate analyses of LCSs, and PDP blind audit samples. The technical supervisor or person responsible for data generation level QA review is responsible for monitoring the results from these measurements, determining if the precision criteria listed in Table 11-1 have been met, and documenting this in the analytical batch data report. The Site Project QA Officer evaluates the organic laboratory performance and decides if corrective action should be initiated based on the results of these precision calculations.

\section{Accuracy}

Headspace gas sample analysts measure accuracy by determining \% R through the analysis of LCS and PDP blind audit samples. The technical supervisor or person responsible for data generation level QA review are responsible for monitoring the results from these measurements and determining if the accuracy criteria listed in Table 11-1 have been met. The Site Project QA Officer evaluates the organic laboratory performance and decides if corrective action should be initiated based on the results of these accuracy calculations.

Table 11-1. Hydrogen and Methane Analysis QAOs

\begin{tabular}{|c|c|c|c|c|c|c|}
\hline Analyte & CAS Number & $\begin{array}{c}\text { Precision }^{\mathrm{a}} \\
\text { (\%RSD or RPD) }\end{array}$ & $\begin{array}{c}\text { Accuracy }^{2} \\
(\% \mathrm{R})\end{array}$ & $\begin{array}{l}\text { MDL } \\
\text { (vol\%) }\end{array}$ & $\begin{array}{l}\text { PRQL } \\
\text { (vol\%) }\end{array}$ & $\begin{array}{c}\text { Completeness } \\
(\%)\end{array}$ \\
\hline Hydrogen & $1333-74-0$ & $\leq 25$ & $70-130$ & 0.05 & 0.1 & 90 \\
\hline Methane & $74-82-8$ & $\leq 25$ & $70-130$ & 0.05 & 0.1 & 90 \\
\hline
\end{tabular}




\section{Method Detection Limit}

Headspace gas sample analysts determine MDLs, expressed in volume percent according to Gas Chromatography Determination of Hydrogen and Methane in Waste Container Headspace (TWCPDTP-1.2-019). They ensure that MDLs are less than or equal to those listed in Table 11-1.

\section{Program Required Quantitation Limit}

Headspace gas sample analysts also set the concentration of one calibration standard below the PRQLs given in Table 11-1. Calibration procedures are included in the analytical procedure referenced above.

\section{Completeness}

Headspace gas sample analysts or the technical supervisor measure completeness by calculating the number of samples analyzed with valid results as a percent of the total number of samples submitted for analysis. The organic laboratory achieves the completeness criterion listed in Table 11-1. The Site Project QA Officer evaluates the organic laboratory performance and decides if corrective action should be initiated based on these completeness calculations.

\section{Comparability}

Headspace gas sample analysts achieve comparability by using standardized methods, traceable standards, and by participating in the PDP.

\section{$\underline{\text { Representativeness }}$}

Headspace gas sample analysts achieve representativeness through the collection of unbiased samples according to the requirements described in Section 7.0 of this QAPjP.

\subsection{Methods Requirements}

Headspace gas sample analysts use GC for analysis of hydrogen and methane. They perform GC in accordance with Gas Chromatography Determination of Hydrogen and Methane in Waste Container Headspace (TWCP-DTP-1.2-019). This procedure is based on Methods Manual Procedure 520.1. Headspace gas sample size is minimized within the constraint that the QAOs specified in Section 11.1 of the QAPP are achieved.

\subsubsection{Criteria for Standards}

Headspace gas sample analysts purchase manufacturer-certified primary hydrogen and methane standards from Scott Specialty Gases (or equivalent).

\subsubsection{Criteria for Qualitative and Quantitative Analysis}

All instruments used to analyze TWCP samples for hydrogen and methane meet the requirements of the Methods Manual. Operating requirements are detailed in Gas Chromatography Determination of Hydrogen and Methane in Waste Container Headspace (TWCP-DTP-1.2-019). Headspace gas sample 
analysts quantitate hydrogen and methane within the calibration range of the analytical instrument being used. They dilute samples with concentrations greater than the calibration range of the analytical instrument or the calibration curve.

For GC, headspace gas sample analysts identify hydrogen and methane by retention time (RT). RT windows are determined about the mean absolute RT of analyzed standards such that the occurrence of both false positive and false negative results are minimized. Analysts quantitate hydrogen and methane based on the peak height or area response and report concentrations as volume percent.

\subsection{Quality Control}

Headspace gas sampling and analysis operates directly under the TWCP QA program. The Site Project QA Officer is responsible for ensuring that procedure performance, including the analysis of QC samples, is monitored. The Site Project QA Officer and the headspace gas analysis technical supervisor are responsible for implementing corrective action when acceptable procedure performance is not met.

TWCP operates an at-line headspace gas sampling and analysis system, where the headspace gas samples are collected into sample injection loops valved directly to the GC (see Record of Variance number 97-016). Therefore the COC and sample handling requirements outlined in Section 6.0 of the QAPP associated with discrete field samples do not apply. Specific QC sample and frequency requirements also are modified to combine sampling batch and analytical batch QA samples as follows:

- The LCS serves the purpose of both the LCS and the field reference sample

- The laboratory duplicate serves the purpose of both the lab duplicate and the field duplicate

- The laboratory blank serves the purpose of both the lab blank and the equipment blank

A separate field blank must still be collected and analyzed for each headspace gas analysis batch. However, if the results a field blank collected and analyzed in the same manner as headspace gas samples meet the acceptance criteria, a separate on-line blank need not be collected or analyzed. QC sample and frequency requirements are summarized in Table 11-2.

Headspace gas sample analysts demonstrate acceptable laboratory performance prior to the analysis of any waste samples through the analysis of method performance samples in accordance with Gas Chromatography Determination of Hydrogen and Methane in Waste Container Headspace (TWCPDTP-1.2-019). They purchase method performance samples that contain hydrogen and methane at concentrations appropriate to verify that all of the QAOs in Table 11-1 are met. Initially, they analyze seven method performance samples to demonstrate acceptable precision and accuracy and determine MDLs for hydrogen and methane. They demonstrate acceptable procedure performance semiannually by analyzing four method performance samples. Method performance sample results are transmitted to the Site Project QA Officer in a memo report.

For QC purposes, an analytical batch is defined as a suite of samples of a similar matrix that is processed as a unit using the same analytical method within a specific time period. An analytical batch can be up to 20 samples (excluding laboratory QC samples). For use with the at-line sampling and 
analysis system, the TWCP defines the headspace gas analysis batch as up to 20 samples that are analyzed within 14 days.

Headspace gas sample analysts analyze duplicates at a frequency of one per analytical batch. They obtain field blanks using the same procedure used to obtain headspace gas samples for analysis. They obtain laboratory blanks from Tedlar bags filled with high-purity nitrogen (99.999-percent pure). (See Record of Variance number 97-016.) They analyze blanks daily or once per analytical batch, whichever is more frequent.

Headspace gas sample analysts prepare LCSs with commercially purchased gas standards independent of those used for instrument calibration. They ensure that LCSs contain hydrogen and methane at concentrations in the calibration range of the analytical instrument and must be analyzed at a frequency of one per analytical batch. They also analyze PDP blind audit samples biannually to determine acceptable laboratory performance.

Table 11-2. Summary of Laboratory QC Samples and Frequencies for Hydrogen and Methane Analysis

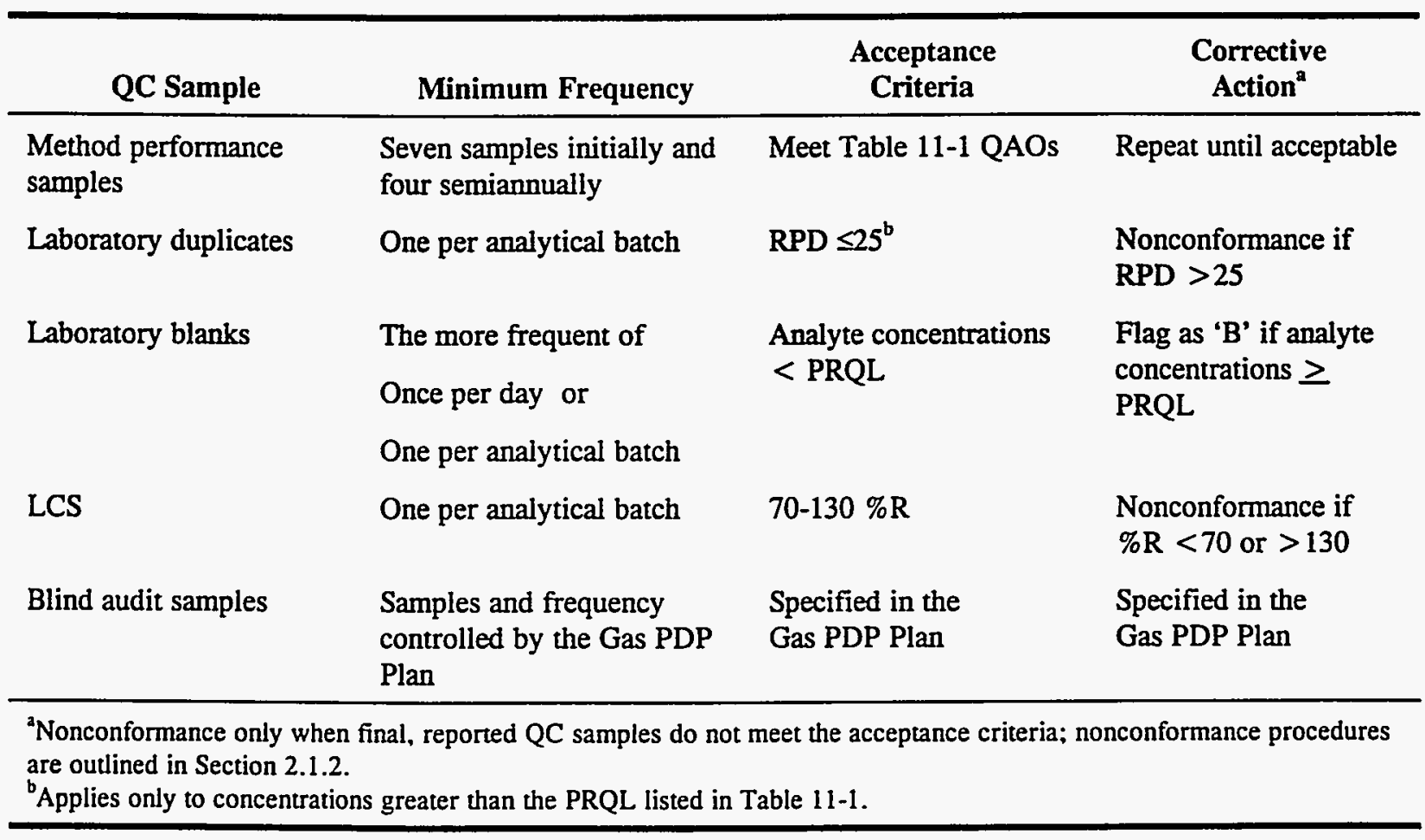

\subsection{Instrument Testing, Inspection, and Maintenance Requirements}

Headspace gas sample analysts perform instrument testing, and inspection according to Gas Chromatography Determination of Hydrogen and Methane in Waste Container Headspace (TWCPDTP-1.2-019). Maintenance is performed by the manufacturers' representative following manufacturers' recommendations and documented according to the Equipment Calibration and Maintenance (TWCP-QP-1.1-018). 


\subsection{Instrument Calibration and Frequency}

Headspace gas sample analysts calibrate all instruments before use and verify calibration at routine intervals during analysis according to Gas Chromatography Determination of Hydrogen and Methane in Waste Container Headspace (TWCP-DTP-1.2-019). They also maintain instrument run logs that permit the reconstruction of the calibration sequence and frequency. Table 11-3 summarizes these calibration requirements.

Table 11-3. Summary of GC Calibration Requirements for Hydrogen and Methane Analysis

\begin{tabular}{|c|c|c|c|}
\hline Technique & Procedure & Frequency of Procedure & Acceptance Criteria \\
\hline GC & $\begin{array}{l}\text { Three-point initial } \\
\text { calibration } \\
\text { (three standards) }\end{array}$ & Initially and as needed & $\begin{array}{l}\% \text { RSD of response factor for each } \\
\text { analyte } \leq 35 \\
\text {-or- } \\
\text { Linear regression plot yields straight } \\
\text { line and \%R for each analyte is } \\
70-130\end{array}$ \\
\hline & Continuing calibration & Every 12 hours & $\% D^{a} \leq 30$ for each analyte \\
\hline
\end{tabular}

Headspace gas sample analysts obtain an initial GC multipoint calibration curve for hydrogen and methane that consists of three standards. They ensure that the low standard is at a concentration less than the PRQL listed in Table 11-1 and the high standard is at a concentration such that it brackets the expected sample concentrations, yet remains within the linear range of the instrument. Alternately, they may generate a linear regression equation by plotting area response versus concentration. They ensure that initial calibrations meet the criteria listed in Table 11-3, regardless of the technique used.

Headspace gas sample analysts analyze a continuing calibration check standard at the beginning of each 12-hour shift. They compare the response factor (or concentration) of the continuing calibration check standard to the corresponding average response factor (or concentration) from the most recent valid initial calibration. They ensure the GC system is calibrated by meeting the criteria listed in Table 11-3 and, if the acceptance criteria are not met, they either run another continuing calibration or generate a new calibration curve. They do not continue sample analysis until the requirements in Table 11-3 are met.

Headspace gas sample analysts may use the LCS for a GC continuing calibration; however, if they do not use the LCS for continuing calibration, they run the LCS during the analytical sequence. They ensure that the continuing calibration gas is a separate standard from that used for the initial instrument calibration and that the continuing calibration standard contains both hydrogen and methane at concentrations within the calibration range of the analytical instrument. 


\subsection{Data Management}

The TWCP employs the data review, validation, and verification procedures described in Section 3.1.1 as well as those described below for hydrogen and methane analysis results. Data analysis and reporting is largely automated, using the Hewlett-Packard software code "Enviro Quant," which is maintained under Software Management (TWCP-QP-1.1-006). Analysts follow Gas Chromatography Determination of Hydrogen and Methane in Waste Container Headspace (TWCP-DTP-1.2-019), which includes specific equations for data reduction and Headspace Gas Analysis Batch Data Report Preparation (TWCP-DTP-1.2-025), which includes instructions for using the software as well as forms for data validation and reporting.

\section{Data Reduction}

Headspace gas sample analysts do not blank-correct hydrogen and methane results. They report results from blank analysis separately from field sample results. They quantify hydrogen and methane concentrations determined by GC using average response factors or linear regression equations obtained from certified calibration standards.

\section{Data Validation}

Headspace gas sample analysts review and approve all analytical data, as defined in Section 3.1.1, and report all hydrogen and methane results in units of volume percent.

\section{Data Reporting}

The headspace gas sampling and analysis technical supervisor or operations leader submits analytical batch data reports for each analytical batch to the Site Project QA Officer on approved standard forms included in Headspace Gas Analysis Batch Data Report Preparation (TWCP-DTP-1.2-025).

Headspace gas analysis batch data reports consist of the following:

- Cover page that includes the batch number and sample numbers included in that batch (and the signature releases of organic laboratory personnel, as specified in Section 3.1.1)

- Table of contents

- Only if SUMMA® canisters are used under Headspace Gas Sampling Using the Direct Canister Method (TWCP-DTP-1.2-007); original COC forms, cross reference to field sample numbers, and field canister documentation

- Data review checklists for each analytical batch verifying that the data generation level review, validation, and verification, as described in Section 3.1.1, have taken place. Checklists contain tables showing the results of the batch QC samples (laboratory duplicate results are recorded along with the original sample results, and the RPD between the two results is calculated; LCS results are entered with the accepted value, and the \% R calculated; blanks results are entered and compared with the PRQLs; continuing calibration check results are entered with the corresponding average response factor or concentration, and the $\% \mathrm{D}$ is calculated) 
- A separate analytical report sheet for each sample and QC sample in the batch that includes the TWCP name, the title "Hydrogen and Methane Analysis Data Sheet," batch number, sample number, date sampled and analyzed, method number, list of hydrogen and methane results in volume percent. The following data qualifying flags are used:

- B-Analyte detected in blank

- E-Analyte exceeds the calibration curve

- J-Analyte less than PRQL, but greater than or equal to MDL

- U-Analyte was undetected (report MDL)

- D-Analyte was quantitated from a secondary dilution or reduced volume sample aliquot

- Z-One or more QC samples do not meet acceptance criteria

- H-Holding time exceeded (only if SUMMA® canisters are used)

- Nonconformance reports, if applicable

- Clean copies of the pages in the instrument run log that pertain to the analysis batch

- Clean copies of the pages of laboratory notebooks that pertain to the sampling or analysis batch

The TWCP maintains the following items in its files (see Record of Variance number 97-017):

- All raw data, including original instrument readouts, calculation records, and QC sample results, stored electronically and retrievable by the file name noted in the instrument run $\log$

- Reports of results of method performance samples that include the accepted and measured values of the results for all analytes, the source or preparation of the samples, method identification, analysis dates, and a reference to the electronic raw data file name(s)

- Reports of results of multipoint calibration curves that include the accepted and measured values of the calibration results for all analytes, the initial calibration verification source, method identification, calibration date, and a reference to the electronic raw data file name(s)

\subsection{Procedures Specific to This Section}

Table 11-4 lists the procedures specific to this section of the QAPjP. 
Table 11-4. Section 11.0 Procedures

\begin{tabular}{ll}
\hline \multicolumn{1}{c}{ Document Number } & \multicolumn{1}{c}{ Title } \\
\hline TWCP-QP-1.1-006 & Software Management \\
TWCP-QP-1.1-018 & Equipment Calibration and Maintenance Procedure \\
TWCP-DTP-1.2-019 & Gas Chromatography Determination of Hydrogen and Methane \\
& in Waste Container Headspace \\
TWCP-DTP-1.2-025 & Headspace Gas Analysis Batch Data Report Preparation \\
\hline
\end{tabular}




\subsection{GAS VOLATILE ORGANIC COMPOUND ANALYSIS}

The TWCP achieves the QA elements defined in this section for the analysis of VOCs in headspace gas samples. The analytical techniques and procedures referenced include the specific activities to determine the concentration of headspace VOCs in TWCP samples. The headspace gas operations leader is responsible for implementation and compliance with all requirements specified in this section and further defined by Determination of Volatile Organic Compounds in Waste Container Headspace by the Gas Chromatography/Mass Spectrometry Method (TWCP-DTP-1.2-018).

\subsection{Quality Assurance Objectives}

The QAOs for headspace gas VOC analysis are listed in Table 12-1. Key data quality indicators for organic laboratory measurements are defined below, and the methods to assess compliance with these indicators are presented in Section 3.2 of this QAPjP.

\section{Precision}

Headspace gas sample analysts measure precision by determining \% RSD or RPD through the analysis of laboratory duplicates, replicate analyses of LCSs, and PDP blind audit samples. The technical supervisor or person responsible for data generation level QA review is responsible for monitoring the results from these measurements, determining if the precision criterion listed in Table 12-1 has been met, and documenting this in the analytical batch report. The Site Project QA Officer evaluates the organic laboratory performance and decides if corrective action should be initiated based on the results of these precision calculations.

\section{Accuracy}

Headspace gas sample analysts measure accuracy by determining \% R through the analysis of LCS and PDP blind audit samples. The technical supervisor or person responsible for data generation level QA review is responsible for monitoring the results from these measurements and determining if the accuracy criterion listed in Table 12-1 has been met. The Site Project QA Officer evaluates the organic laboratory performance and decides if corrective action should be initiated based on the results of these accuracy calculations.

\section{Method Detection Limit}

Headspace gas sample analysts determine MDLs according to Determination of Volatile Organic Compounds in Waste Container Headspace by the Gas Chromatography/Mass Spectrometry Method (TWCP-DTP-1.2-018). They express MDLs in nanograms and ensure the MDLs are less than or equal to those listed in Table 12-1.

\section{Program Required Quantitation Limit}

Headspace gas sample analysts set the concentration of one calibration standard below the PRQLs given in Table 12-1. 

Table 12-1. Gas Volatile Organic Compounds Target Analyte List
and QAOs

\begin{tabular}{|c|c|c|c|c|c|c|}
\hline Compound & $\begin{array}{l}\text { CAS } \\
\text { Number }\end{array}$ & $\begin{array}{c}\text { Precision }^{2} \\
(\% \text { RSD or RPD })\end{array}$ & $\begin{array}{c}\text { Accuracy }^{a} \\
(\% R)\end{array}$ & $\begin{array}{c}\mathrm{MDL}^{\mathrm{b}} \\
\text { (ng) }\end{array}$ & $\begin{array}{l}\mathrm{PRQL}^{\mathrm{b}} \\
\text { (ppmv) }\end{array}$ & $\begin{array}{l}\text { Completeness } \\
\text { (percent) }\end{array}$ \\
\hline Benzene & $71-43-2$ & $\leq 25$ & $70-130$ & 10 & 10 & 90 \\
\hline Bromoform & $75-25-2$ & $\leq 25$ & $70-130$ & 10 & 10 & 90 \\
\hline Carbon tetrachloride & $56-23-5$ & $\leq 25$ & $70-130$ & 10 & 10 & 90 \\
\hline Chlorobenzene & $108-90-7$ & $\leq 25$ & $70-130$ & 10 & 10 & 90 \\
\hline Chloroform & $67-66-3$ & $\leq 25$ & $70-130$ & 10 & 10 & 90 \\
\hline Cyclohexane & $110-87-7$ & $\leq 25$ & $70-130$ & 10 & 10 & 90 \\
\hline 1,1-Dichloroethane & $75-34-3$ & $\leq 25$ & $70-130$ & 10 & 10 & 90 \\
\hline 1,2-Dichloroethane & $107-06-2$ & $\leq 25$ & $70-130$ & 10 & 10 & 90 \\
\hline 1,1-Dichloroethylene & $75-35-4$ & $\leq 25$ & $70-130$ & 10 & 10 & 90 \\
\hline cis-1,2-Dichloroethylene & $156-59-2$ & $\leq 25$ & $70-130$ & 10 & 10 & 90 \\
\hline Ethyl benzene & $100-41-4$ & $\leq 25$ & $70-130$ & 10 & 10 & 90 \\
\hline Ethyl ether & $60-29-7$ & $\leq 25$ & $70-130$ & 10 & 10 & 90 \\
\hline Formaldehyde $^{c}$ & $50-00-0$ & $\leq 25$ & $70-130$ & 10 & 10 & 90 \\
\hline Methylene chloride & $75-09-2$ & $\leq 25$ & $70-130$ & 10 & 10 & 90 \\
\hline 1,1,2,2-Tetrachloroethane & $79-34-5$ & $\leq 25$ & $70-130$ & 10 & 10 & 90 \\
\hline Tetrachloroethylene & $127-18-4$ & $\leq 25$ & $70-130$ & 10 & 10 & 90 \\
\hline Toluene & $108-88-3$ & $\leq 25$ & $70-130$ & 10 & 10 & 90 \\
\hline 1,1,1-Trichloroethane & $71-55-6$ & $\leq 25$ & $70-130$ & 10 & 10 & 90 \\
\hline Trichloroethylene & $79-01-6$ & $\leq 25$ & $70-130$ & 10 & 10 & 90 \\
\hline $\begin{array}{l}\text { 1,1,2-Trichloro-1,2,2- } \\
\text { trifluoroethane }\end{array}$ & $76-13-1$ & $\leq 25$ & $70-130$ & 10 & 10 & 90 \\
\hline 1,2,4-Trimethylbenzene & $95-63-6$ & $\leq 25$ & $70-130$ & 10 & 10 & 90 \\
\hline 1,3,5-Trimethylbenzene & $108-67-8$ & $\leq 25$ & $70-130$ & 10 & 10 & 90 \\
\hline$m$-Xylene ${ }^{d}$ & $108-38-3$ & $\leq 25$ & $70-130$ & 10 & 10 & 90 \\
\hline o-Xylene & $95-47-6$ & $\leq 25$ & $70-130$ & 10 & 10 & 90 \\
\hline$p$-Xylene ${ }^{\mathrm{d}}$ & $106-42-3$ & & $70-130$ & 10 & 10 & 90 \\
\hline Acetone & $67-64-1$ & $\leq 25$ & $70-130$ & 150 & 100 & 90 \\
\hline Butanol & $71-36-3$ & $\leq 25$ & $70-130$ & 150 & 100 & 90 \\
\hline Methanol & $67-56-1$ & $\leq 25$ & $70-130$ & 150 & 100 & 90 \\
\hline Methyl ethyl ketone & $78-93-3$ & $\leq 25$ & $70-130$ & 150 & 100 & 90 \\
\hline Methyl isobutyl ketone & $108-10-1$ & $\leq 25$ & $70-130$ & 150 & 100 & 90 \\
\hline
\end{tabular}

\section{Completeness}

Headspace gas sample analysts measure completeness by calculating the number of samples analyzed with valid results as a percent of the total number of samples submitted for analysis. The organic laboratory achieves the completeness criterion listed in Table 12-1. The Site Project QA Officer evaluates the organic laboratory performance and decides if corrective action should be initiated based on these completeness calculations. 


\section{Comparability}

Headspace gas sample analysts achieve comparability by using standardized methods, traceable standards, and participation in the PDP.

\section{Representativeness}

Headspace gas sample analysts achieve representativeness by the collection of unbiased samples. Sample collection requirements are described in Section 7.0 of this QAPjP.

\subsection{Methods Requirements}

Headspace gas sample analysts use GC/MS in accordance with Determination of Volatile Organic Compounds in Waste Container Headspace by the Gas Chromatography/Mass Spectrometry Method (TWCP-DTP-1.2-018) to analyze all of the analytes listed in Table 12-1. These analytical DTPs are based on Methods Manual procedures. Table 12-2 lists the analytes segregated into flammable and nonflammable groups. Headspace gas sample size is minimized within the constraint that the QAOs specified in Section 12.1 of the QAPP are achieved.

Headspace gas sample analysts use equipment and materials that meet all Methods Manual requirements for GC/MS methods. They equip gas chromatographs with two capillary columns based on those recommended in the Methods Manual. They operate GC/MS systems in the full scan mode to detect and quantitate target analytes and identify nontarget compounds.

\section{Criteria for Standards}

Headspace gas sample analysts either purchase certified primary standards from Scott Specialty Gases (or equivalent) for gases, and Supelco (or equivalent) for liquids, or prepare these standards for the target analytes specified in Table 12-1. They prepare all primary, secondary, and calibration standards according to the analytical procedure Determination of Volatile Organic Compounds in Waste Container Headspace by the Gas Chromatography/Mass Spectrometry Method (TWCP-DTP-1.2-018), and analyze these standards at the same temperature as the samples $\left( \pm 2^{\circ} \mathrm{C}\right)$.

\section{Criteria for Qualitative and Quantitative Analysis}

Headspace gas sample analysts use internal standard quantitation for GC/MS analysis, as detailed in Determination of Volatile Organic Compounds in Waste Container Headspace by the Gas Chromatography/Mass Spectrometry Method (TWCP-DTP-1.2-018). They qualitatively identify target VOCs by ensuring the analytes elute within \pm 0.06 relative retention time (RRT) units of the RRT of the continuing calibration check standard and have a mass spectrum that corresponds to the standard mass spectrum. They determine RRT windows for all analytes prior to the analysis of any samples and whenever a new GC column is installed.

Headspace gas sample analysts meet the \%RSD criteria for all analytes, or generate a second- or thirdorder regression calibration curve. They calculate $\%$ RSD as the standard deviation of average response factors for an analyte divided by the mean of the five initial response factors for that analyte. They ensure that the internal standard area counts for sample analyses are within 50 to 200-percent of 
the average internal standard area counts from the most recent continuing calibration. They use the integrated abundance from the extracted ion current profile (EICP) of the primary characteristic ion to calculate concentrations. They quantitate analytes within the calibration range of the analytical instrument, dilute samples with concentrations greater than the calibration range of the instrument or calibration curve, and report the method used for quantitation with the results.

Table 12-2. Flammable and Nonflammable Volatile Organic Compounds

\begin{tabular}{|c|c|}
\hline Flammable VOCS & Nonflammable VOCs \\
\hline $\begin{array}{l}\text { Acetone } \\
\text { Benzene } \\
\text { Butanol } \\
\text { Chlorobenzene } \\
\text { Cyclohexane } \\
\text { 1,1-Dichloroethane } \\
\text { 1,2-Dichloroethane } \\
\text { 1,1-Dichloroethylene } \\
\text { cis-1,2-Dichloroethylene } \\
\text { Ethyl benzene } \\
\text { Ethyl ether } \\
\text { Methanol } \\
\text { Methyl ethyl ketone } \\
\text { Methyl isobutyl ketone } \\
\text { Toluene } \\
\text { 1,2,4-Trimethylbenzene } \\
\text { 1,3,5-Trimethylbenzene } \\
\text { Xylenes }\end{array}$ & $\begin{array}{l}\text { Bromoform } \\
\text { Carbon tetrachloride } \\
\text { Chloroform } \\
\text { Formaldehyde } \\
\text { Hydrazine } \\
\text { Methylene chloride } \\
\text { 1,1,2,2-Tetrachloroethane } \\
\text { Tetrachloroethylene } \\
\text { 1,1,1-Trichloroethane } \\
\text { Trichloroethylene } \\
\text { 1,1,2-Trichloro-1,2,2-trifluoroethane }\end{array}$ \\
\hline
\end{tabular}

\subsection{Quality Control}

Headspace gas sampling and analysis operates directly under the TWCP QA program. The Site Project QA Officer is responsible for ensuring that procedure performance, including the analysis of QC samples, is monitored. The Site Project QA Officer and the headspace gas technical supervisor are responsible for implementing corrective action when procedure performance is not acceptable.

TWCP operates an at-line headspace gas sampling and analysis system, where the headspace gas samples are collected into sample injection loops valved directly to the GC (see Record of Variance number 97-003). Therefore, the COC and sample handling requirements outlined in Section 6.0 of the QAPP associated with discrete field samples do not apply. Specific QC sample and frequency requirements also are modified to combine sampling batch and analytical batch $\mathrm{QA}$ samples as follows:

- The LCS serves the purpose of both the LCS and the field reference sample

- The laboratory duplicate serves the purpose of both the lab duplicate and the field duplicate

- The laboratory blank serves the purpose of both the lab blank and the equipment blank 
A separate field blank must still be collected and analyzed for each headspace gas analysis batch. However, if the results of a field blank collected and analyzed in the same manner as headspace gas samples meet the acceptance criteria. a separate on-line blank need not be collected or analyzed. Table 12-3 summarizes QC sample requirements and acceptance criteria.

Table 12-3. Summary of Laboratory QC Samples and Frequencies for Gas VOC Analysis

\begin{tabular}{|c|c|c|c|}
\hline QC Sample & Minimum Frequency & $\begin{array}{l}\text { Acceptance } \\
\text { Criteria }\end{array}$ & $\begin{array}{c}\text { Corrective } \\
\text { Action }^{2}\end{array}$ \\
\hline $\begin{array}{l}\text { Method performance } \\
\text { samples }\end{array}$ & $\begin{array}{l}\text { Seven samples initially and } \\
\text { four semiannually }\end{array}$ & Meet Table 12-1 QAOs & $\begin{array}{l}\text { Repeat until } \\
\text { acceptable }\end{array}$ \\
\hline Laboratory duplicates & One per analytical batch & $\mathrm{RPD} \leq 25^{\mathrm{b}}$ & $\begin{array}{l}\text { Nonconformance if } \\
\text { RPD }>25\end{array}$ \\
\hline Laboratory blanks & $\begin{array}{l}\text { Daily prior to sample } \\
\text { analysis }\end{array}$ & $\begin{array}{l}\text { Analyte amounts } \\
<3 \times \text { MDLs }\end{array}$ & $\begin{array}{l}\text { Flag as " } B \text { " if analyte } \\
\text { amounts } \geq 3 \mathrm{x} \\
\text { MDLs }\end{array}$ \\
\hline LCS & One per analytical batch & $70-130 \% R$ & $\begin{array}{l}\text { Nonconformance if } \\
\% R<70 \text { or }>130\end{array}$ \\
\hline Blind audit samples & $\begin{array}{l}\text { Samples and frequency } \\
\text { controlled by the Gas } \\
\text { PDP Plan }\end{array}$ & $\begin{array}{l}\text { Specified in the Gas } \\
\text { PDP Plan }\end{array}$ & $\begin{array}{l}\text { Specified in the Gas } \\
\text { PDP Plan }\end{array}$ \\
\hline \multicolumn{4}{|c|}{$\begin{array}{l}\text { 2Nonconformance only when final, reported QC samples do not meet the acceptance criteria; nonconformance procedures } \\
\text { are outlined in Section 2.1.2. }\end{array}$} \\
\hline${ }^{\mathrm{b}}$ Applies only to concent & eater than the PRQLs listed $\mathrm{i}$ & ble $12-1$ & \\
\hline
\end{tabular}

Headspace gas sample analysts demonstrate acceptable laboratory performance prior to the analysis of any waste samples through the analysis of method performance samples in accordance with Determination of Volatile Organic Compounds in Waste Container Headspace by the Gas Chromatography/Mass Spectrometry Method (TWCP-DTP-1.2-018). They either purchase method performance standards from Scott Specialty Gases (or equivalent) or prepare method performance standards (according to TWCP-DTP-1.2-018) and ensure that the standards contain the analytes listed in Table 12-1 at concentrations appropriate to verify that all of the QAOs are met. Initially, they analyze seven method performance samples to demonstrate acceptable precision and accuracy and determine MDLs for all VOC target analytes. They demonstrate acceptable procedure performance semiannually by analyzing four method performance samples. Method performance sample results are transmitted to the Site Project QA Officer in a memo report.

For QC purposes, an analytical batch is defined as a suite of samples of a similar matrix that is processed as a unit using the same analytical method within a specific time period. For use with the at-line sampling and analysis system, the TWCP defines the headspace gas analysis batch as up to 20 
samples (excluding laboratory QC samples) that are analyzed within 14 days. Specific QC samples for each analytical batch include blanks, a laboratory duplicate, and an LCS.

Headspace gas sample analysts analyze duplicates at a frequency of one per analytical batch. They obtain field blanks using the same procedure used to obtain headspace gas samples for analysis. They obtain laboratory blanks from Tedlar bags filled with high-purity nitrogen (99.999-percent pure). (See Record of Variance number 97-016.)

Headspace gas sample analysts prepare LCSs with gas or liquid standards that are independent of those used for instrument calibration. They ensure that LCSs contain at least six of the analytes listed in Table 12-1 at concentrations in the calibration range of the analytical instrument. They also analyze PDP blind audit samples biannually to determine acceptable laboratory performance.

\subsection{Instrument Testing, Inspection, and Maintenance Requirements}

\section{GC/MS Instrument Requirements}

Headspace gas sample analysts meet GC/MS instrument performance criteria prior to the analysis of any standards or samples, tune these systems with perfluorotributylamine (PFTBA), and meet the 4-bromofluorobenzene (BFB) criteria specified in the Methods Manual. They check the BFB criteria at the beginning of each 12 hours of operation.

\subsection{Instrument Calibration and Frequency}

Headspace gas sample analysts calibrate all analytical instruments before use and verify calibration at routine intervals during analysis according to Determination of Volatile Organic Compounds in Waste Container Headspace by the Gas Chromatography/Mass Spectrometry Method (TWCP-DTP-1.2-018). Headspace gas sample analysts ensure that all initial and continuing calibration requirements listed in Table 12-4 are met and maintain instrument run logs that permit the reconstruction of the calibration sequence and frequency.

Headspace gas sample analysts satisfy GC/MS instrument performance criteria, then use at least five internal standards to define the calibration range of the instrument for all target analytes, setting the concentration of one standard less than the PRQLs listed in Table 12-1. They use a midpoint calibration standard, also termed the continuing calibration standard, to verify the initial GC/MS calibration curve at the beginning of every 12 hours of operation after satisfying the instrument performance criteria using BFB, as specified in the Methods Manual. They determine the \%D as the percent difference between the continuing calibration response factors and the average response factors or relative response factors from the most recent calibration. They ensure that the midpoint standard meets all daily calibration criteria for internal standard responses and RRTs. They generate a new five-point calibration curve if the continuing calibration standard does not satisfy the criteria for linearity and consistency and do not proceed with sample analysis until the GC/MS system has satisfied the appropriate daily calibration criteria. 
Table 12-4. Summary of GC/MS Calibration Requirements for Gas VOC Analysis

\begin{tabular}{llll}
\hline Technique & \multicolumn{1}{c}{ Procedure } & \multicolumn{1}{c}{$\begin{array}{c}\text { Frequency of } \\
\text { Procedure }\end{array}$} & \multicolumn{1}{c}{ Acceptance Criteria } \\
\hline GC/MS & BFB tune & Every 12 hours & $\begin{array}{l}\text { Abundance criteria for all key ions are } \\
\text { met (see TWCP-DTP-1.2-018) }\end{array}$ \\
& $\begin{array}{l}\text { Five point initial } \\
\text { calibration (five } \\
\text { standards) }\end{array}$ & Initially, and as needed & $\begin{array}{l}\text { \%RSD of response factor for each } \\
\text { analyte }<35\end{array}$ \\
& Continuing calibration & Every 12 hours & $\begin{array}{l}\text { \%D for all compounds } \leq 30 \text { of initial } \\
\text { calibration }\end{array}$ \\
\hline
\end{tabular}

\subsection{Data Management}

The TWCP employs the data review, validation, and verification procedures defined in Section 3.1.1 as well as those described below for headspace gas VOC analysis results. Data analysis and reporting is largely automated, using the Hewlett-Packard software code "Enviro Quant," which is maintained under Software Management (TWCP-QP-1.1-006). Analysts follow TWCP-DTP-1.2-018, which includes specific equations for data reduction and Headspace Gas Analysis Batch Data Report Preparation (TWCP-DTP-1.2-025), which also includes instructions for using the software as well as forms for data validation and reporting.

\section{Data Reduction}

Headspace gas sample analysts quantify analyte concentrations using average relative response factors for internal standard quantitation. They do not blank-correct target analyte concentrations. They report blank results separately, flagging any target compounds detected. They report nontarget compounds as tentatively identified compounds (TICs) with a higher uncertainty than target analyte concentrations. They perform appropriate search routines of a 1996 or later, NIST or equivalent, mass spectral library on the 20 TICs with the greatest area counts and with total ion current peaks greater than 10 percent of the nearest (RT) internal standard. The SPM adds the positively identified TICs listed in 40 CFR Part 264, Appendix IX, to the target analyte list if they are detected in 25 percent of all samples from a given waste stream. Organic laboratory personnel assume a relative response factor equal to one, using the nearest internal standard, when calculating concentration for TICs.

\section{Data Validation}

Headspace gas sample analysts or their technical supervisor review and approve all headspace gas VOC analytical data, as outlined in Section 3.1.1, and report results in parts per million on a volume per volume basis, limited to two significant figures. 


\section{Data Reporting}

The technical supervisor submits analytical batch data reports for each analytical batch to the Site Project QA Officer on approved standard forms included in the analytical procedures. Analytical batch data reports consist of the following:

- Cover page that includes the batch number and sample numbers included in that batch (and the signature releases of organic laboratory personnel as specified in Section 3.1.1)

- Table of contents

- Only if SUMMA ${ }^{\star}$ canisters are used according to Headspace Gas Sampling Using the Direct Canister Method (TWCP-DTP-1.2-007); original COC forms, cross reference to field sample numbers, and field canister documentation

- Data review checklists for each analytical batch verifying that the data generation level review, validation and verification, as described in Section 3.1.1, have taken place. Checklists contain tables showing the results of the batch QC samples (laboratory duplicate results are recorded along with the original sample results, and the RPD between the two resuits is calculated; LCS results are entered with the accepted value, and the $\% \mathrm{R}$ calculated; blanks results are entered and compared with the PRQLs; continuing calibration check results are entered with the corresponding average response factor or concentration, and the \% $\mathrm{D}$ is calculated)

- A separate analytical report sheet for each sample and QC sample in the batch that includes the TWCP name, the title "Gas VOC Analysis Data Sheet," batch number, sample number, date sampled and analyzed, method number, listing of analytes, and analytical results in ppmv. The following data qualifying flags are used:

- B-Analyte detected in blank

- E-Analyte exceeds the calibration curve

- J-Analyte less than PRQL, but greater than or equal to MDL

- U-Analyte was undetected (report MDL)

- D-Analyte was quantitated from a secondary dilution or reduced volume sample aliquot

- Z-One or more QC samples do not meet acceptance criteria

- $\quad$ H-Holding time exceeded (only if SUMMA ${ }^{\otimes}$ canisters are used)

- Nonconformance reports, if applicable

- Clean copies of the pages in the instrument run log that pertain to the analysis batch

- Clean copies of the pages of laboratory notebooks that pertain to the sampling or analysis batch 
The TWCP maintains the following items in its files:

- All raw data, including original instrument readouts, calculation records, and QC sample results stored electronically and retrievable by the file name noted in the instrument run log (see Record of Variance number 97-017)

- Reports of results of method performance samples that include the accepted and measured values of the results for all analytes, the source or preparation of the samples, method identification, analyses dates, and a reference to the electronic raw data file name(s)

- Reports of results of multipoint calibration curves that include the accepted and measured values of the calibration results for all analytes, the initial calibration verification source, method identification, calibration date, and a reference to the electronic raw data file name(s)

\subsection{Procedures Specific to This Section}

Table 12-5 lists the procedures specific to this section of the QAPjP.

Table 12-5. Section 12.0 Procedures

Document Number

$$
\text { TWCP-QP-1.1-006 }
$$

TWCP-DTP-1.2-018

TWCP-DTP-1.2-025
Title

Software Management

Determination of Headspace Gas Volatile Organic Compounds by Gas Chromatography/Mass Spectrometry

Headspace Gas Analysis Batch Data Report Preparation 


\subsection{TOTAL VOLATILE ORGANIC COMPOUND ANALYSIS}

The Laboratory achieves the TWCP QA elements defined in this section for the analysis of total VOCs in samples of homogeneous solids and soil/gravel. The analytical techniques and procedures referenced include the specific activities to determine the concentration of total VOCs in TWCP samples. The analytical services representative is responsible for implementation and compliance with all requirements specified in this section and further defined by the referenced procedures.

\subsection{Quality Assurance Objectives}

The QAOs for total VOC analysis are listed in Table 13-1. Key data quality indicators for organic laboratory measurements are defined below, and the methods to assess compliance with these indicators are presented in Section 3.2 of this QAPjP.

\section{$\underline{\text { Precision }}$}

Organic laboratory personnel measure precision by determining \%RSD or RPD through replicate analysis of matrix spike duplicates, LCSs, and PDP blind audit samples. The Site Project QA Officer is responsible for monitoring the results from these measurements and determining if the precision criterion listed in Table 13-1 has been met. The Site Project QA Officer evaluates the organic laboratory performance and decides if corrective action should be initiated based on the results of these precision calculations.

\section{Accuracy}

Organic laboratory personnel measure accuracy by determining \% $\mathrm{R}$ through the analysis of matrix spikes, surrogate compounds, LCSs, and PDP blind audit samples. The Site Project QA Officer is responsible for monitoring the results from these measurements and determining if the accuracy criterion listed in Table 13-1 has been met. The Site Project QA Officer evaluates the organic laboratory performance and decides if corrective action should be initiated based on the results of these accuracy calculations.

\section{Method Detection Limit}

Organic laboratory personnel determine MDLs, expressed in milligrams per kilogram ( $\mathrm{mg} / \mathrm{kg}$ ), as detailed in "Method Detection Limit Studies" (QC-16) and Total Nonhalogenated Volatile Organic Compounds-GCFID (ANC629), and ensure that MDLs are less than or equal to those listed in Table 13-1.

\section{Program Required Quantitation Limit}

They also set the concentration of at least one QC or calibration standard at or below the PRQLs listed in Table 13-1 for each VOC analyte. The analytical procedures listed in Section 13.7 detail calibration procedures for each analytical technique used. 
Table 13-1. Total VOCs Target Analyte List and QAOs

\begin{tabular}{|c|c|c|c|c|c|c|}
\hline Compound & $\begin{array}{c}\text { CAS } \\
\text { Number }\end{array}$ & $\begin{array}{l}\text { Precision }^{\mathrm{a}} \\
\text { (\%RSD or } \\
\text { RPD) }\end{array}$ & $\begin{array}{c}\text { Accuracy }^{\mathrm{d}} \\
(\% \mathrm{R})\end{array}$ & $\begin{array}{c}\mathrm{MDL} \\
(\mathrm{mg} / \mathrm{kg} \\
\text { ) }\end{array}$ & $\begin{array}{c}\text { PRQL } \\
(\mathrm{mg} / \mathrm{kg})\end{array}$ & $\begin{array}{c}\text { Completeness } \\
(\%)\end{array}$ \\
\hline Benzene & $71-43-2$ & $\leq 45$ & $37-151$ & 1 & 10 & 90 \\
\hline Bromoform & $75-25-2$ & $<47$ & $45-169$ & 1 & 10 & 90 \\
\hline Carbon disulfide & $75-15-0$ & $<50$ & $60-150$ & 1 & 10 & 90 \\
\hline Carbon tetrachloride & $56-23-5$ & $\leq 30$ & $70-140$ & 1 & 10 & 90 \\
\hline Chlorobenzene & $108-90-7$ & $\leq 38$ & $37-160$ & 1 & 10 & 90 \\
\hline Chloroform & $67-66-3$ & $<44$ & $51-138$ & 1 & 10 & 90 \\
\hline 1,4-Dichlorobenzene ${ }^{b}$ & $106-46-7$ & $\leq 60$ & $18-190$ & 1 & 10 & 90 \\
\hline ortho-Dichlorobenzene ${ }^{b}$ & $95-50-1$ & $\leq 60$ & $18-190$ & 1 & 10 & 90 \\
\hline 1,2-Dichloroethane & $107-06-2$ & $\leq 42$ & $49-155$ & 1 & 10 & 90 \\
\hline 1,1-Dichloroethylene & $75-35-4$ & $\leq 250$ & $D-234^{c}$ & 1 & 10 & 90 \\
\hline Ethyl benzene & $100-41-4$ & $\leq 43$ & $37-162$ & $i$ & 10 & 90 \\
\hline Methylene chloride & $75-09-2$ & $<50$ & $D-221^{c}$ & 1 & 10 & 90 \\
\hline 1,1,2,2-Tetrachloroethane & $79-34-5$ & $<55$ & $46-157$ & 1 & 10 & 90 \\
\hline Tetrachloroethylene & $127-18-4$ & $<29$ & $64-148$ & 1 & 10 & 90 \\
\hline Toluene & $108-88-3$ & $\leq 29$ & $47-150$ & 1 & 10 & 90 \\
\hline 1,1,1-Trichloroethane & $71-55-6$ & $\leq 33$ & $52-162$ & 1 & 10 & 90 \\
\hline 1,1,2-Trichloroethane & $79-00-5$ & $\leq 38$ & $52-150$ & 1 & 10 & 90 \\
\hline Trichloroethylene & $79-01-6$ & $\leq 36$ & $71-157$ & 1 & 10 & 90 \\
\hline Trichlorofluoromethane & $75-69-4$ & $\leq 110$ & $17-181$ & 1 & 10 & 90 \\
\hline $\begin{array}{l}\text { 1,1,2-Trichloro-1,2,2- } \\
\text { trifluoroethane }\end{array}$ & $76-13-1$ & $\leq 50$ & $60-150$ & 1 & 10 & 90 \\
\hline Vinyl chloride & $75-01-4$ & $\leq 200$ & $\mathrm{D}-251^{\mathrm{C}}$ & 1 & 4 & 90 \\
\hline$m$-xylene & $108-38-3$ & $\leq 50$ & $60-150$ & 1 & 10 & 90 \\
\hline o-xylene & $95-47-6$ & $<50$ & $60-150$ & 1 & 10 & 90 \\
\hline$p$-xylene & $106-42-3$ & $\leq 50$ & $60-150$ & 1 & 10 & 90 \\
\hline Acetone & 67-64-1 & $<50$ & $60-150$ & $10^{d}$ & 100 & 90 \\
\hline Butanol & $71-36-3$ & $<50$ & $60-150$ & $10^{d}$ & 100 & 90 \\
\hline Ethyl ether & $60-29-7$ & $<50$ & $60-150$ & $10^{\mathrm{d}}$ & 100 & 90 \\
\hline Formaldehyde & $50-00-0$ & $<50$ & $60-150$ & $10^{d}$ & 100 & 90 \\
\hline Isobutanol & $78-83-1$ & $<50$ & $60-150$ & $10^{\mathrm{d}}$ & 100 & 90 \\
\hline Methanol & $67-56-1$ & $<50$ & $60-150$ & $10^{d}$ & 100 & 90 \\
\hline Methyl ethyl ketone & $78-93-3$ & $<50$ & $60-150$ & $10^{d}$ & 100 & 90 \\
\hline Pyridine $^{\mathrm{b}}$ & $110-86-1$ & $<50$ & $60-150$ & $10^{\mathrm{d}}$ & 100 & 90 \\
\hline \multicolumn{7}{|c|}{$\begin{array}{l}{ }^{2} \text { Criteria apply to PRQL concentrations. } \\
\text { bCan also be analyzed as a semi-volatile organic compound. } \\
{ }^{c} \text { Detected; result must be greater than zero. } \\
\text { d Estimate, to be determined. }\end{array}$} \\
\hline
\end{tabular}




\section{Completeness}

Organic laboratory personnel measure completeness by calculating the number of samples analyzed with valid results as a percent of the total number of samples submitted for analysis. The organic laboratory achieves the completeness criterion listed in Table 13-1. The Site Project QA Officer evaluates the organic laboratory performance and decides if corrective action should be initiated based on these completeness calculations.

\section{Comparability}

Organic laboratory personnel achieve comparability by using standardized and approved methods, traceable standards, and by participating in the PDP.

\section{$\underline{\text { Representativeness }}$}

Organic laboratory personnel achieve representativeness through the collection of unbiased samples according to the requirements described in Section 8.0 of this QAPjP.

\subsection{Methods Requirements}

Organic laboratory personnel use the GC/MS method detailed in Volatile Organic Compounds in Radioactive and Nonradioactive Matrices (ANC627), which is based on SW-846 Methods, for the determination of all analytes listed in Table 13-1. They use the gas chromotography/flame ionization detector (GC/FID) method detailed in Total Nonhalogenated Volatile Organic Compounds-GCFID (ANC629), which is based on Methods Manual Procedure 440.2 for the determination of nonhalogenated VOCs that perform poorly by purge and trap methods. They decide if a preparation step is needed based on the nature of the waste samples and use only nationally recognized standard preparation methods, as detailed in the above procedures. Procedures referenced meet the requirements in the Methods Manual.

Organic laboratory personnel use equipment and materials that meet all SW-846 and Methods Manual requirements. They equip gas chromatographs with chromatographic columns selected from among those recommended by the methods. They operate GC/MS systems in the full scan mode to detect and quantitate all Table 13-1 analytes and identify nontarget compounds. They quantitate all analytes within the calibration range of the analytical instrument and dilute samples with analyte concentrations greater than the calibration range.

\section{Criteria for Standards}

Organic laboratory personnel purchase certified primary standards from Supelco (or equivalent) for target analytes. They prepare standards in propanol if methanol is a target analyte. They prepare secondary analytical standards, surrogate standards, internal standards, calibration standards, and matrix spiking standards, as detailed in the analytical procedures, based on the SW-846 and Methods Manual methods.

\section{Criteria for Quantitative and Qualitative Analvsis}

Organic laboratory personnel qualitatively identify analytes using GC/MS by ensuring that the analytes elute within a RRT window of plus or minus 0.06 RRT units of the continuing calibration and have a mass spectrum that corresponds to the standard analyte mass spectrum. They calculate RRT windows 
from the individual RTs for each analyte from a calibration run within the same 12 hours as the sample. They qualitatively identify analytes using GC/FID by ensuring that the analytes elute within the RT window set by the most recent continuing calibration for each analytical column. They determine RT windows for each analyte on each analytical column by injecting at least three standards containing all target analytes over 72 hours. They calculate RT windows as the mean plus or minus three times the standard deviation of the individual RTs for each analyte.

Organic laboratory personnel use internal standard quantitation, as described in the SW-846 methods and detailed in the procedures cited above for GC/MS analysis. They meet the criteria for system performance check compounds (SPCCs) and calibration check compounds (CCCs) and calculate response factors and the \%RSD for response factors for all analytes. To ensure that the GC/MS system is in control, they meet all daily calibration criteria for BFB, SPCCs, CCCs, internal standard responses, and RTs. They quantitate an analyte based on the integrated abundance from the EICP of the primary ion.

Organic laboratory personnel use external standard quantitation for GC/FID analysis and base analyte quantitation on the peak area response or peak height response from one of the two analytical columns. They ensure that the column used for quantitation is free of interferants in the analyte's RT window and quantitate by a three-point calibration curve or response factor. They consider the GC/FID system to be in control if, after analyzing a mid-range continuing calibration standard, the response factor (or calculated concentration) for any analyte is less than $15 \% \mathrm{D}$ from the initial calibration average response factor (or true concentration) and all criteria for RT windows are met.

\subsection{Quality Control}

The Site Project QA Officer is responsible for monitoring and documenting procedure performance, including the analysis of QC samples. The Site Project QA Officer and the analytical services project leader are responsible for implementing corrective actions when procedure performance is not acceptable. The Analytical Chemistry Quality Management Plan (QA-1) describes the implementation actions to ensure the daily quality of analytical data for total VOC analysis, specifies acceptance criteria for TWCP QC samples, and specifies corrective action measures to be taken when these criteria are not satisfied. Organic laboratory personnel operate a formal QC program and maintain records to document the quality of the data generated. They implement all QC practices established by the SW-846 and Methods Manual methods, including QC sample requirements, as detailed in the analytical procedures and summarized in Table 13-2. They prepare and analyze QC samples as detailed in the analytical procedures.

Organic laboratory personnel demonstrate acceptable performance prior to the analysis of any waste samples through the analysis of method performance samples in accordance with Volatile Organic Compounds in Radioactive and Nonradioactive Matrices (ANC627) and Total Nonhalogenated Volatile Organic Compounds-GCFID (ANC629). They ensure that method performance samples contain all of the analytes listed in Table 13-1 at concentrations appropriate to verify that all QAOs are met. Initially, they analyze seven method performance samples to demonstrate acceptable precision and accuracy and to determine MDLs for all analytes. They repeat this demonstration semiannually by the analysis of four method performance samples.

For QC purposes, an analytical batch is defined as a suite of samples of a similar matrix, processed as a unit, using the same analytical method within a specific time period. An analytical batch can be up to 20 samples (excluding laboratory QC samples), all of which must be received by the laboratory within 14 
days of the VTSR of the first sample in the batch. Specific QC samples for each analytical batch include blanks, a matrix spike, a laboratory duplicate and/or a matrix spike duplicate, and an LCS.

Organic laboratory personnel choose surrogate compounds based on guidance provided in SW-846 and add these compounds to each field sample and laboratory QC sample. They may analyze matrix spike duplicates in place of laboratory duplicates. They ensure that matrix spikes and matrix spike duplicates contain at least five of the VOCs listed in Table 13-1 at concentrations at the PRQLs listed in Table 13-1. They demonstrate on-going laboratory performance through the analysis of LCSs.

Table 13-2. Summary of Laboratory QC Samples and Frequencies for Total VOC Analysis

\begin{tabular}{|c|c|c|c|}
\hline QC Sample & Minimum Frequency & $\begin{array}{l}\text { Acceptance } \\
\text { Criteria }\end{array}$ & $\begin{array}{c}\text { Corrective } \\
\text { Action }^{2}\end{array}$ \\
\hline $\begin{array}{l}\text { Method performance } \\
\text { samples }\end{array}$ & $\begin{array}{l}\text { Seven samples initially } \\
\text { and four semiannually }\end{array}$ & Meet Table 13-1 QAOs & Repeat until acceptable \\
\hline Laboratory duplicates ${ }^{b}$ & One per analytical batch & Meet Table 13-1 RPDs & $\begin{array}{l}\text { Nonconformance if RPDs } \\
>\text { Table 13-1 values }\end{array}$ \\
\hline Laboratory blanks & One per analytical batch & $\begin{array}{l}\text { Analyte concentrations } \\
>3 \times \text { MDLs }\end{array}$ & $\begin{array}{l}\text { Nonconformance if } \\
\text { analyte concentrations } \\
\geq 3 \times \text { MDLs }\end{array}$ \\
\hline Matrix spikes & One per analytical batch & Meet Table $13-1 \%$ Rs & $\begin{array}{l}\text { If \%Rs are outside the } \\
\text { range specified in Table } \\
13-1 \text { due to matrix } \\
\text { interference, document in } \\
\text { case narrative and flag } \\
\text { data ' } Z \text { '. \%Rs outside } \\
\text { range for other reason is a } \\
\text { nonconformance }\end{array}$ \\
\hline Matrix spike duplicates & One per analytical batch & $\begin{array}{l}\text { Meet Table 13-1 RPDs } \\
\text { and \%Rs }\end{array}$ & $\begin{array}{l}\text { If } \% R \text { is outside criteria } \\
\text { due to matrix, document } \\
\text { in case narrative. } \\
\text { Nonconformance if for } \\
\text { other reason and flag data } \\
\text { ' } Z \text { ' }\end{array}$ \\
\hline LCS & One per analytical batch & $80-120 \% R$ & $\begin{array}{l}\text { Nonconformance if } \% R< \\
80 \text { or }>120\end{array}$ \\
\hline Surrogate compounds & Each analytical sample & $\begin{array}{l}\text { Average } \% R \text { from } \\
\text { minimum of } 30 \text { samples } \\
\text { for a given matrix } \pm 3 \\
\text { standard deviations }\end{array}$ & $\begin{array}{l}\text { If } \% R \text { is outside criteria } \\
\text { due to matrix, document } \\
\text { in case narrative. } \\
\text { Nonconformance if for } \\
\text { other reason and flag data } \\
\text { ' } Z \text { ' }\end{array}$ \\
\hline Blind audit samples & $\begin{array}{l}\text { Samples and frequency } \\
\text { controlled by the Solid } \\
\text { PDP Plan }\end{array}$ & $\begin{array}{l}\text { Specified in the Solid } \\
\text { PDP Plan }\end{array}$ & $\begin{array}{l}\text { Specified in the Solid } \\
\text { PDP Plan }\end{array}$ \\
\hline \multicolumn{4}{|c|}{$\begin{array}{l}{ }^{\circ} \text { Corrective action when QC samples do not meet the acceptance criteria; nonconformance only if final, reported QC } \\
\text { samples do not meet criteria: nonconformance procedures are outlined in Section } 2.1 .2 \text {. } \\
\text { bay be satisfied using matrix spike duplicate; acceptance criteria apply only to concentrations greater than the PRQLs } \\
\text { listed in Table 13-1. }\end{array}$} \\
\hline
\end{tabular}


They prepare LCSs, in water, to contain at least 10 of the analytes listed in Table 13-1 at PQRL concentrations from standards independent of those used for instrument calibration. They employ all the sample preparation procedures performed on field samples for LCSs. They also demonstrate acceptable laboratory performance biannually by analyzing PDP blind audit samples.

\subsection{Instrument Testing, Inspection, and Maintenance Requirements}

Organic laboratory personnel meet GC/MS instrument performance criteria prior to the analysis of any standards or samples, tune these systems with PFTBA, and meet the BFB criteria specified in the appropriate SW-846 method and the applicable Methods Manual procedure. They check the BFB criteria at the beginning of each 12 hours of operation by analyzing $50 \mathrm{ng}$ of BFB. They equip GC/FID gas chromatographs with two chromatographic columns selected from among those recommended in Methods Manual Procedure 440.2. They periodically clean splitless glass injection liners with nitric acid.

\subsection{Instrument Calibration and Frequency}

Organic laboratory personnel calibrate all analytical instruments before use and verify calibration at routine intervals during analysis according to the Laboratory's Calibration Handbook and the analytical procedures. These procedures detail all aspects of calibration, as summarized in Table 13-3. Organic laboratory personnel ensure that all the initial and continuing calibration requirements listed in Table 133 are met and maintain instrument run logs that permit the reconstruction of the calibration sequence and frequency.

Organic laboratory personnel satisfy GC/MS instrument performance criteria, then use at least five penetration levels to define the calibration range of the instrument for all target analytes and set the concentration of one standard less than the PRQLs listed in Table 13-1. They use average relative response factors for each analyte if the \%RSD is less than or equal to 15 and use a linear regression equation if the \%RSD is greater than 15 . They use a midpoint calibration standard to verify the initial GC/MS calibration curve at the beginning of every 12 hours of operation after satisfying the instrument performance criteria using $50 \mathrm{ng}$ of BFB according to the applicable Methods Manual procedure. They ensure that the midpoint standard meets all of the daily calibration criteria for surrogate compound recovery, SPCCs, CCCs, internal standard area count criteria, and RTs, as specified in Table 13-3. They choose SPCCs and CCCs common to Table 13-1 and the appropriate SW-846 method. They generate a new five-point calibration curve if the continuing calibration standard does not satisfy the criteria for linearity and consistency and do not proceed with sample analysis until the GC/MS system has satisfied the appropriate daily calibration criteria.

Organic laboratory personnel use at least three external standards to define the calibration range of the GC/FID system for the appropriate nonhalogenated VOC analytes listed in Table 13-1. They set the concentration of one standard less than the PRQLs specified in Table 13-1. They verify the initial GC/FID calibration curve with a midpoint calibration standard (continuing calibration standard) at the beginning of each 12 hours of operation. They ensure that the midpoint standard meets the daily calibration criteria, as specified in Table 13-3. They prepare a new calibration curve or response factor for any analyte in the continuing calibration standard that does not satisfy the criteria for linearity and consistency and do not proceed with sample analysis until the GC/FID system has satisfied the appropriate daily calibration criteria. 
Table 13-3. Summary of Calibration Requirements for Total VOC Analysis

\begin{tabular}{|c|c|c|c|}
\hline Technique & Procedure & $\begin{array}{l}\text { Frequency of } \\
\text { Procedure }\end{array}$ & Acceptance Criteria \\
\hline \multirow[t]{3}{*}{ GC/MS } & BFB tune & Every 12 hours & $\begin{array}{l}\text { Abundance criteria for all key ions are } \\
\text { met }\end{array}$ \\
\hline & $\begin{array}{l}\text { Five point initial } \\
\text { calibration (five } \\
\text { standards) }\end{array}$ & $\begin{array}{l}\text { Initially, and as } \\
\text { needed }\end{array}$ & $\begin{array}{l}\text { Response factor \%RSD for CCCs } \leq 30 \text {; } \\
\text { response factor for } \mathrm{SPCCs} \geq 30^{\mathrm{a}} \text {; } \\
\text { average relative response factor is used } \\
\text { if } \% \mathrm{RSD} \leq 15 ; \text { linear regression } \\
\text { equation is generated if } \% \mathrm{RSD}>15\end{array}$ \\
\hline & Continuing calibration & Every 12 hours & $\begin{array}{l}\text { Response factor or conc. } \% \mathrm{D} \text { for } \mathrm{CCCs} \\
\leq 20 \text {; response factor for SPCCs } \geq .30^{\mathrm{a}} \text {; } \\
\mathrm{RT} \text { for internal standards must be } \pm 30 \\
\text { seconds from last daily calibration } \\
\text { check; internal standard area count } \\
\text { must be }>50 \% \text { or }<200 \% \text { of the area } \\
\text { counts from the last daily calibration } \\
\text { check; surrogate compound \%R must } \\
\text { be met }\end{array}$ \\
\hline \multirow[t]{2}{*}{ GC/FID } & $\begin{array}{l}\text { Three point initial } \\
\text { calibration (three } \\
\text { standards) }\end{array}$ & $\begin{array}{l}\text { Initially, and as } \\
\text { needed }\end{array}$ & $\begin{array}{l}\text { Correlation coefficient } \geq 0.93 \\
\text { (calibration curves) or } \% \text { RSD for } \\
\text { response factors }<35 \text { for all analytes }\end{array}$ \\
\hline & Continuing calibration & Every 12 hours & $\begin{array}{l}\text { Response factor or measured } \\
\text { concentration \%D for all analytes } \\
\leq 15 \text { of initial calibration; } \mathrm{RT} \pm 3 \\
\text { standard deviations from initial } \\
\text { calibration }\end{array}$ \\
\hline
\end{tabular}

\subsection{Data Management}

The Laboratory employs the data review, validation, and verification procedures described in Section 3.1.1 as well as those described below for total VOC analysis results. The organic laboratory employs data management procedures defined in the analytical methods, which include specific equations, sample calculations, and example forms for data reduction, validation, and reporting.

\section{Data Reduction}

Organic laboratory personnel quantify analyte concentrations using average relative response factors for internal standard quantitation (GC/MS) and average response factors for external standard quantitation or a linear regression equation (GC/FID). They do not blank-correct target analyte concentrations. They report blank results separately, flagging any target compounds detected. They report nontarget compounds as TICs with a higher uncertainty than target analyte concentrations. They perform appropriate search routines of the latest NIST or equivalent mass spectral library on the 20 TICs with the 
greatest area count and with total ion current peaks greater than 10 percent of the nearest (RT) internal standard. The SPM adds the positively identified TICs listed in 40 CFR Part 264, Appendix IX, to the target analyte list if they are detected in 25 percent of all samples from a given waste stream.

\section{Data Validation}

Organic laboratory personnel review and approve all total VOC analytical data, as outlined in Section 3.1.1, and report the results in $\mathrm{mg} / \mathrm{kg}$ on a weight per wet-weight basis, limited to two significant figures.

\section{Data Reporting}

The analytical services representative submits analytical batch data reports for each analytical batch to the Site Project QA Officer on approved standard forms included in the analytical procedures. Analytical batch data reports consist of the following:

- Report that includes the organic laboratory name, analytical batch number, sample numbers included in that analytical batch, a cross reference to field sample numbers, and the signature releases of organic laboratory personnel as specified in Section 3.1.1.

- Table of contents

- Summary COC form that shows the date and time of sample transfer, and name of individuals handling the samples from the time of sampling through receipt at the organic laboratory

- Data review checklists for each analytical batch verifying that the data generation level review, validation, and verification, as described in Section 3.1.1, have taken place. Checklists contain tables showing the results of the analytical batch QC samples. These tables may also be attached to the checklists.

- A separate analytical report sheet for each sample in the analytical batch that includes the organic laboratory name, TWCP name, the title "Total VOCs Analysis Data Sheet," analytical batch number, sampling batch number, organic laboratory sample number, field sample number, date sampled, date extracted (if applicable), date analyzed, methods number(s), listing of analytes, and analytical results in $\mathrm{mg} / \mathrm{kg}$. The following data qualifying flags are used:

- B-Analyte detected in blank

- E-Analyte exceeds the calibration curve

- J-Analyte less than PRQL, but greater than or equal to MDL

- U-Analyte was undetected (report MDL)

- D-Analyte was quantitated from a secondary dilution or reduced volume sample aliquot

- Z-One or more QC samples do not meet acceptance

- $\mathrm{H}-$ Holding time is exceeded

- Nonconformance reports, if applicable 
The organic laboratory maintains the following items in its files, documented and retrievable by analytical batch number:

- Original COC forms

- All raw data, including original instrument readouts and/or bench reports, calculation records, and QC sample results; laboratory duplicate results are recorded along with the original sample results, and the RPD between the two results is calculated; LCS results are entered along with the accepted value and the $\% R$

- All instrument calibration reports that include the accepted and measured values of calibration verification for all analytes; these reports also contain the organic laboratory name, initial and continuing calibration verification source, methods number, and calibration date and time

- QC result summary, that includes true and found values for all QC samples plus associated result calculations; QC data include blanks, LCSs, matrix spikes, matrix spike duplicates, surrogate compounds, initial calibration data, initial and continuing calibration verifications, and all other applicable QC listed in Table 13-3; the QC summary report also contains the organic laboratory name, the analytical batch number (if applicable), and method numbers

\subsection{Procedures Specific to This Section}

Table 13-4 lists the procedures specific to this section of the QAPjP.

Table 13-4. Section 13.0 Procedures

\begin{tabular}{cl}
\hline Document Number & \multicolumn{1}{c}{ Title } \\
\hline ANC627 & $\begin{array}{l}\text { Volatile Organic Compounds in Radioactive and Nonradioactive } \\
\text { Matrices }\end{array}$ \\
ANC629 & Total Nonhalogenated Volatile Organic Compounds GCFID \\
QC-16 & Method Detection Limit Studies \\
\hline
\end{tabular}




\subsection{TOTAL SEMIVOLATILE ORGANIC COMPOUND ANALYSIS}

The Laboratory achieves the TWCP QA elements defined in this section for the analysis of total SVOCs in samples of homogeneous solids and soil/gravel. The analytical techniques and procedures referenced include the specific activities to determine the concentration of total SVOCs in TWCP samples. The analytical services representative is responsible for implementation and compliance with all requirements specified in this section and further defined by the referenced procedures.

\subsection{Quality Assurance Objectives}

The QAOs for total SVOC analysis are listed in Table 14-1. Key data quality indicators for organic laboratory measurements are defined below, and the methods to assess compliance with these indicators are presented in Section 3.2 of this QAPjP.

\section{$\underline{\text { Precision }}$}

Organic laboratory personnel measure precision by determining \%RSD or RPD through replicate analysis of matrix spike duplicates, LCSs, and PDP blind audit samples. The Site Project QA Officer is responsible for monitoring the results from these measurements and determining if the precision criterion listed in Table 14-1 has been met. The Site Project QA Officer evaluates the organic laboratory performance and decides if corrective action should be initiated based on the results of these precision calculations.

\section{Accuracy}

Organic laboratory personnel measure accuracy by determining \% $\mathrm{R}$ through the analysis of matrix spikes, surrogate compounds, LCSs, and PDP blind audit samples. The Site Project QA Officer is responsible for monitoring the results from these measurements and determining if the accuracy criterion listed in Table 14-1 has been met. The Site Project QA Officer evaluates the organic laboratory performance and decides if corrective action should be initiated based on the results of these accuracy calculations.

\section{Method Detection Limit}

Organic laboratory personnel determine MDLs, expressed in $\mathrm{mg} / \mathrm{kg}$, as detailed in Method Detection Limit Studies (QC-16). They ensure that MDLs are less than or equal to those listed in Table 14-1.

\section{Program Required Quantitation Limit}

Organic laboratory personnel also set the concentration of at least one QC or calibration standard at or below the PRQLs listed in Table 14-1 for each SVOC analyte. The analytical procedures listed in Section 14.7 detail calibration procedures for each analytical technique used. 


\section{Completeness}

Organic laboratory personnel measure completeness by calculating the number of samples analyzed with valid results as a percent of the total number of samples submitted for analysis. The organic laboratory achieves the completeness criterion listed in Table 14-1. The Site Project QA Officer evaluates the organic laboratory performance and decides if corrective action should be initiated based on these completeness calculations.

Table 14-1. SVOC Target Analyte List and QAOs

\begin{tabular}{|c|c|c|c|c|c|c|}
\hline Compound & $\begin{array}{c}\text { CAS } \\
\text { Number }\end{array}$ & $\begin{array}{l}\text { Precision }^{2} \\
\text { (\%RSD or } \\
\text { RPD) }\end{array}$ & $\begin{array}{c}\text { Accuracy }^{a} \\
(\% R)\end{array}$ & $\begin{array}{c}\mathrm{MDL} \\
(\mathrm{mg} / \mathrm{kg})\end{array}$ & $\begin{array}{c}\text { PRQL } \\
(\mathrm{mg} / \mathrm{kg})\end{array}$ & $\begin{array}{l}\text { Completeness } \\
\text { (percent) }\end{array}$ \\
\hline Cresols & $1319-77-3$ & $\leq 50$ & $60-150$ & 5 & 40 & 90 \\
\hline 1,4-Dichlorobenzene & $106-46-7$ & $\leq 86$ & $20-124$ & 5 & 40 & 90 \\
\hline ortho-Dichlorobenzene ${ }^{b}$ & $95-50-1$ & $\leq 64$ & $32-129$ & 5 & 40 & 90 \\
\hline 2,4-Dinitrophenol & $51-28-5$ & $\leq 119$ & $D-172^{d}$ & 5 & 40 & 90 \\
\hline 2,4-Dinitrotoluene & $121-14-2$ & $\leq 46$ & $39-139$ & 0.3 & 2.6 & 90 \\
\hline Hexachlorobenzene & $118-74-1$ & $\leq 319$ & $D-152^{d}$ & 0.3 & 2.6 & 90 \\
\hline Hexachloroethane & $67-72-1$ & $\leq 44$ & $40-113$ & 5 & 40 & 90 \\
\hline Nitrobenzene & $98-95-3$ & $\leq 72$ & $35-180$ & 5 & 40 & 90 \\
\hline PCBs & & & & 5 & 40 & 90 \\
\hline Aroclor $1016^{c}$ & $12674-11-2$ & $\leq 33$ & $50-114$ & 5 & 40 & 90 \\
\hline Aroclor $1221^{c}$ & $11104-28-2$ & $\leq 110$ & $15-178$ & 5 & 40 & 90 \\
\hline Aroclor $1232^{c}$ & $11141-16-5$ & $\leq 128$ & $10-215$ & 5 & 40 & 90 \\
\hline Aroclor $1242^{c}$ & $53469-21-9$ & $\leq 49$ & $39-150$ & 5 & 40 & 90 \\
\hline Aroclor $1248^{c}$ & $12672-29-6$ & $\leq 55$ & $38-158$ & 5 & 40 & 90 \\
\hline Aroclor $1254^{c}$ & $11097-69-1$ & $\leq 62$ & $29-131$ & 5 & 40 & 90 \\
\hline Aroclor $1260^{c}$ & $11096-82-5$ & $\leq 56$ & $8-127$ & 5 & 40 & 90 \\
\hline Pentachlorophenol & $87-86-5$ & $\leq 128$ & $14-176$ & 5 & 40 & 90 \\
\hline Pyridine $^{\mathrm{b}}$ & $110-86-1$ & $\leq 50$ & $60-150$ & 5 & 40 & 90 \\
\hline $\begin{array}{l}{ }^{2} \text { Criteria apply to PRQL } \\
\text { bCan also be analyzed as } \\
{ }^{\mathrm{c}} \mathrm{PCBs} \text {; required only for } \\
\text { dDetected; result must be }\end{array}$ & $\begin{array}{l}\text { centrations. } \\
\text { OC. } \\
\text { trix parameter } \\
\text { eater than zero. }\end{array}$ & c2070 & nic sludges). & & & \\
\hline
\end{tabular}

Comparability

Organic laboratory personnel achieve comparability by using standardized and approved methods, traceable standards, and participating in the PDP. 


\section{$\underline{\text { Representativeness }}$}

Organic laboratory personnel achieve representativeness through the collection of unbiased samples according to the requirements described in Section 8.0 of this QAPjP.

\subsection{Methods Requirements}

Organic laboratory personnel use the GC/MS methods detailed Semivolatile Organics-GCMS (ANC611) and TRU Waste Characterization Program-Semivolatile Extraction and Analysis (ANC613), which is based on SW-846 methods, for the analysis of all analytes listed in Table 14-1. They use the Gas Chromatography/Electron Capture Detection (GC/ECD) method detailed in TRU Waste Characterization Program-Polychlorinated Biphenyl (PCB) Extraction and Analysis (ANC614), which is based on Methods Manual Procedure 440.3, for the analysis of PCBs if necessary. They decide which preparation methods to use based on the nature of the waste samples and use only nationally recognized standard preparation methods such as SW-846, as detailed in Semivolatile Organics in Solid Matrices Solvent Extraction (ANC609) and TRU Waste Characterization Program-Semivolatile Extraction and Analysis (ANC613). Procedures referenced meet the requirements in the Methods Manual.

Organic laboratory personnel use equipment and materials that meet all of the SW-846 and Methods Manual requirements. They equip gas chromatographs with chromatographic columns selected from among those recommended by the methods. They operate-GC/MS systems in the full scan mode to detect and quantitate all Table 14-1 analytes and identify nontarget compounds. They quantitate all analytes within the calibration range of the analytical instrument and dilute samples with analyte concentrations greater than the calibration range.

\section{Criteria for Standards}

Organic laboratory personnel purchase certified primary standards from Supelco (or equivalent) for target analytes. They prepare secondary analytical standards, surrogate standards, internal standards, calibration standards, and matrix spiking standards as detailed in Semivolatile Organic CompoundsStandard Preparation (ANC612), based on the appropriate SW-846 and Methods Manual methods.

\section{Criteria for Quantitative and Qualitative Analysis}

Organic laboratory personnel qualitatively identify analytes using GC/MS by ensuring that the analytes elute within a RRT window of \pm 0.06 RRT units of the continuing calibrations and have a mass spectrum that corresponds to the standard analyte mass spectrum. They calculate RRT windows from the individual RTs for each analyte from a calibration run within the same 12 hours as the sample.

They qualitatively identify PCBs by GC/ECD by ensuring that the analytes elute within the RT window set by the most recent standards. Initially, they run at least three standards for Aroclors 1016, $1221,1232,1242,1248,1254$, and 1260 , and define RT windows as plus or minus three times the standard deviation of the absolute RT for each of the characteristic peaks of each Aroclor. They determine RT windows over 72 hours when a new initial calibration curve is generated or a new GC column is installed. They use RT windows, but also rely heavily on pattern recognition.

Organic laboratory personnel use internal standard quantitation, as described in SW-846 and detailed in the procedures cited above for GC/MS analysis. They meet the criteria for SPCCs and CCCs and calculate response factors and the \% RSD for response factors for all analytes. To ensure the GC/MS 
system is in-control, they meet all daily calibration criteria for decafluorotriphenylphosphine (DFTPP), SPCCs, CCCs, internal standard responses, and RTs. They quantitate an analyte based on the integrated abundance from the EICP of the primary ion.

Organic laboratory personnel use external standard quantitation for GC/ECD quantitative analysis and base analyte quantitation on the total area or height response measured from a common baseline under three to five major peaks for each Aroclor. They produce a calibration curve for the appropriate Aroclor or Aroclor mixture once qualitative analysis has been confirmed.

\subsection{Quality Control}

The Site Project QA Officer is responsible for monitoring and documenting procedure performance, including the analysis of QC samples. The Site Project QA Officer and the analytical services project leader are responsible for implementing corrective actions when procedure performance is not acceptable. The Analytical Chemistry Quality Management Plan (QA-1) describes the implementation actions to ensure the daily quality of analytical data for total SVOC analysis, specifies acceptance criteria for TWCP QC samples, and specifies corrective action measures to be taken when these criteria are not satisfied. Organic laboratory personnel operate a formal QC program and maintain records to document the quality of the data generated. They implement all QC practices established by the SW-846 and Methods Manual, including QC sample requirements, as detailed in the analytical procedures and summarized in Table 14-2. They prepare and analyze QC samples as detailed in the analytical procedures.

Organic laboratory personnel demonstrate acceptable performance prior to the analysis of any waste samples through the analysis of method performance samples. They ensure that method performance samples contain all of the analytes listed in Table 14-1 at concentrations appropriate to verify that all QAOs are met. Initially, they analyze seven method performance samples to demonstrate acceptable precision and accuracy and to determine MDLs for all analytes. They repeat this demonstration semiannually by the analysis of four method performance samples.

For QC purposes, an analytical batch is defined as a suite of samples of a similar matrix, processed as a unit, using the same analytical method within a specific time period. An analytical batch can be up to 20 samples (excluding laboratory QC samples), all of which must be received by the laboratory within 14 days of the VTSR of the first sample in the batch. Specific QC samples for each analytical batch include blanks, a matrix spike, a laboratory duplicate and/or a matrix spike duplicate, and an LCS.

Organic laboratory personnel choose surrogate compounds based on guidance provided in SW-846 and add these compounds to each field sample and laboratory QC sample. They may analyze matrix spike duplicates in place of laboratory duplicates. They ensure that matrix spikes and matrix spike duplicates contain at least three of the SVOCs listed in Table 14-1 at the PRQL concentrations listed in Table 14-1. For PCB analysis, they ensure matrix spikes and matrix spike duplicates contain at least one of the Aroclors listed in Table 14-1 at the PRQL concentration listed in Table 14-1. They demonstrate on-going laboratory performance through the analysis of LCSs.

They prepare LCSs in water to contain 1,4-dichlorobenzene; 2,4-dinitrotoluene; hexachloroethane; and nitrobenzene at PRQL concentrations per laboratory control analyte from standards independent of those used for instrument calibration. They employ all the sample preparation procedures performed on field samples for LCSs. For PCBs, they prepare the LCS to contain only the most representative 
mixture at PRQL concentrations. They also demonstrate acceptable laboratory performance biannually by analyzing PDP blind audit samples.

Table 14-2. Summary of Laboratory QC Samples and Frequencies for Total SVOC Analysis

\begin{tabular}{|c|c|c|c|}
\hline QC Sample & Minimum Frequency & $\begin{array}{l}\text { Acceptance } \\
\text { Criteria }\end{array}$ & $\begin{array}{l}\text { Corrective } \\
\text { Action }^{2}\end{array}$ \\
\hline $\begin{array}{l}\text { Method performance } \\
\text { samples }\end{array}$ & $\begin{array}{l}\text { Seven samples initially } \\
\text { and four semiannually }\end{array}$ & Meet Table 14-1 QAOs & Repeat until acceptable \\
\hline Laboratory duplicates ${ }^{b}$ & One per analytical batch & Meet Table 14-1 RPDs & $\begin{array}{l}\text { Nonconformance if RPDs } \\
>\text { Table } 14-1 \text { values }\end{array}$ \\
\hline Laboratory blanks & One per analytical batch & $\begin{array}{l}\text { Analyte concentrations } \\
>3 \times \text { MDLs }\end{array}$ & $\begin{array}{l}\text { Nonconformance if } \\
\text { analyte concentrations } \\
\geq 3 \times \text { MDLs }\end{array}$ \\
\hline Matrix spikes & One per analytical batch & Meet Table 14-1 \%Rs & $\begin{array}{l}\text { If } \% \text { Rs outside range in } \\
\text { Table } 14-1 \text { due to matrix } \\
\text { interference, document in } \\
\text { case narrative and flag } \\
\text { data ' } Z \text { '. If } \% \text { Rs outside } \\
\text { of range for other } \\
\text { reasons, use a } \\
\text { nonconformance. }\end{array}$ \\
\hline $\begin{array}{l}\text { Matrix spike } \\
\text { duplicates }\end{array}$ & One per analytical batch & $\begin{array}{l}\text { Meet Table 14-1 RPDs } \\
\text { and \%Rs }\end{array}$ & $\begin{array}{l}\text { If } \% R \text { is outside criteria } \\
\text { due to matrix, document } \\
\text { in case narrative and flag } \\
\text { data ' } Z \text { '. } \\
\text { Nonconformance if } \\
\text { outside criteria for other } \\
\text { reasons }\end{array}$ \\
\hline LCS & One per analytical batch & $80-120 \% \mathrm{Rs}$ & $\begin{array}{l}\text { Nonconformance if } \% R \\
<80 \text { or }>120\end{array}$ \\
\hline Surrogate compounds & Each analytical sample & $\begin{array}{l}\text { Average } \% R \text { from minimum } \\
\text { of } 30 \text { samples from a given } \\
\text { matrix } \pm 3 \text { standard } \\
\text { deviations }\end{array}$ & $\begin{array}{l}\text { If } \% \mathrm{R} \text { is outside criteria } \\
\text { due to matrix, document } \\
\text { in case narrative and flag } \\
\text { data ' } \mathrm{Z} \text { '. } \\
\text { Nonconformance if } \\
\text { outside criteria for other } \\
\text { reasons. }\end{array}$ \\
\hline Blind audit samples & $\begin{array}{l}\text { Samples and frequency } \\
\text { controlled by the Solid } \\
\text { PDP Plan }\end{array}$ & $\begin{array}{l}\text { Specified in the Solid } \\
\text { PDP Plan }\end{array}$ & $\begin{array}{l}\text { Specified in the Solid } \\
\text { PDP Plan }\end{array}$ \\
\hline \multicolumn{4}{|c|}{$\begin{array}{l}{ }^{2} \text { Corrective action when QC samples do not meet the acceptance criteria: nonconformance only if final reported QC } \\
\text { samples do not meet criteria: nonconformance procedures are outlined in Section } 2.1 .2 \text {. } \\
\text { "May be satisfied by using matrix spike duplicate: acceptance criteria apply only to concentrations greater than the PRQLS } \\
\text { listed in Table 14-1. }\end{array}$} \\
\hline
\end{tabular}




\subsection{Instrument Testing, Inspection, and Maintenance Requirements}

Organic laboratory personnel meet GC/MS instrument performance criteria prior to the analysis of any standards or samples, tune these systems with PFTBA, and meet the DFTPP criteria specified in the appropriate SW-846 method and the applicable Methods Manual procedure. They check the DFTPP criteria at the beginning of each 12 hours of operation by analyzing $50 \mathrm{ng}$ of DFTPP.

\subsection{Instrument Calibration and Frequency}

Organic laboratory personnel calibrate all analytical instruments before use and verify calibration at routine intervals during analysis according to the Laboratory's Calibration Handbook and the analytical procedures. These detail all aspects of calibration, which are summarized in Table 14-3.

Table 14-3. Summary of Calibration Requirements for SVOC Analysis

\begin{tabular}{|c|c|c|c|}
\hline Technique & Procedure & $\begin{array}{l}\text { Frequency of } \\
\text { Procedure }\end{array}$ & Acceptance Criteria \\
\hline \multirow[t]{3}{*}{ GC/MS } & DFTPP tune & Every 12 hours & $\begin{array}{l}\text { Abundance criteria for all key ions are } \\
\text { met }\end{array}$ \\
\hline & $\begin{array}{l}\text { Five-point initial } \\
\text { calibration } \\
\text { (five standards) }\end{array}$ & Initially and as needed & $\begin{array}{l}\text { Response factor } \% \text { RSD for CCCs } \leq 30 \text {; } \\
\text { response factor for SPCCs } \geq 0.05 \text {; } \\
\text { average relative response factor used if } \\
\% \mathrm{RSD} \leq 15 \text {; linear regression equation } \\
\text { generated if } \% \mathrm{RSD}>15\end{array}$ \\
\hline & Continuing calibration & Every 12 hours & $\begin{array}{l}\% \mathrm{D} \leq 20 \text { for all analytes; response } \\
\text { factor for SPCCs } \geq 0.05 ; \mathrm{RT} \text { for } \\
\text { internal standards must be } \pm 30 \\
\text { seconds from last daily calibration } \\
\text { check; internal standards area count } \\
\text { must be }>50 \% \text { or }<200 \% \text { of the } \\
\text { area count from daily calibration } \\
\text { check; surrogate compound } \% \mathrm{R} \text { must } \\
\text { be met }\end{array}$ \\
\hline \multirow[t]{2}{*}{$\mathrm{GC} / \mathrm{ECD}$} & $\begin{array}{l}\text { Three-point initial } \\
\text { calibration } \\
\text { (three standards) }\end{array}$ & Initially and as needed & Response factor \%RSD $\leq 20$ \\
\hline & Continuing calibration & $\begin{array}{l}\text { Every } 12 \text { hours as } \\
\text { needed }\end{array}$ & $\begin{array}{l}\text { Response factor or measured } \\
\text { concentration } \% \mathrm{D} \text { for all analytes } \leq 15 \\
\text { of initial calibration: } \mathrm{RT} \pm 3 \text { standard } \\
\text { deviations from initial calibration }\end{array}$ \\
\hline
\end{tabular}


Organic laboratory personnel ensure that all initial and continuing calibration requirements as listed in Table 14-3 are met, and maintain instrument run logs that permit the reconstruction of the calibration sequence and frequency. Organic laboratory personnel satisfy GC/MS instrument performance criteria, then use at least five concentration levels to define the calibration range of the instrument for all target analytes and set the concentration of one standard less than the PRQLs listed in Table 14-1. They use average relative response factors for each analyte if the \%RSD is less than or equal to 15 and use a linear regression equation if the \%RSD is greater than 15 . They use a midpoint calibration standard to verify the initial GC/MS calibration curve at the beginning of every 12 hours of operation after satisfying the instrument performance criteria using $50 \mathrm{ng}$ of DFTPP according to the applicable Methods Manual procedure. They ensure the midpoint standard meets all of the daily calibration criteria for surrogate compound recovery, SPCCs, CCCs, internal standard area count criteria, and RTs as specified in Table 14-3. They choose SPCCs and CCCs common to Table 14-1 and the appropriate SW-846 method. They generate a new five-point calibration curve if the continuing calibration standard does not satisfy the criteria for linearity and consistency and do not proceed with sample analysis until the GC/MS system has satisfied the appropriate daily calibration criteria.

Organic laboratory personnel use at least three analytical external standards to define the calibration range of the GC/ECD instrument after qualitative analysis has identified the appropriate Aroclor(s). They prepare a calibration curve by plotting peak height or area against concentration or they may use the average response factor if the response factor \%RSDs are less than or equal to 20 . They verify the GC/ECD calibration curve using a midpoint calibration standard (continuing calibration standard) at the beginning of every 12 hours of operation. They ensure the continuing calibration standard meets the calibration criteria specified in Table 14-3.

\subsection{Data Management}

The Laboratory employs the data review, validation, and verification procedures defined in Section 3.1.1 as well as those described below for total SVOC analysis results. The organic laboratory employs data management procedures defined in the analytical methods, which include specific equations, sample calculations, and example forms for data reduction, validation, and reporting.

\section{$\underline{\text { Data Reduction }}$}

Organic laboratory personnel quantify analyte concentrations using average relative response factors for internal standard quantitation (GC/MS) and total peak height or area for external standard quantitation (GC/ECD). They do not blank-correct target analyte concentrations. They report blank results separately, flagging any target compounds detected. They report nontarget compounds as TICs with a higher uncertainty than target analyte concentrations. They perform appropriate search routines of the latest NIST or equivalent mass spectral library on the 20 TICs with the greatest area count and with total ion current peaks greater than 10 percent of the nearest (RT) internal standard. The SPM adds the positively identified TICs listed in 40 CFR Part 264, Appendix IX, to the target analyte list if they are detected in 25 percent of all samples from a given waste stream. 


\section{$\underline{\text { Data Validation }}$}

Organic laboratory personnel review and approve all total SVOC analytical data, as outlined in Section 3.1.1, and report the results in $\mathrm{mg} / \mathrm{kg}$ on a weight per wet-weight basis, limited to two significant figures.

\section{Data Reporting}

The analytical services representative submits analytical batch data reports for each analytical batch to the Site Project QA Officer on approved standard forms included in the analytical procedures. Analytical batch data reports consist of the following:

- Cover page that includes the organic laboratory name, analytical batch number, sample numbers included in that analytical batch, a cross reference to field sample numbers, and the signature releases of organic laboratory personnel as specified in Section 3.1.1

- Table of contents

- Summary COC form that shows the date and time of sample transfer, and name of individuals handling the samples from the time of sampling through receipt at the organic laboratory

- Data review checklists for each analytical batch verifying that the data generation level review, validation, and verification, as described in Section 3.1.1, have taken place. Checklists contain tables showing the results of the analytical batch QC samples. These tables may also be attached to the checklists.

- A separate analytical report sheet for each sample in the analytical batch that includes the organic laboratory name, TWCP name, the title "Total SVOCs Analysis Data Sheet," analytical batch number, sampling batch number, organic laboratory sample number, field sample number, date sampled, date extracted, date analyzed, method number(s), listing of analytes, and analytical results in $\mathrm{mg} / \mathrm{kg}$. The following data qualifying flags are used:

- B-Analyte detected in blank

- E-Analyte exceeds the calibration curve

- J-Analyte less than PRQL, but greater than or equal to MDL

- U-Analyte was undetected (report MDL)

- D-Analyte was quantitated from a secondary dilution or reduced volume sample aliquot

- Z-One or more QC samples do not meet acceptance criteria

- $\mathrm{H}-$ Holding time exceeded

- Nonconformance repors, if applicable

The organic laboratory maintains the following items in its files, documented and retrievable by analytical batch number: 
- Original $\mathrm{COC}$ forms

- All raw data, including original instrument readouts and/or bench reports, calculation records, and QC sample results; laboratory duplicate results are recorded along with the original sample results, and the RPD between the two results is calculated: LCS results are entered along with the accepted value and the $\% R$

- All instrument calibration reports that include the accepted and measured values of calibration verification for all analytes; these reports also contain the organic laboratory name, initial and continuing calibration verification source, methods number, and calibration date and time

- QC result summary that includes true and found values for all QC samples plus associated result calculations; QC data include blanks, LCSs, matrix spikes, matrix spike duplicates, surrogate compounds, initial calibration data, initial and continuing calibration verifications, and all other applicable QC listed in Table 14-3; the QC summary report also contains the organic laboratory name, the analytical batch number (if applicable), and methods numbers

\subsection{Procedures Specific to this Section}

Table 14-4 lists the procedures specific to this section of the QAPjP.

Table 14-4. Section 14.0 Procedures

\begin{tabular}{ll}
\hline \multicolumn{1}{c}{ Document Number } & \multicolumn{1}{c}{ Title } \\
\hline ANC609 & Semivolatile Organics in Solid Matrices-Solvent Extraction \\
ANC611 & Semivolatile Organics-GCMS \\
ANC612 & Semivolatile Organic Compounds-Standard Preparation \\
ANC613 & TRU Waste Characterization Program-Semivolatile Extraction and \\
& Analysis \\
ANC614 & TRU Waste Characterization Program-Polychlorinated Biphenyl \\
& (PCB) Extraction and Analysis \\
QC-16 & Method Detection Limit Studies \\
\end{tabular}




\subsection{TOTAL METAL ANALYSIS}

The Laboratory achieves the TWCP QA elements defined in this section for the analysis of total metals in samples of homogeneous solids and soil/gravel. The analytical techniques referenced include the specific activities to determine the concentration of total metals in TWCP samples. The analytical services representative is responsible for implementation and compliance with all requirements specified in this section and further defined by the referenced methods.

\subsection{Quality Assurance Objectives}

The QAOs for total metal analysis are listed in Table 15-1. Key data quality indicators for inorganic laboratory measurements are defined below, and the methods to assess compliance with these indicators are presented in Section 3.2.

\section{Precision}

Inorganic laboratory personnel measure precision by determining \% RSD or RPD through the analysis of matrix spike duplicates, replicate analyses of LCSs, and PDP blind audit samples. The Site Project QA Officer is responsible for monitoring the results from these measurements and determining if the precision criterion listed in Table 15-1 has been met. The Site Project QA Officer evaluates the inorganic laboratory performance and decides if corrective action should be initiated based on the results of these precision calculations.

\section{$\underline{\text { Accuracy }}$}

Inorganic laboratory personnel measure accuracy by determining \% $\mathrm{R}$ through the analysis of matrix spikes, PDP blind audit samples, and LCSs. The Site Project QA Officer is responsible for monitoring the results from these measurements and determining if the accuracy criterion listed in Table 15-1 has been met. The Site Project QA Officer evaluates the inorganic laboratory performance and decides if corrective action should be initiated based on the results of these accuracy calculations.

\section{Program Required Detection Limits}

Inorganic laboratory personnel determine instrument detection limit (IDLs) semiannually (i.e., every six months) using CST Analytical Chemistry procedure Method Detection Limit Studies (QC-16). They ensure that IDLs are less than or equal to the PRDLs listed in Table 15-1 unless sample concentrations exceed five times the IDL of the instrument being used for analysis.

\section{Program Required Quantitation Limit}

Inorganic laboratory personnel also set the concentration of at least one QC or calibration standard at or below the solution concentration equivalent of the PRQLs listed in Table 15-1 for each metal analyte. The analytical methods detail calibration procedures for each analytical technique used. 


\section{Completeness}

Inorganic laboratory personnel measure completeness by calculating the number of samples analyzed with valid results as a percent of the total number of samples submitted for analysis. The inorganic laboratory achieves the completeness criterion listed in Table 15-1. The Site Project QA Officer evaluates the inorganic laboratory performance and decides if corrective action should be initiated based on these completeness calculations.

Table 15-1. Total Metal Target Analyte List and QAOs

\begin{tabular}{|c|c|c|c|c|c|c|}
\hline Analyte & CAS Number & $\begin{array}{c}\text { Precision }^{\mathrm{a}} \\
\text { (\%RSD or RPD) }\end{array}$ & $\begin{array}{c}\text { Accuracy } \\
(\% \mathrm{R})\end{array}$ & $\begin{array}{l}\mathrm{PRDL}^{\mathrm{c}} \\
(\mu \mathrm{g} / \mathrm{L})\end{array}$ & $\begin{array}{c}\mathrm{PRQL} \\
(\mathrm{mg} / \mathrm{kg})\end{array}$ & $\begin{array}{c}\text { Completeness } \\
\text { (\%) }\end{array}$ \\
\hline Antimony & $7440-36-0$ & $\leq 30$ & $80-120$ & 100 & 100 & 90 \\
\hline Arsenic & $7440-38-2$ & $\leq 30$ & $80-120$ & 100 & 100 & 90 \\
\hline Barium & $7440-39-3$ & $\leq 30$ & $80-120$ & 2000 & 2000 & 90 \\
\hline Beryllium & $7440-41-7$ & $\leq 30$ & $80-120$ & 100 & 100 & 90 \\
\hline Cadmium & $7440-43-9$ & $\leq 30$ & $80-120$ & 20 & 20 & 90 \\
\hline Chromium & $7440-47-3$ & $\leq 30$ & $80-120$ & 100 & 100 & 90 \\
\hline Lead & $7439-92-1$ & $\leq 30$ & $80-120$ & 100 & 100 & 90 \\
\hline Mercury & $7439-97-6$ & $\leq \mathbf{3 0}$ & $80-120$ & 4.0 & 4.0 & 90 \\
\hline Nickel & $7440-02-0$ & $\leq \mathbf{3 0}$ & $80-120$ & 100 & 100 & 90 \\
\hline Selenium & $7782-49-2$ & $\leq 30$ & $80-120$ & 20 & 20 & 90 \\
\hline Silver & $7440-22-4$ & $\leq 30$ & $80-120$ & 100 & 100 & 90 \\
\hline Thallium & $7440-28-0$ & $\leq 30$ & $80-120$ & 100 & 100 & 90 \\
\hline Vanadium & $7440-62-2$ & $\leq 30$ & $80-120$ & 100 & 100 & 90 \\
\hline Zinc & $7440-66-6$ & $\leq 30$ & $80-120$ & 100 & 100 & 90 \\
\hline \multicolumn{7}{|c|}{$\begin{array}{l}\text { a } \leq 30 \% \text { control limits apply when sample and duplicate concentrations are } \geq 10 \times \text { IDL for Inductively Coupled Plasma- } \\
\text { Atomic Emission Spectroscopy (ICP-AES) and Atomic Absorption (ICP-AA) techniques and } \geq 100 \times \text { IDL for } \\
\text { Inductively Coupled Plasma-Mass Spectrometry techniques. If less than these limits, the absolute difference between } \\
\text { the two values is less than or equal to the PRDL. } \\
\text { bApplies to LCSs. If a solid LCS material that has established statistical control limits is used, the established control } \\
\text { limits for that material are used for accuracy requirements. } \\
{ }^{c} \text { PRDL set such that it is a factor of } 10 \text { below the PRQL for } 100 \% \text { solid samples, assuming a 100-times dilution during } \\
\text { digestion. }\end{array}$} \\
\hline
\end{tabular}




\section{Comparability}

Inorganic laboratory personnel achieve comparability by using standardized and approved methods, traceable standards, and participation in the PDP.

\section{Representativeness}

Inorganic laboratory personnel achieve representativeness through the collection of unbiased samples according to the requirements described in Section 8.0.

\subsection{Methods Requirements}

Total metal analysis includes sample preparation followed by analysis and is implemented using procedures found in the Methods Manual. Multiple preparation methods and analytical techniques may be required to complete the analysis of all metal target analytes depending on the specific wastes encountered during TWCP activities. Microwave-assisted hot acid digestion may be used for sample preparation for mercury analysis by cold vapor atomic absorption spectroscopy (CVAA). If this digestion method is not used, standards must be prepared in the same way as the samples. Inorganic laboratory personnel use sample preparation methods as detailed in Microwave-Assisted Sample Preparation of Transuranic Waste Samples (ANC100) as the primary preparation methods for samples. However, they use alternate sample preparation methods if needed for complex sample matrices. Ignorganic laboratory personnel prepare and gain approval for additional methods for alternate sample preparation methods used for TWCP samples. Percent solids determination is outlined in Percent Solids Determination (ANC190).

Inorganic laboratory personnel use several analytical techniques for the determination of total metals in samples of TRU waste. These techniques include Inductively Coupled Plasma-Atomic Emission Spectroscopy (ICP-AES), Inductively Coupled Plasma-Mass Spectrometry (ICP-MS), and Cold Vapor Atomic Fluorescence Spectroscopy (CVAF). Table 15-2 indicates which techniques are used to determine specific analytes.

Inorganic laboratory personnel perform ICP-AES for the analytes indicated in Table 15-2 in accordance with Inductively Coupled Plasma-Mass Spectrometry Using the VG Plasma Quad $2+$ (ANC102). They perform ICP-MS for the analytes indicated in Table 15-2 in accordance with Cold Vapor Atomic Fluorescence Spectroscopy Using the PS Analytical Merlin (ANC101). The graphite furnace atomic absorption spectrometry (GFAA) is not currently being used. Inorganic laboratory personnel perform CVAA for mercury in accordance with Inductively Coupled Plasma-Atomic Emission Spectroscopy Using the Thermo Jarrell-Ash IRIS Spectrometer (ANC189). These analytical methods are based on methods found in SW-846 and the Methods Manual. Each procedure details the implementation of the analytical method.

\section{Criteria for Standards}

Inorganic laboratory personnel purchase or prepare stock standard solutions from ultra-high purity grade chemicals or metals ( 99.99 to 99.999 -percent pure). All stock standard solutions have a known valid relationship to a nationally recognized standard material (e.g., NIST). They maintain a certificate of analysis from the manufacturer, documenting traceability on tile if commercial stock 
solutions are used. They label and track commercial stock solutions to ensure that they are not used beyond their manufacturer-specified shelf life.

Table 15-2. Total Metal Analytical Techniques

\begin{tabular}{|c|c|c|c|c|}
\hline \multirow[b]{2}{*}{ Analyte } & \multirow{2}{*}{$\begin{array}{c}\text { CAS } \\
\text { Number }\end{array}$} & \multicolumn{3}{|c|}{ Technique $^{\mathbf{a}}$} \\
\hline & & ICP-AES $^{b}$ & ICP-MS $^{c}$ & CVAF $^{d}$ \\
\hline Antimony & $7440-36-0$ & $\checkmark$ & $\checkmark$ & \\
\hline Arsenic & $7440-38-2$ & $\checkmark$ & $\checkmark$ & \\
\hline Barium & $7440-39-3$ & $\checkmark$ & $\checkmark$ & \\
\hline Beryllium & $7440-41-7$ & $\checkmark$ & $\checkmark$ & \\
\hline Cadmium & $7440-43-9$ & $\checkmark$ & $\checkmark$ & \\
\hline Chromium & $7440-47-3$ & $\checkmark$ & $\checkmark$ & \\
\hline Lead & $7439-92-1$ & $\checkmark$ & $\checkmark$ & \\
\hline Mercury & $7439-97-6$ & & & $\checkmark$ \\
\hline Nickel & $7440-02-0$ & $\checkmark$ & $\checkmark$ & \\
\hline Selenium & $7782-49-2$ & $\checkmark$ & $\checkmark$ & \\
\hline Silver & $7440-22-4$ & $\checkmark$ & $\checkmark$ & \\
\hline Thallium & $7440-28-0$ & $\checkmark$ & $\checkmark$ & \\
\hline Vanadium & $7440-62-2$ & $\checkmark$ & $\checkmark$ & \\
\hline Zinc & $7440-66-6$ & $\checkmark$ & $\checkmark$ & \\
\hline
\end{tabular}

Inorganic laboratory personnel prepare working calibration and QC standards by diluting from the stock standard solutions using Class A volumetric glassware and calibrated pipettors according to the analytical methods. They prepare working calibration standards, blanks, and QC standards using the same type of acids, at the same concentrations present in the prepared samples. Standards used for LCSs are independent of those used for calibration. They also verify working calibration standards with each use by an initial calibration verification standard prepared fresh daily from an independent source.

Inorganic laboratory personnel prepare working calibration and QC standards for ICP-AES and ICP-MS weekly. They prepare low concentration standards (i.e., less than $1 \mathrm{mg} / \mathrm{L}$ ) and all working calibration and QC standards for CVAF fresh daily prior to use. They prepare working standards for 
cold vapor atomic fluorescent spectroscopy (CVAF), using the same preparation method as the samples. The inorganic laboratory stores standard solutions containing silver in the dark or in opaque containers.

\section{Criteria for Quantitative Analysis}

All analytical instruments used to quantitate metal analytes meet the requirements of the Methods Manual and SW-846. Operating requirements are detailed in the analytical methods. Inorganic laboratory personnel establish and document in log books instrument settings for each analyte on each applicable instrument. They quantitate all analytes within the calibration range of the analytical instrument. They dilute samples with concentrations greater than the calibration range of the instrument and use two integrations to quantitate all analytes, with the average reported.

Inorganic laboratory personnel examine interferences for all techniques; if interferences are detected, appropriate corrective action, based on SW-846, is taken to minimize their effects. Background correction is required only for ICP-MS and ICP-AES. They use the method of standard additions (MSA) when appropriate, as outlined in the analytical methods. The analytical methods also document the use and choice of proven matrix modifiers.

All reagents used during total metal analysis (e.g., laboratory water, chemicals, gases) are of sufficient purity to prevent sample contamination. Inorganic laboratory personnel prepare and analyze blanks in the course of sample analysis to document acceptable purity by showing analyte levels no greater than three times the analyte IDLs.

\subsection{Quality Control}

The Site Project QA Officer is responsible for monitoring and documenting procedure performance, including the analysis of QC samples. The Site Project QA Officer and the analytical services project leader are responsible for implementing corrective actions when procedure performance is not acceptable. The CST TRU Waste Characterization Program-Quality Control Requirements for the Analysis of Metals (ANC146) describes the implementation actions to ensure the daily quality of analytical data for total metal analysis. QC sample requirements and acceptance criteria for total metal analysis are included in the analytical methods and summarized in Table 15-3.

Inorganic laboratory personnel demonstrate acceptable performance prior to the analysis of any waste samples through the analysis of method performance samples, according to ANC101, ANC102, and ANC189. Method performance samples contain all of the analytes listed in Table 15-1 at concentrations appropriate to verify that all QAOs are met. Initially, they analyze seven method performance samples to demonstrate acceptable precision and accuracy and to determine IDLs for all analytes. They repeat this demonstration semiannually by the analysis of four method performance samples. Inorganic laboratory personnel conduct method performance demonstration over a period of several days to account for long-term variability. A nonconformance report is written only if the final, reported QC sample results do not meet acceptance criteria. Matrix spikes, matrix spike duplicates, and surrogate compounds that do not meet acceptance criteria due to matrix interference affects are flagged as ' $\mathrm{Z}$ ' and a nonconformance report is not required. 
Table 15-3. Summary of Laboratory QC Samples and Frequencies for Total Metal Analysis

\begin{tabular}{|c|c|c|c|}
\hline QC Samples & Minimum Frequency & $\begin{array}{l}\text { Acceptance } \\
\text { Criteria }\end{array}$ & Corrective Actions $^{2}$ \\
\hline $\begin{array}{l}\text { Method performance } \\
\text { samples }\end{array}$ & $\begin{array}{l}\text { Seven samples initially, } \\
\text { and four semiannually }\end{array}$ & Meet Table 15-1 QAOs & Repeat until acceptable \\
\hline Laboratory blanks & One per analytical batch & 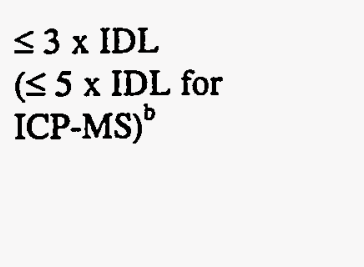 & $\begin{array}{l}\text { Nonconforming } \\
\text { laboratory blanks } \\
\text { should be flagged as } \\
\text { ' } \mathrm{B} \text { ' and a separate } \\
\text { nonconformance report } \\
\text { is not required. }\end{array}$ \\
\hline Matrix spikes & One per analytical batch & $80-120 \% R$ & $\begin{array}{l}\text { Nonconformance if } \% R \\
<80 \text { or }>120\end{array}$ \\
\hline Matrix spike duplicates & One per analytical batch & $\begin{array}{l}\mathrm{RPD} \leq 30 \\
80-120 \% \mathrm{R}\end{array}$ & $\begin{array}{l}\text { Nonconformance if } \\
\mathrm{RPD}>30 \text { or if } \% \mathrm{R} \\
<80 \text { or }>120\end{array}$ \\
\hline LCSs & One per analytical batch & $80-120 \% R$ & $\begin{array}{l}\text { Redigest and reanalyze } \\
\text { for affected analytes }\end{array}$ \\
\hline Blind audit samples & $\begin{array}{l}\text { Samples and frequency } \\
\text { controiled by the Solid } \\
\text { PDP Plan }\end{array}$ & $\begin{array}{l}\text { Specified in the Solid } \\
\text { PDP Plan }\end{array}$ & $\begin{array}{l}\text { Specified in the Solid } \\
\text { PDP Plan }\end{array}$ \\
\hline
\end{tabular}

For QC purposes, an analytical batch is defined as a suite of samples of a similar matrix, processed as a unit, using the same analytical method within a specific time period. An analytical batch can be up to 20 samples (excluding laboratory QC samples), all of which must be received by the laboratory within 14 days of the VTSR of the first sample in the batch. Specific QC samples for each analytical batch includes blanks, a matrix spike, a matrix spike duplicate, and an LCS. Inorganic laboratory personnel prepare QC samples according to the analytical methods.

Inorganic laboratory personnel digest and analyze blanks according to the same procedures used for waste samples. They prepare matrix spikes and matrix duplicates to contain the metal(s) being analyzed at the PRQL concentrations listed in Table 15-1. They use standards for LCSs that are independent of those used for calibration. They use solid LCSs (e.g., characterized surrogate sludges) whenever it is possible to match the matrix of the waste samples; otherwise, they use commercially purchased standards to prepare LCSs. They prepare LCSs to contain the metal(s) being analyzed and quantitate these samples within the calibration range of the instrument. They also analyze PDP blind audit samples biannually to demonstrate acceptable analytical laboratory performance. 


\subsection{Instrument Testing, Inspection, and Maintenance Requirements}

Inorganic laboratory personnel test, inspect, and maintain instruments according to the analytical methods. The schedules and actions contained in the methods are based on manufacturers' recommendations and SW-846 methods.

\subsection{Instrument Calibration and Frequency}

Inorganic laboratory personnel calibrate all analytical instruments before use and verify calibration at routine intervals during analysis according to the Laboratory's Calibration Handbook and the analytical methods. Calibration requirements and analytical run QC included in the methods are summarized in Table 15-4.

\subsection{Data Management}

The Laboratory employs the data review, validation, and verification procedures defined in Section 3.1.1 as well as those described below for total metal analysis. The inorganic laboratory employs data management procedures defined in the analytical methods, which include specific equations, sample calculations, and example forms for data reduction, validation, and reporting.

\section{Data Reduction}

Inorganic laboratory personnel calculate results taking appropriate dilution factors into account. They verify and document automated data reduction spreadsheets, algorithms, and programs, according to Software Management (TWCP-QP-1.1-006).

\section{Data Validation}

They review and approve all analytical data, as defined in Section 3.1.1, and report all quantitative values in $\mathrm{mg} / \mathrm{kg}$ on a wet weight basis, limited to two significant figures.

\section{Data Reporting}

The analytical services representative submits analytical batch data reports for each analytical batch to the Site Project QA Officer on approved standard forms included in the analytical methods. Analytical batch data reports consist of the following:

- Cover page that includes the inorganic laboratory name, analytical batch number, sample numbers included in that analytical batch, a cross reference to field sample numbers, and the signature releases of inorganic laboratory personnel as specified in Section 3.1.1

- Table of contents

- Summary COC form that shows the date and time of sample transfer, and name of individuals handling the samples from the time of sampling through receipt at the inorganic laboratory 
Table 15-4. Summary of Calibration Requirements and Analysis QC for Total Metal Analysis

\begin{tabular}{|c|c|c|c|c|c|}
\hline Technique & Procedure & Frequency of Procedure & Acceptance Criteria & Corrective Action & \\
\hline \multirow[t]{5}{*}{ ICP-AES } & $\begin{array}{l}\text { 1-pt. initial } \\
\text { calibration } \\
\text { (1 standard and a } \\
\text { blank) }\end{array}$ & Daily & $\begin{array}{l}\text { 90-110\% } \mathrm{R} \text { for independent initial } \\
\text { calibration verification solution } \\
95-105 \% \mathrm{R} \text { for highest calibration standard }\end{array}$ & $\begin{array}{l}\text { Correct problem and repeat } \\
\text { initial calibration }\end{array}$ & \\
\hline & $\begin{array}{l}\text { Continuing } \\
\text { calibration }\end{array}$ & $\begin{array}{l}\text { Every } 10 \text { samples plus beginning } \\
\text { and end of run }\end{array}$ & $\begin{array}{l}90-110 \% \mathrm{R} \text { for check standard; blank must } \\
\text { measure } \leq 3 \times \text { IDL }\end{array}$ & $\begin{array}{l}\text { Recalibrate and rerun last } 10 \\
\text { samples }\end{array}$ & \\
\hline & $\begin{array}{l}\text { Interference } \\
\text { correction } \\
\text { verification }\end{array}$ & $\begin{array}{l}\text { Beginning and end of run or twice } \\
\text { per } 8 \text { hours, whichever is more } \\
\text { frequent }\end{array}$ & $\begin{array}{l}\text { Solution containing interferants only must } \\
\text { measure } \leq 3 \times \text { IDL for analytes; solution } \\
\text { containing interferants plus analytes must be } \\
80-120 \% \mathrm{R} \text { for all analytes }\end{array}$ & $\begin{array}{l}\text { Correct problem and } \\
\text { recalibrate }\end{array}$ & \\
\hline & Serial dilution & $\begin{array}{l}\text { Once per analytical batch or per } \\
\text { matrix within an analytical batch }\end{array}$ & $\begin{array}{l}5 x \text { dilution of sample which is }>50 \times \text { IDL } \\
\text { must be } \leq 10 \% D \text { of initial value }\end{array}$ & Define in Laboratory SOPs & \\
\hline & $\begin{array}{l}\text { Post-digestion } \\
\text { spike }\end{array}$ & $\begin{array}{l}\text { Once per analytical batch or per } \\
\text { matrix within an analytical batch } \\
\text { if serial dilution, matrix spike, or } \\
\text { matrix spike duplicate does not } \\
\text { meet acceptance criteria }\end{array}$ & $75-125 \% \mathrm{R}$ & Define in Laboratory SOPs & \\
\hline ICP-MS & Mass Tune & Daily & $\begin{array}{l}4 \text { Replicate } \% \text { RSD }<10 \text {; mass calibration } \\
\text { within } 0.1 \mathrm{amu} \text {; resolution }<1.0 \mathrm{amu} \text { full } \\
\text { width at } 10 \text { percent peak height }\end{array}$ & $\begin{array}{l}\text { Manufacturer } \\
\text { recommendations }\end{array}$ & \\
\hline \multirow[t]{2}{*}{, } & $\begin{array}{l}\text { One-point initial } \\
\text { calibration } \\
\text { (one standard and a } \\
\text { blank) }\end{array}$ & Daily & $\begin{array}{l}90-110 \% \mathrm{R} \text { for initial calibration } \\
\text { verification solution } \\
95-105 \% \mathrm{R} \text { for highest calibration standard }\end{array}$ & Repeat initial calibration & \\
\hline & $\begin{array}{l}\text { Continuing } \\
\text { calibration }\end{array}$ & $\begin{array}{l}\text { Every } 10 \text { samples plus beginning } \\
\text { and end of mun }\end{array}$ & $\begin{array}{l}90-110 \% R \text { for check standard; blank must } \\
\text { measure } \leq 5 \times \text { IDL; internal standard areas } \\
\text { must be } \leq 20 \% \mathrm{D} \text { of calibration blank }\end{array}$ & $\begin{array}{l}\text { Correct problem, recalibrate } \\
\text { and rerun last } 10 \text { samples }\end{array}$ & 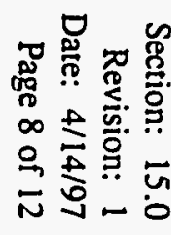 \\
\hline
\end{tabular}




\begin{tabular}{|c|c|c|c|c|c|}
\hline Technique & Procedure & Frequency of Procedure & Acceptance Criteria & Corrective Action & \\
\hline & & & internal standard areas & & \\
\hline & $\begin{array}{l}\text { Interference } \\
\text { correction } \\
\text { verification }\end{array}$ & $\begin{array}{l}\text { Beginning and end of run or every } \\
12 \text { hours, whichever is more } \\
\text { frequent }\end{array}$ & $\begin{array}{l}\text { Solution containing interferants only must } \\
\text { measure } \leq 5 \times \text { IDL for analytes; solution } \\
\text { containing interferants plus analytes must be } \\
\text { within } 80-120 \% R \text { for all analytes }\end{array}$ & $\begin{array}{l}\text { Correct problem and } \\
\text { recalibrate }\end{array}$ & \\
\hline \multirow[t]{3}{*}{$\begin{array}{l}\text { ICP-MS } \\
\text { (Continued) }\end{array}$} & Serial dilution & $\begin{array}{l}\text { once per analytical batch or per } \\
\text { matrix within an analytical batch }\end{array}$ & $\begin{array}{l}5 x \text { dilution of sample which is }>100 x \\
\text { IDL must be } \leq 10 \% D \text { of initial value }\end{array}$ & $\begin{array}{l}\text { Define in Laboratory } \\
\text { Methods }\end{array}$ & \\
\hline & $\begin{array}{l}\text { Post-digestion } \\
\text { spike }\end{array}$ & $\begin{array}{l}\text { once per analytical batch or per } \\
\text { matrix within an analytical batch } \\
\text { if serial dilution, matrix spike, or } \\
\text { matrix spike duplicate does not } \\
\text { meet acceptance criteria }\end{array}$ & $75-125 \% \mathrm{R}$ & $\begin{array}{l}\text { Define in Laboratory } \\
\text { Methods }\end{array}$ & \\
\hline & $\begin{array}{l}\text { Internal standard } \\
\text { area verification }\end{array}$ & Every sample & $\begin{array}{l}\text { Area must be } \leq 30 \% \mathrm{D} \text { of calibration blank } \\
\text { internal standard areas }\end{array}$ & $\begin{array}{l}\text { Dilute sample } 5 x \text { and } \\
\text { reanalyze }\end{array}$ & \\
\hline \multirow[t]{4}{*}{ GFAA } & $\begin{array}{l}\text { Three-point initial } \\
\text { calibration } \\
\text { (three standards } \\
\text { and a blank) }\end{array}$ & Daily & $\begin{array}{l}90-110 \% \mathrm{R} \text { for independent initial } \\
\text { calibration verification solution } \\
95-105 \% \mathrm{R} \text { for highest calibration standard } \\
\text { Regression coefficient }\left(r^{2}\right) \text { must be } \geq 0.995\end{array}$ & $\begin{array}{l}\text { Correct problem and repeat } \\
\text { initial calibration }\end{array}$ & \\
\hline & $\begin{array}{l}\text { Continuing } \\
\text { calibration }\end{array}$ & $\begin{array}{l}\text { Every } 10 \text { samples plus beginning } \\
\text { and end of nun }\end{array}$ & $\begin{array}{l}80-120 \% R \text { for check standard; blank must } \\
\text { measure } \leq 3 \times \text { IDL }\end{array}$ & $\begin{array}{l}\text { Recalibrate and rerun last } \\
10 \text { samples }\end{array}$ & \multirow{3}{*}{ 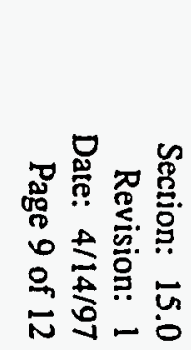 } \\
\hline & Serial dilution & $\begin{array}{l}\text { Once per analytical batch or per } \\
\text { matrix within an analytical batch }\end{array}$ & $\begin{array}{l}5 x \text { dilution of sample which is }>25 \times \text { IDL } \\
\text { must be } \leq 10 \% D \text { of initial value }\end{array}$ & $\begin{array}{l}\text { Use MSA to quantitate } \\
\text { samples of like matrix }\end{array}$ & \\
\hline & Post-digestion & $\begin{array}{l}\text { Once per analytical batch or per } \\
\text { matrix within an analytical batch }\end{array}$ & $85-115 \% R$ & Use MSA to quantitate & \\
\hline
\end{tabular}




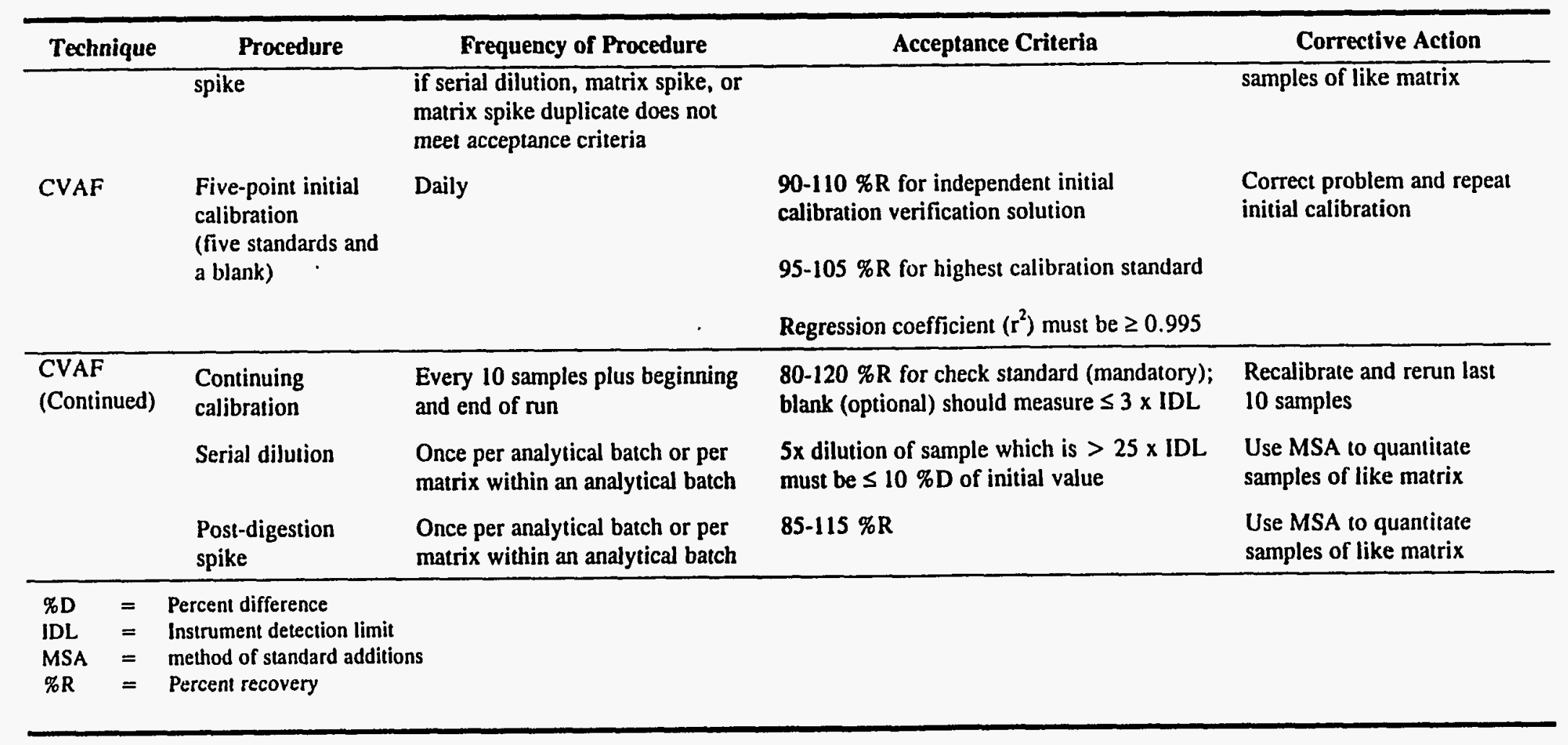


- Data review checklists for each analytical batch that verify the data generation level review, validation, and verification, as described in Section 3.1.1, have taken place; checklists contain tables showing the results of the analytical batch QC samples; these tables may also be attached to the checklists

- A separate analytical report sheet for each sample in the analytical batch that includes the inorganic laboratory name, the TWCP name, the title "Total Metal Analysis Data Sheet," analytical batch number, sampling batch number, inorganic laboratory sample number, field sample number, date sampled, date extracted, date analyzed, procedure number, target analytes, percent solids, reference to instrument calibration reports, and analytical results in $\mathrm{mg} / \mathrm{kg}$; the following metal analysis data qualifying flags are used:

-B-Analyte blank concentration (laboratory or calibration verification) greater than or equal to 20 percent of the sample concentration prior to dilution correction -J-Analyte greater than or equal to IDL but less than $5 x$ IDL before dilution correction -U-Analyte was undetected (report IDL corrected for dilution)

-Z-One or more QC samples do not meet acceptance criteria

$-\mathrm{H}-$ Holding time exceeded

- Nonconformance reports, if applicable

The inorganic laboratory maintains the following items in their files, documented and retrievable by analytical batch number:

- Original COC forms

- All raw data, including original instrument readouts and/or bench reports, calculation records, and QC sample results; duplicate results are recorded along with the original sample results, and the RPD between the two results are calculated; LCS results are entered along with the accepted value and the $\% \mathrm{R}$

- All instrument calibration reports that include the accepted and measured values of calibration verification for all analytes, the inorganic laboratory name, analytical batch number(s), initial and continuing calibration verification source, method number, and calibration date and time

- QC result summary that includes true and found values for all QC samples plus associated result calculations; QC data includes results for blanks, LCSs, matrix spikes, matrix spike duplicates, initial calibration data, initial and continuing calibration verifications, and all other applicable QC listed in Table 15-4; the QC summary report also contains the inorganic laboratory name, the analytical batch number, and method numbers

\subsection{Procedures Specific to this Section}

Table 15-5 lists the procedures specific to this section of the QAPjP. 
Table 15-5. Section 15.0 Procedures

\begin{tabular}{ll}
\hline \multicolumn{1}{c}{ Document Number } & \multicolumn{1}{c}{ Title } \\
\hline ANC100 & $\begin{array}{l}\text { Microwave-Assisted Sample Preparation of Transuranic Waste } \\
\text { Samples } \\
\text { ANC101 }\end{array}$ \\
Cold Vapor Atomic Fluorescence Spectroscopy Using the PS \\
Analytical Merlin
\end{tabular}




\subsection{REFERENCES}

10 CFR Part 830. "Nuclear Safety Management." Code of Federal Regulations, Washington, D.C., Office of the Federal Register National Archives and Records Administration.

40 CFR Part 191. "Environmental Radiation Protection Standards for the Management and Disposal of Spent Nuclear Fuel, High-Level and Transuranic Radioactive Wastes." Code of Federal Regulations, Washington, D.C., Office of the Federal Register National Archives and Records Administration.

40 CFR Part 261. "Identification and Listing of Hazardous Waste." Code of Federal Regulations, Washington, D.C., Office of the Federal Register National Archives and Records Administration.

40 CFR Part 264. "Standards for Owners and Operators of Hazardous Waste Treatment, Storage, and Disposal Facilities." Code of Federal Regulations, Washington, D.C., Office of the Federal Register National Archives and Records Administration.

40 CFR Part 268. "Land Disposal Restrictions." Code of Federal Regulations, Washington, D.C., Office of the Federal Register National Archives and Records Administration.

40 CFR Part 270. "EPA Administered Permit Programs: The Hazardous Waste Permit Program." Code of Federal Regulations, Washington, D.C., Office of the Federal Register National Archives and Records Administration.

Acceptable Knowledge Interim Laboratory Implementation Guidance Document. LIG404-00-01.0. Waste Management Policies and Procedures Committee.

Calibration Handbook. LALP-93-47, Los Alamos, New Mexico, Standards and Calibration Group, Los Alamos National Laboratory.

CST Waste Management Facilities Waste Acceptance Criteria and Certification. WASTEMGMTPLAN-002, Los Alamos, New Mexico, Waste Management Facilities, Los Alamos National Laboratory.

CST/CMR Chain-of-Custody and Sample Transfer Plan. Los Alamos, New Mexico, Chemical Sciences and Technology Division, Los Alamos National Laboratory.

DOE Order 1324.2A

DOE Order 200.1. Information Management Program. Washington, D.C., U.S. Department of Energy.

DOE Order 5480.20. Personnel Selection, Qualification, Training, and Staffing Requirements at DOE Reactor and Non-Reactor Nuclear Facilities. Washington, D.C., U.S. Department of Energy. 
DOE Waste Treatability Group Guidance. DOE/LLW-217, Idaho Falls, Idaho, INEL-Lockheed Idaho Technologies Company, U.S. Department of Energy.

EPA Requirements for Quality Assurance Project Plans for Environmental Data Operations. EPA QA/R-5, Washington D.C., Quality Assurance Management Staff, U.S. Environmental Protection Agency.

EPA. 1991a. National Enforcement Investigations Center Policies and Procedures. EPA-330/9-78001-R, Denver, Colorado, National Enforcement Investigations Center, U.S. Environmental Protection Agency.

Los Alamos National Laboratory Transuranic Waste Certification Plan. TWCP-PLAN-0.2.4-001, Transuranic Waste Characterization/Certification Program, Los Alamos, New Mexico.

Los Alamos National Laboratory Transuranic Waste Characterization Sampling Plan. DRAFTCSTDO-PLAN-003, Los Alamos, New Mexico, Environmental Systems and Waste Characterization, Los Alamos National Laboratory.

Los Alamos TRU Waste Certification Plan. WCP-HSE7-CP-01, Los Alamos New Mexico, Waste Management Facilities, Los Alamos National Laboratory.

NMED Title 20 New Mexico Administrative Code, Chapter 4, Part 1.

Performance Demonstration Program Plan for Nondestructive Assay for the TRU Waste Characterization Program. CAO-94-1045, Current Revision, Carlsbad, New Mexico, Carlsbad Area Office, U.S. Department of Energy.

Performance Demonstration Program Plan for RCRA Constituent Analysis of Solidified Wastes. CAO95-1077, Current Revision, Carisbad, New Mexico, Carisbad Area Office, U.S. Department of Energy.

Performance Demonstration Program Plan for the Analysis of Simulated Headspace Gases for the TRU Waste Characterization Program. CAO-95-1076, Current Revision, Carlsbad, New Mexico, Carlsbad Area Office, U.S. Department of Energy.

Quality Assurance Program Description. CAO-94-1012, Current Revision, Carisbad, New Mexico, Carisbad Area Office, U.S. Department of Energy.

Quality Assurance Requirements of Computer Software for Nuclear Facility Applications. NQA-2a, Part 2.7 - 1990 Addenda, New York, New York, American Society of Mechanical Engineers.

Quality Assurance Requirements for Nuclear Facilities. ASME NQA-1-1989 Edition, New York, New York, American Society of Mechanical Engineers.

Soil Sampling and Analysis for Volatile Organic Compounds. EPA/540/4-91/001, T. E. Lewis, A. B. Crockett, R. L. Siegrist, K. Zarrabi, Office of Research and Development, U.S. Environmental Protection Agency. 
Specifications and Guidance for Obtaining Contaminant-Free Sample Containers. Directive No. 9240.0-05A, Office of Solid Waste and Emergency Response, U.S. Environmental Protection Agency.

Test Methods for Evaluating Solid Waste, Physical/Chemical Methods. SW-846, Third Edition, Final Update I and Final Update II, Washington, D.C., Office of Solid Waste and Emergency Response, U.S. Environmental Protection Agency.

Transuranic Waste Characterization Quality Assurance Program Plan. CAO-94-1010, Current Revision, Carlsbad, New Mexico, Carisbad Area Office, U.S. Department of Energy.

Transuranic Waste Characterization Sampling and Analysis Methods Manual. DOE/WIPP-91-043, Current Revision, Carlsbad, New Mexico, Carlsbad Area Office, U.S. Department of Energy.

\section{TRUPACT II Authorized Methods for Payload Control}

Waste Isolation Pilot Plant Transuranic Waste Baseline Inventory Report. CA0-94-1005, Current Revision, Carlsbad, New Mexico, Carlsbad Area Office, U.S. Department of Energy. 


\section{DISCLAIMER}

Portions of this document may be illegible in electronic image products. Images are produced from the best available original document. 